A Preliminary Evaluation of the Neutron and Photon-Production Cross Sections for Aluminum 
This report was prepared as an account of work sponsored by the United States Government. Neither the United States nor the United States Atomic Energy Commission, nor any of their employees, nor any of their contractors, subcontract irs, or their employees, makes any warranty, expi ess or im. plied, or assumes any legal liability or responsibility for the accuracy, completeness or usefulness of any information, apparatus, product or process disclosed, or represents that its use would not infringe privately owned rights.

Printed in the United States of America. Available from

National Technical Information Service

U. S. Department of Commerce

5285 Port Royal Road

Springfield, Virginia 22151

Price: Printed Copy $\$ 3.00$; Microfiche $\$ 0.95$ 


\section{A Preliminary Evaluation of the Neutron and Photon-Production Cross Sections for Aluminum}

by

P. G. Young

D. G. Foster, Jr.

This report was prepared as an account of work
sponsored by the United States Government. Neither
the United States nor the United States Atomic Energy
Commission, nor any of their employees, nor any of
their contractors, subcontractors, or thel employees,
makes any warranty, express or implied, or assumes any
legal liability or responsibility for the gccuracy, com-
pleteness or usefulness of any information, apparatus,
product or process disclosed, or represents that its use
would not infringe privately owned rights.

This work was supported by the Defense Nuclear Agency under Subtask PC102. 
ABSTRACT

1. INTRODUCTION 1

2. NEUTRON CROSS SECTIONS

2.1. Total Cross Section 1

2.2. Elastic Scattering Cross Section 5

2.3. Radlative-Capture Cross Section 8

2.4. Inelast1c Scattering Cross Sections 13

2.4.1. The ${ }^{27} \mathrm{Al}\left(\mathrm{n}, \mathrm{n}^{\prime}\right)$ Crass Sections for $\mathrm{E}_{\mathrm{x}}\left({ }^{27} \mathrm{Al}\right)<5 \mathrm{MeV} 13$

2.4.2. The ${ }^{27} \mathrm{Al}\left(n, n^{\prime}\right)$ Cross Sections for $E_{x}\left({ }^{27} \mathrm{Al}\right)>5 \mathrm{MeV} 14$

2.5. The ${ }^{27} \mathrm{Al}(\mathrm{n}, \mathrm{np}){ }^{26} \mathrm{Mg},{ }^{27} \mathrm{Al}(\mathrm{n}, \mathrm{n} \alpha)^{23} \mathrm{Na}$, and ${ }_{\mathrm{Al}}^{27}(\mathrm{n}, 2 \mathrm{n}){ }_{\mathrm{Al}}$

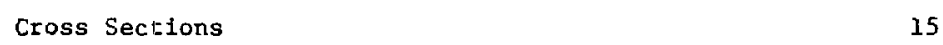

2.6. The ${ }^{27} \mathrm{Al}(\mathrm{n}, \mathrm{p})^{27} \mathrm{Mg}$ Cross Section 18

2.7. The ${ }^{27} \mathrm{Al}(\mathrm{n}, \mathrm{d}){ }^{26} \mathrm{Mg}$ and ${ }^{27} \mathrm{Al}(\mathrm{n}, \mathrm{t})^{25} \mathrm{Mg}$ Cross Sections 18

2.8. The ${ }^{27} \mathrm{Al}(n, \alpha){ }^{24} \mathrm{Na}$ Cross Section 20

3. PHOTON-PRODUCTION CRUSS SECTIONS AND ENERGY SPECTRA 21

3.1. Photon Production from the ${ }^{27} \mathrm{Al}(\mathrm{n}, \gamma)^{28} \mathrm{Al}$ Reaction 21

3.2. Photon Production from ${ }^{27} \mathrm{Al}(\mathrm{n}, \mathrm{x} y)$ Reactlons 22

3.2.1. Discrete Photons from ${ }^{27} \mathrm{Al}(\mathrm{n}, \mathrm{x} \gamma)$ Reactions 22

3.2.2. Cont.1nuum Photons from ${ }^{27} \mathrm{Al}(\mathrm{n}, \mathrm{x} \gamma)$ Reactions 29

4. NEUTRON ENERGY DISTRIBUTIONS 29

5. ANGULAR DISTRIBUT IONS 30

5.1. Elastic Neutron Angular Distributions 31

5.2. Nonelastic Neutron Angular Distributions 31

5.3. Secondary Piroton Angular Distributions 32

6. DISCUSSION 33

ACKNOWLEDGRENTS

REFERENCES 


\section{A PRELTMINARY EVAIUATION OF THE NEUTRON AND PHOTON-PRODUCTION CROSS SECTIONS FOR ALUMINUM}

by

P. G. Young and D. G. Foster, Jr.

\section{ABSTRACT}

A preliminary evaluation of the neutron-induced cross sections of $27_{\mathrm{Al}}$ has been completed for the energy range $10^{-5} \mathrm{eV}$ to $20 \mathrm{MeV}$. The evaluation Includes specification of energy and angular distributions for secondary neutrons and photons. The recommended data are based mainly on experiment, and extensive comparisons with measured results are provided. In certain areas model calculations were used to augment the experiniental data. Tine evaluated resulte are available on magnetic tape in ENDF/B(III) format.

\section{INTRODUCTION}

A preliminary evaluation of the neutron-induced cross sections for ${ }^{27} \mathrm{Al}$ has been completed for the energy region from $10^{-5} \mathrm{eV}$ to $20 \mathrm{MeV}$. The evaluation includes specification of angular and energy distributions for secondary gamma rays, as well as for secondary neutrons. The data are in ENDF/B format and have been filed with the National Neutron Cros: Section Center at Brookhaven (MAT 1135) and with the Defense Nuclear Agency's (DNA) military applications library at the Radiation Shielding Information Center in Oak Ridge (MAT 4135).

The pirpose of this work was to provide DNA with a preliminary aluminum evaluation that contains consistent neutron and photon-production data and that includes consideration of several Inportant new measurements: Because time was limited, we did not perform a complete literature survey, and in some areas previous evaluations were accepted without Improvement. The treatment in the resolved-resonance region is sketchy with some fine structure smoothed out, and only a bare minlmum of supporting nuclear-model calculations were carried out. Therefore, the evaluation should be regarded as tentative.

A sumary of the $Q$-values and thresholds for the significant neutron reactions with aluminum is given in Table I. Because natural aluminum is $100 \%{ }^{27} \mathrm{Al}$, only reactions with ${ }^{27} \mathrm{Al}$ are listed. The reactions 1isted in Table I, together with the total cross section, were evaluated in varying amounts of detall. The evaluated results are based mainly on experimental data although simple model calculations were used in some areas to supplement the measurements. Several charged-particle processes with thresholds above $14 \mathrm{MeV}$, such as the $\left(n,{ }^{3} \mathrm{Hc}\right),(n, 2 p),(n, 2 \alpha)$, and $(n, p a)$ reactions, are omfited from Table $I$. These reactions are expected to have small cross sections and are not treated explicitly in the evaluation. The detailed considerations that went into the evaluation are described in the following sections.

\section{NEUTRON CROSS SECTIONS}

\subsection{Total Cross Section}

Below $0.5 \mathrm{MeV}$, the total cross section is based mainly on the work of Merrison and Wiblin (Me52) from $1.1 \mathrm{eV}$ to $3.6 \mathrm{keV}$, and of Hibdon (Hi59, H164) between 1.5 and $450 \mathrm{keV}$, which we normallzed to each other over their small overlap regton. To tle these to our evaluation in the $\mathrm{MeV}$ region, we used the results of Chien and Smith (Ch66) to bridge a gap between 450 and $460 \mathrm{keV}$. However, to produce general agreement, we had to lower theln results by 5.37 and 
TABLE I

Q-VALUES AND THRESHOLDS GF IMIPORTANT NEUTRON-INDUCED REACTIONS FOR $27 \mathrm{~A} 1$

\begin{tabular}{|c|c|c|}
\hline Reaction & $\begin{array}{c}\text { Q-Value } \\
(\mathrm{MeV})\end{array}$ & $\begin{array}{c}\text { Threshold } \\
(\mathrm{MeV})\end{array}$ \\
\hline $27 \mathrm{Al}(\mathrm{n}, \gamma)^{28} \mathrm{Al}$ & 7.724 & --- \\
\hline${ }^{27} \mathrm{Al}(\mathrm{n}, \mathrm{n}){ }^{27} \mathrm{Al}$ & 0 & $\cdots$ \\
\hline${ }^{27} \mathrm{Al}\left(\mathrm{n}, \mathrm{n}^{\prime}\right)^{27} \mathrm{Al}^{\text {* }}$ & -0.843 & 0.875 \\
\hline${ }^{27} \mathrm{Al}(\mathrm{n}, \mathrm{p})^{27} \mathrm{Mg}$ & -1.831 & 1.899 \\
\hline${ }^{27} \mathrm{Al}(\mathrm{n}, \mathrm{d}){ }^{26} \mathrm{Mg}$ & -6.046 & 6.272 \\
\hline${ }^{27} \mathrm{Al}(\mathrm{n}, \mathrm{t})^{25_{\mathrm{Mg}}}$ & -10.884 & 11.291 \\
\hline${ }_{\mathrm{A}}^{27}(\mathrm{n}, \alpha)^{24} \mathrm{Na}$ & -3.131 & 3.248 \\
\hline${ }^{27} \mathrm{Al}(n, 2 \mathrm{n}){ }_{\mathrm{Al}}^{26}$ & -13.057 & 13.545 \\
\hline $27 \mathrm{Al}(\mathrm{n}, \mathrm{np}){ }^{26} \mathrm{Mg}$ & -8.271 & 8.580 \\
\hline$\left.{ }^{27} \mathrm{Al}(\mathrm{n}, \mathrm{n} \alpha)\right)^{23} \mathrm{Na}$ & -10.101 & 10.479 \\
\hline
\end{tabular}

raise those of Merrison and Wiblin by $11.3 \%$. The work of Hibdon and Muehlhause (H149) and Rayburn and l.ollan (Ra65) indicate that below $100 \mathrm{keV}$ this composite may be about $5 \%$ too high. Unfortunately, the absolute cross sections from the time-of--flight work of Garg et al. (Ga65) are untrustworthy within rough1y 20\%; therefore we cannot use them to resolve this problem. Instead, we have used the Garg data mainly to supply the fine structure deta1ls below $150 \mathrm{keV}$. We have not corrected Hibdon's energy scale (Hi59, H164) above $100 \mathrm{keV}$, although the scale of Garg et al. (Ga65) is almost certainly more accurate.

From our total cross section above $1 \mathrm{eV}$, we deduced a potential-scattering cross section of 1.511 b. By combining this value with the $2200-m / s e c$ radiativecapture cross section of $232 \mathrm{mb}$ from the evaluation by Goldman et al. (Go71; see Sec. 2.3), and assuming $1 / \mathrm{v}$ variation for the latter up to about $10 \mathrm{eV}$, we synthesized the total cross section between $10^{-5} \mathrm{eV}$ and $1 \mathrm{eV}$. This region inluerits the $5 \%$ uncertainty of the total cross section that is present in the keV region.

Figure 1 shows the resulting evaluated curve below $1 \mathrm{keV}$, together with the previous $\mathrm{ENDF} / \mathrm{B}(\mathrm{II})$

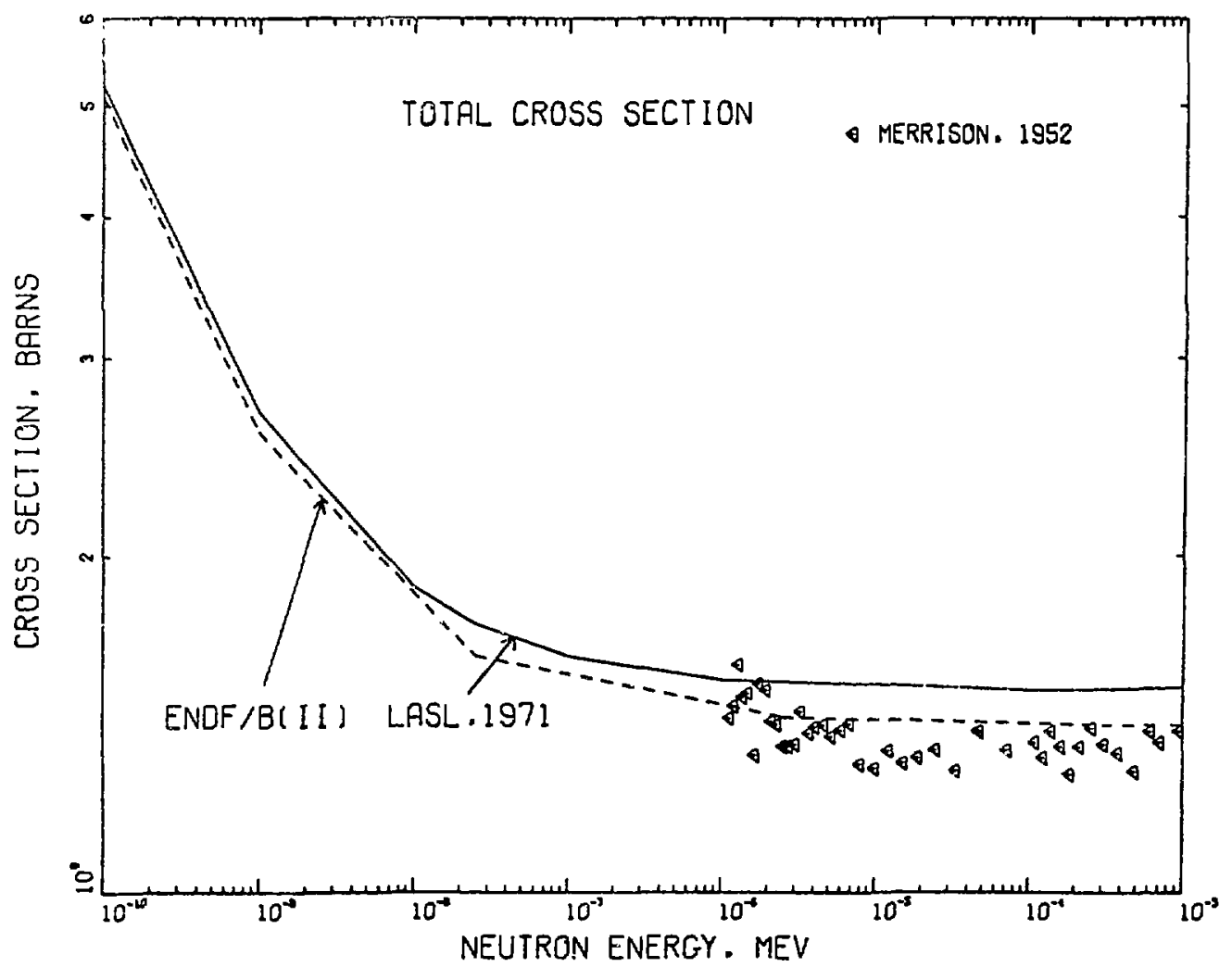

Fig. 1. Measured and evaluated total cross section for ${ }^{27} \mathrm{Al}$ from $10^{-4} \mathrm{eV}$ to $1 \mathrm{keV}$. The experimental data are averages of two adjacent points. 
evaluation and the data of Merrison and Wiblin (Me52). The differences result primarily from the chain of normalizations that we applied to the older data to force agreement with more recent data in the $\mathrm{MeV}$ range. In this and in all subsequent figures, the measurements are displayed in their original (unnormalized) form.

The measured and evaluated total cross sections from 1 to $100 \mathrm{keV}$ are shown in Fig. 2. The data of Garg et al. (Ga65) are impossible to plot individually on this scale, so we have given many-point averages that fail to justify the rine structure shown in the evaluated curves, although the data of
Garg etal. form the basis of the curves. The ENDF/B (II) curve follows the Garg data without correction for their "tilt" relative to the other measurements. This anomaly might have been caused by uncorrected dead-time errors in the Columbia Untversity (Ga65) work.

The evaluated total cross section in the MeV region is based on a composite of three recent measurements that agree to within $\pm 1 \%$ in their regions of mutual overlap. The results of Schwartz (Sc70) and Foster and Glasgow (Fo71) were obtained by timeof-flight techniques using continuous spectra of incldent neutrons. We discarded the erratic portion of Schwartz's data above $10 \mathrm{MeV}$, where background

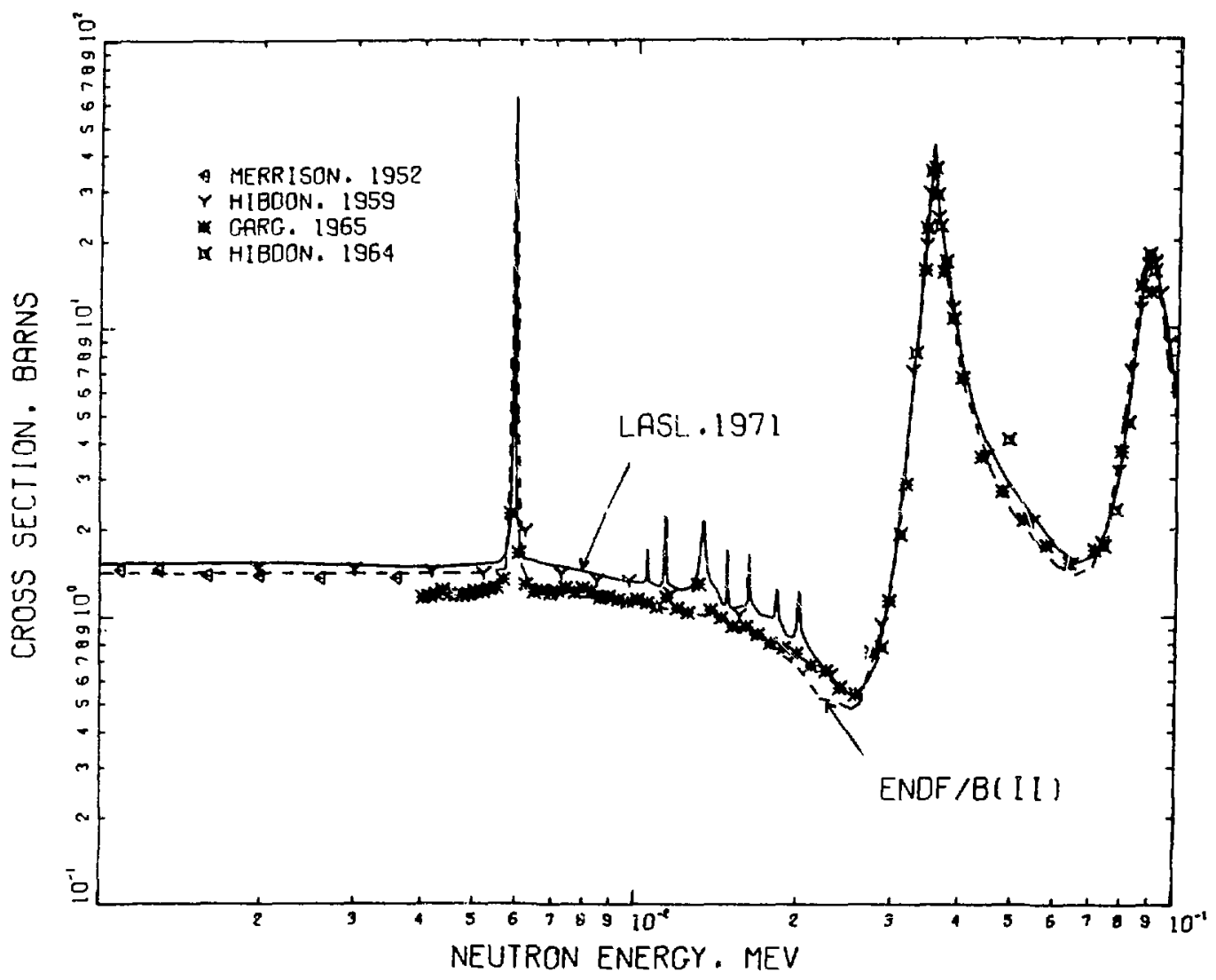

Fig. 2. Measured and evaluated total cross section for ${ }^{27} \mathrm{Al}$ from 1 to $100 \mathrm{keV}$. The experimental data are averages of 30 adjacent points for the Garg (Ga65) results, 5 points for the Hibdon (H159) results, and 4 points for the Hibdon (Hi64) results. 
was a severe problem in that measurement. The third experiment used in the composite is that of Carlson. and Barschall ( $\mathrm{Ca} 67$ ), which is one of the few extensive measurements made point-by-point with monoenergetlc neutrons that agrees systematically with modern time-of-flight data. A fourth data set, the detailed results from Karlsruhe $t_{j}$ Cierfacks et al, (C168), was found, even after the latest round of dead-time corrections, still to lie systematically higher than our composite standard by amounts varying between 1.5 and $4 \%$. To preserve the best available resolution, however, we normalized the Cierjacks data piecewise to our composite and used the results between 0.46 and $7.5 \mathrm{MeV}$ for our final evaluation. Above $7.5 \mathrm{Mev}$, the energy resolution of the Carison and Barschall measurement is as good as that of the Karlsruhe measurement, so we used a composite of their normalized data up to $1.4 \mathrm{MeV}$, and the norma1- 1zed Karlsruhe values alone from 14 to $20 \mathrm{MeV}$. We estimate the overall accuracy between 0.5 and $20 \mathrm{MeV}$ to be about $1 \%$.

Figure 3 gives the measured and evaluated total cross section from 0.05 to $0.50 \mathrm{MeV}$. As noted earlier, we have not corrected Hibdon's energy scale (Hi59, Hi64), although we followed his data because their resolution is better than Garg's in this region. The extensive measurements of Cierjacks $\in t$ al. (Ci68) and Schwartz (Sc70) begin at the right edge of Fig. 3 .

The synthetic total cross section below the first resonance at $5.9 \mathrm{keV}$ is aIready smooth. In the resolved-resonance region, we smoothed the data by using approximate single-level fits to the peaks, joined together by sliding-polynomial fits between resonances. Above the resolved-resonance region, sliding-polynomial smoothing was used. We trled to

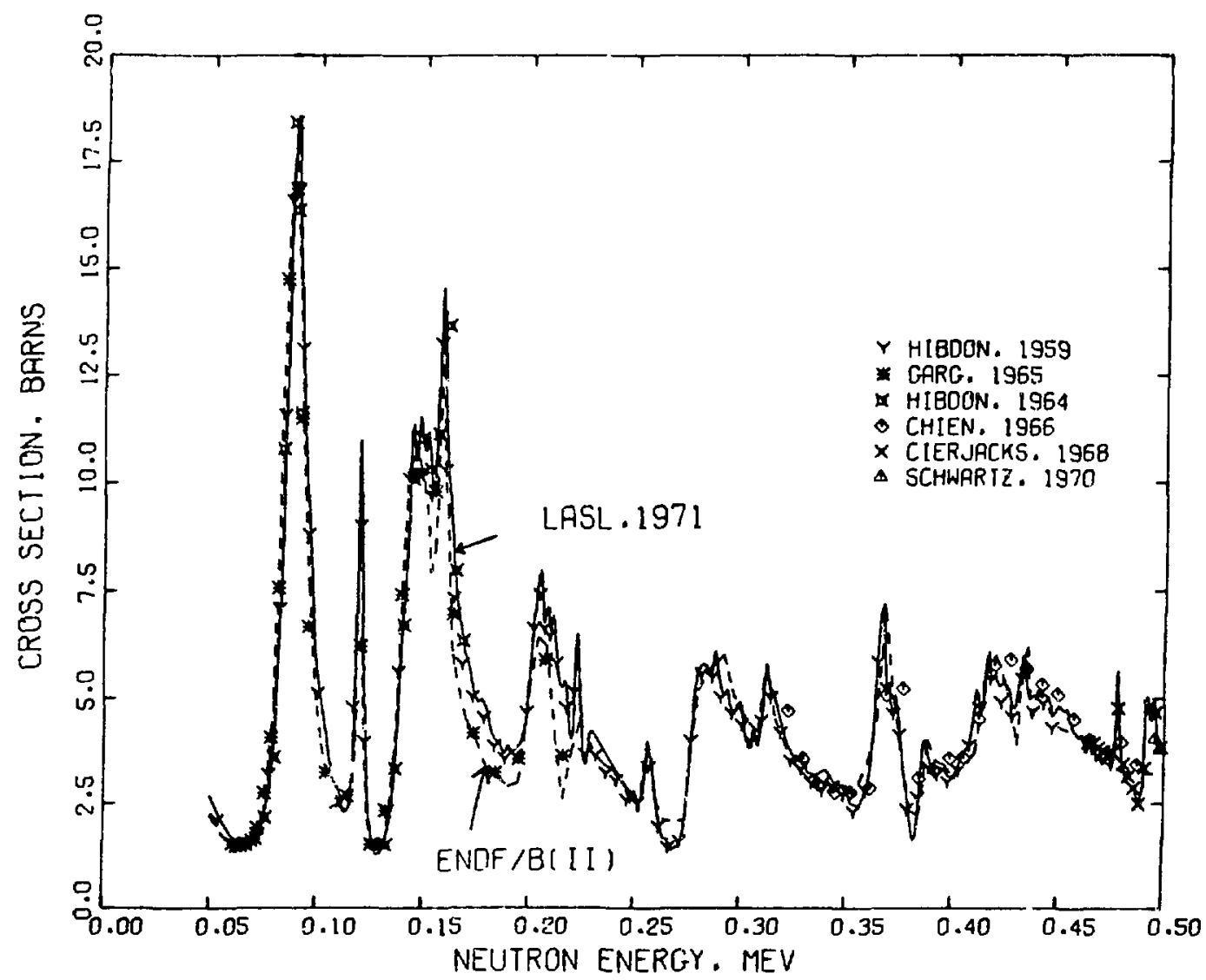

Fig. 3. Measured and evaluated total cross section for ${ }^{27}$ Al from 0.05 to $0.50 \mathrm{MeV}$. The experimental data are averages of 5 points for the Hibdon (H159) results, 10 points for Garg (Ga65), 4 points for Hibdon (H164), 5 points for Chien (Ch66), 15 points for Cierjacks (C168), and 10 points for Schwartz (Sc70). 
preserve the fluctuations between 0.5 and $3 \mathrm{MeV}$ but they are represerited on such a coarse mesh that linear interpolation may give errors of as much as $2 \%$, Above $3 \mathrm{MeV}$, we drastically oversmonthed the fluctuations to reduce the number of polnts in the evaluated $f i l e$.

The transition region from resolved resonances to fluctuations, covering the caergy region from 0.5 to $4 \mathrm{MeV}$, is shown in Figs. 4-6. Throughout this range our evaluation follows the Karlsruhe data (C168) normalized to Schwartz's results (Sc70). Fjgure 6 includes the beginning of the moderate-resolution results of Foster and Glasgow (Fo71) and illustrates the good average agreement of the foster and Schwartz time-of-flight measurements. It also illustrates the oversmoothing of fluctuations * above $3 \mathrm{MeV}$, which can still be seen in the mult1-polnt averages of the Karlsruhe data.

Figure 7 covers the energy range from 4 to 9

MeV. The measurement of Carlson and Barschall (Ca67), * Figures 4-8 have suppressed zero puints on the cross-section scales, which overemphasizes the fluctuations. which is the third constituent of our composite "standard," begins near $4.5 \mathrm{MeV}$ and closely follows the fluctuations in the data of Cierjacks et al. (Ci68).

The total cross sectic!. for the remaining energy range from 9 to $20 \mathrm{MeV}$ is given in Fig. 8. The disagreement between our evaluation and the ENDF/B(II) data set that began near $7.5 \mathrm{MeV}$ is eren more apparent in F1g. 8. The resules of Carlson and Barschall (Ca67) and Foster and Glasgow (Fo71) continue to display guod agreemert, whereas Schwartz's data (Sc70) become increaslingly discordant, reflecting the background problem mentloned earlier. The ENDF/B(II) curvc foliows vider measurements, not shown here, and reflects the relat. $c$ ease of making accurate monoenergetic measurements near $14 \mathrm{MeV}$ as compared to the comparatively inaccessible region near 10 MeV.

\subsection{The Elastic Scattering Crass Section}

The potential scittering cross section in the $\mathrm{eV}$ energy region was determined to be $1.511 \mathrm{~b}$ from the analysis described in Sec, 2.1. At other energies below $5 \mathrm{MeV}$, the evaluated elastic cross section

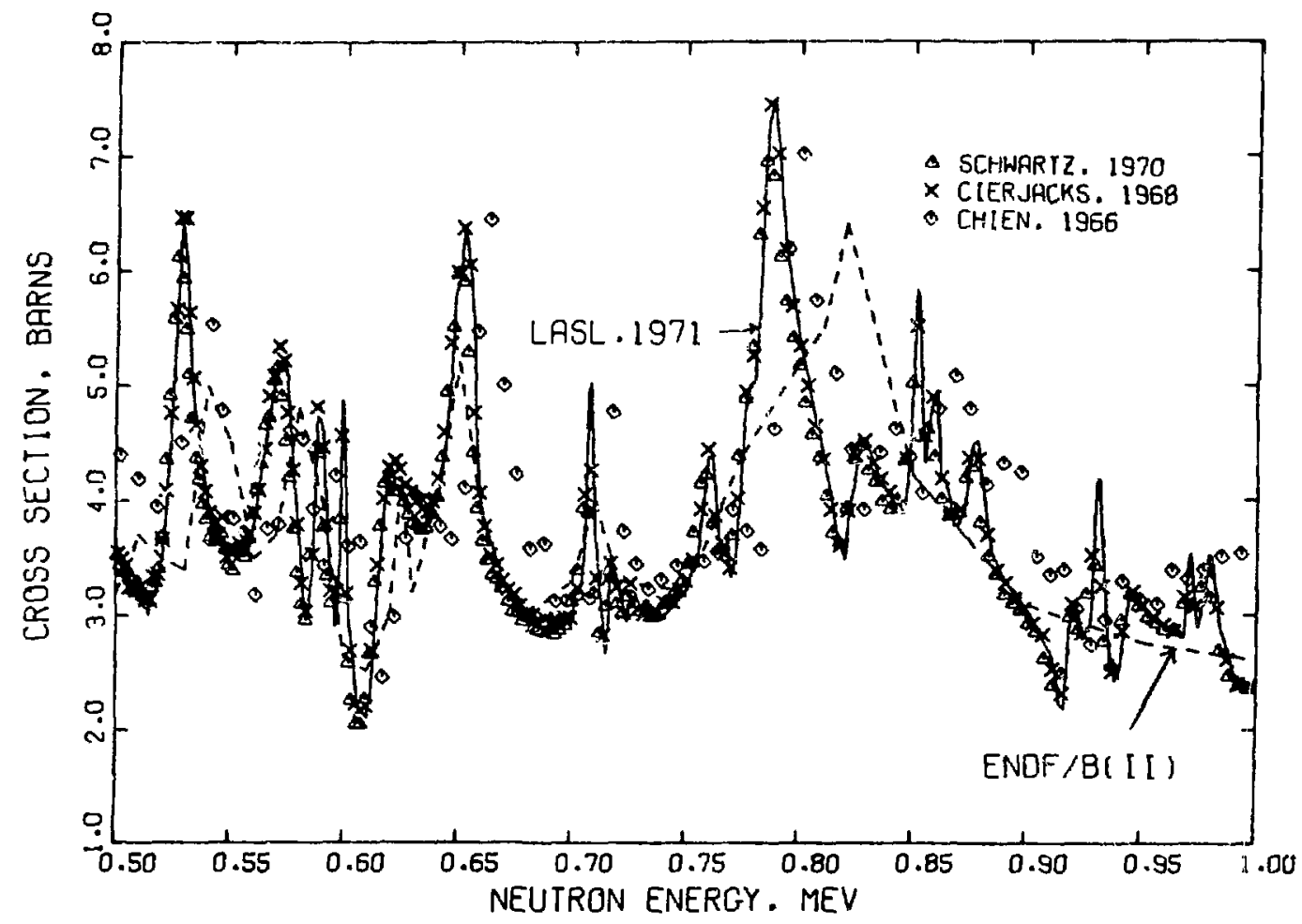

Fig. 4. Measured and evaluated total cross section for ${ }^{27}$ Al from 0.5 to $1.0 \mathrm{MeV}$. The exper1mental data are averages of 6 points for the Schwartz (Sc70) results, 10 points for Cierjacks (Ci68), and 5 points for Chien (Ch66). 


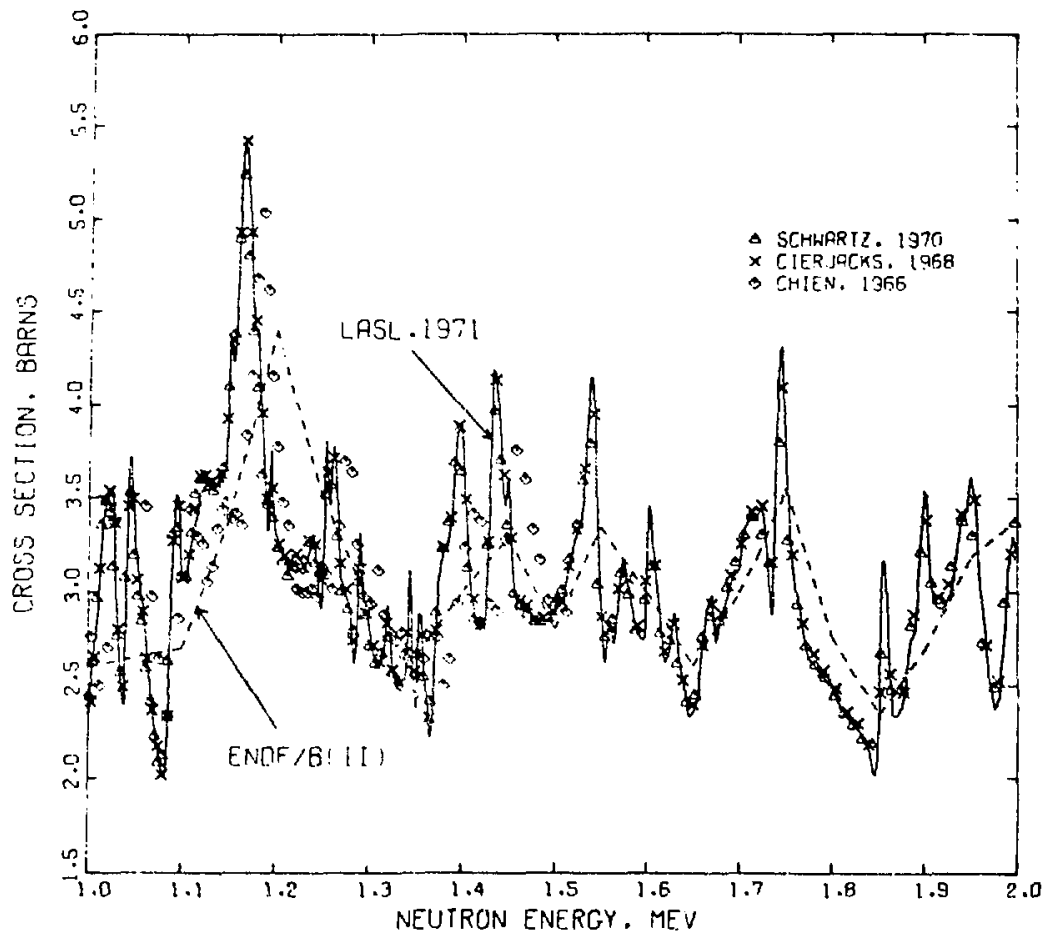

Fig. 5. Measured and evaluat:d total cioss section for ${ }^{27}$ Al from 1 to 2 MeV. The experimental data are averages of 5 points for the Schwartz (Sc70) results, 10 points for Cierjacks (Ci68), and 5 points for Chien (Ch66).

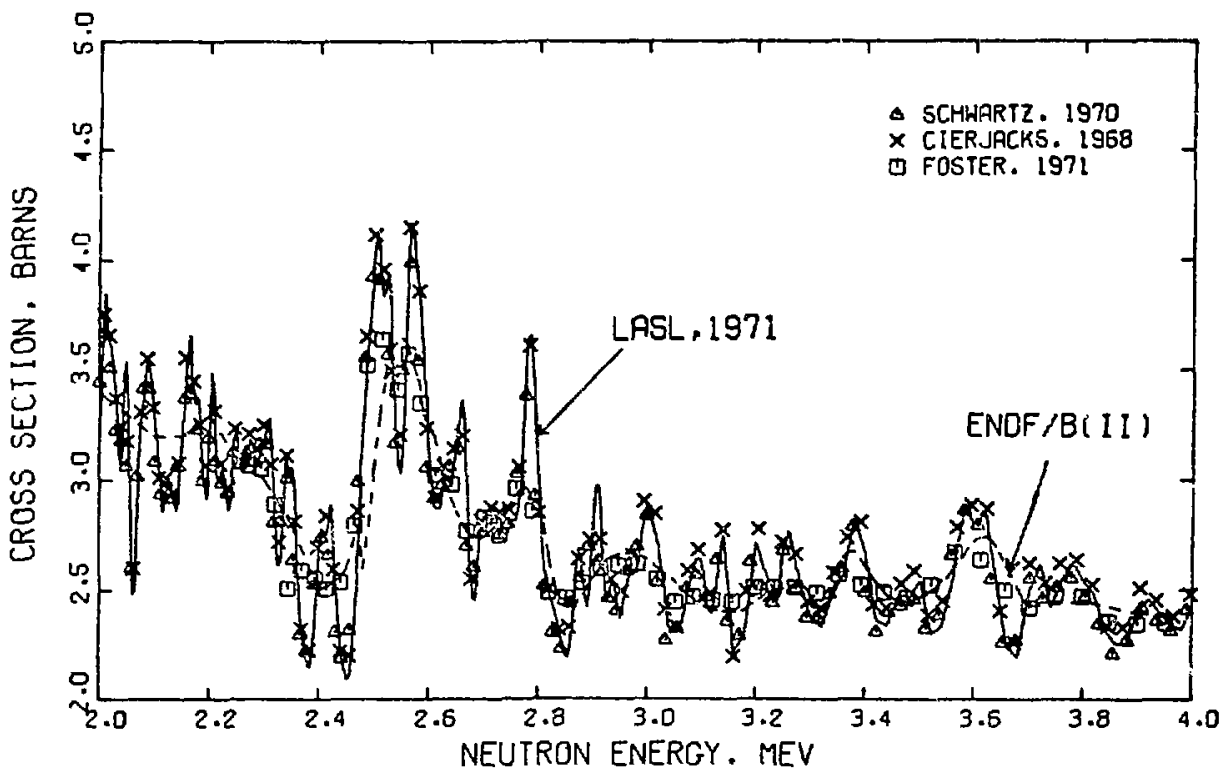

Fig. 6. Measured and evalui ted total cross section for ${ }^{27} \mathrm{Al}$ from 2 to $4 \mathrm{MeV}$. The experimental data are averages of 5 points for the Schwartz (Sc70) results, 8 points for Clerjacks (C168), and 2 points for Foster (Fo71). 
was determined by subtracting the sum of the Individual reaction cross sections from the evaluated total cross section. Discussion of the evaluation of the individual reaction channels is given in Secs. 2.3 through 2.8 .

The evaluated elastic cross section from $50 \mathrm{keV}$ to $5 \mathrm{MeV}$ is compared in Figs. 9-12 to the ENDF/B(II) evaluation and to the available measurements. The experimental points for the elastic cross section in these and in subsequent figures were obtained by integrating angular-distrfbution measurements. The agreement between the elastic measurements and the evaiuated curve is good in this region, although the resolution of the measurements is generally too poor to verffy the detailed structure in the cross section. The structure is taken, of course, from the high-resolution total-cross-section measurements.

The evaluated nonelastic cross section below 5 $\mathrm{MeV}$ is compared to experimental data in Fig. 13.
The curve was obtained by suming the partial reaction cross sections and was used to determine the elastic, as described above. Except for Pasechnik's (Pa55) measurement at $2.5 \mathrm{MeV}$, the agreement between the evaluated curve and the nonelastic measurements lo reasonably good. Detalled information on the fine structure in the nonelastic cross section is not available, and unknown structure might account for the inconsistencies in Fig. 13.

From 5 to $20 \mathrm{MeV}$, the evaluated elastic cross section was determined from elastic and nonelastic measurements, assuming the total cross section to be a known quantity. From 5 to $9 \mathrm{MeV}$, additional nonelastic information was included in the analyst.s by combining the evaluated $(n, p)$ and $(n, \alpha)$ cross sections with the total $\left(n, n^{\prime}\right)$ cross section, as estimated by Dickens (D17I) from the sum of all groundstate transitions in $\left(n, n^{\prime} \gamma\right.$ ) measurements (see Sec. 2.4). The resulting elastic cross section from 5 to

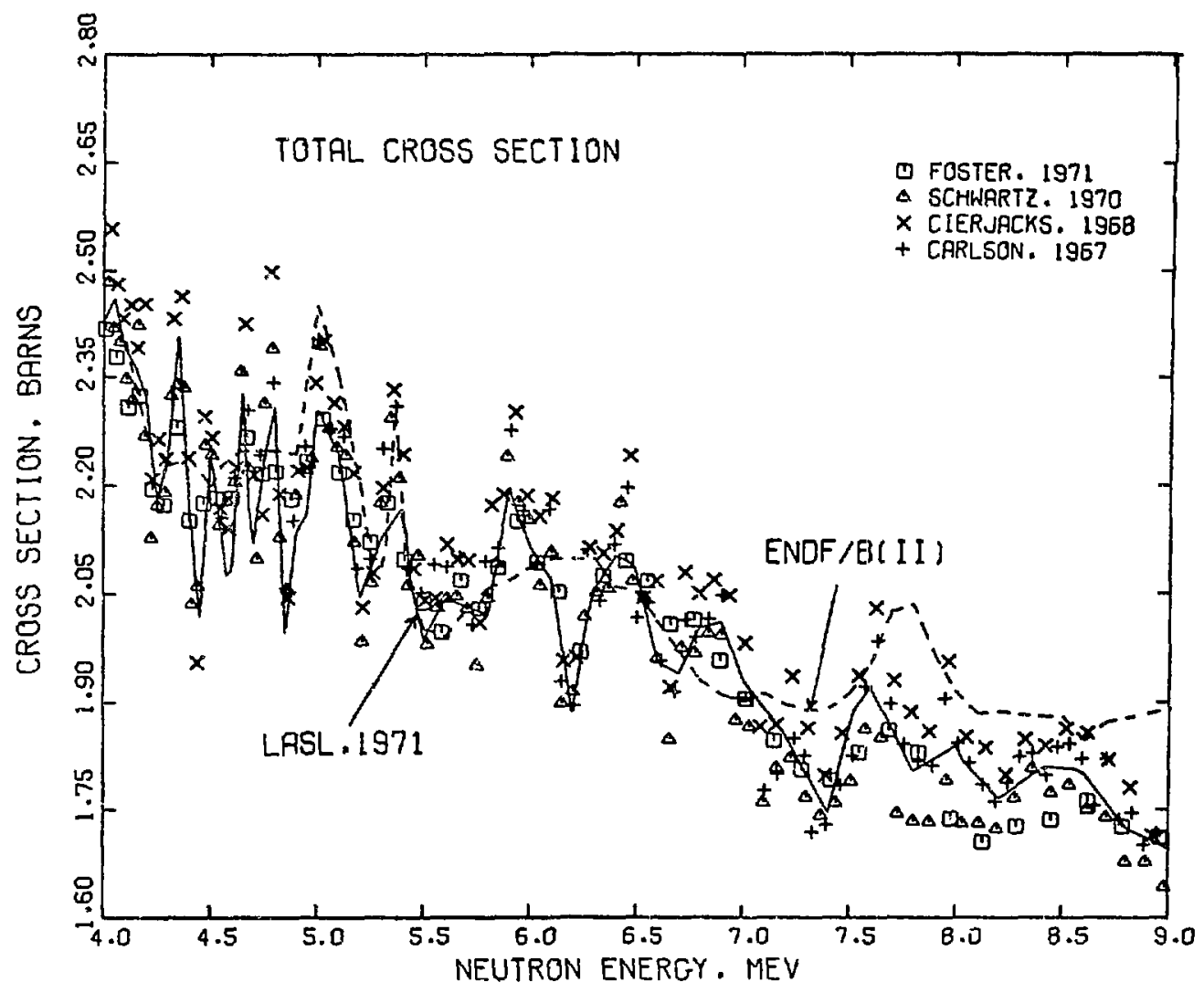

F1g. 7. Measured and evaluated total cross section for ${ }^{27}$ Al from 4 to $9 \mathrm{MeV}$. The experimental data are averages of 2 points for the Foster (Fo71) results, 5 points for Schwartz (Sc70), 8 points for Clerjacks (C168), and 3 points for Carlson (Ca67). 
$20 \mathrm{MeV}$ is compared to the measurements in Fig. 14, and the norelastic cross section for the same energy region is given in Fig. 15. The evaluated elastic that results from this analysis is somewhat lower than is usual, falling below half the total cross section at neutron energles above $8 \mathrm{MeV}$. Therefore, we prejudiced the evaluation slightly toward higher values at some energles. Even lower values for the elastic are suggested, however, by the Nellis (Ne71) measurements at 9 and $11 \mathrm{MeV}$, and the recent result of Glasgow et a1. (G172) at $9 \mathrm{MeV}$, which was not avallable for the evaluation, supports our cholce. We extrapolated the elastlc curve to $20 \mathrm{MeV}$ by folning the lower-energy results smosthly to a value of $\sigma_{\text {tot }} / 2$ at $22 \mathrm{MeV}$. The evaluated elastic curve in Fig. 14 differs significantly from ENDF/B(II) at some energies.

\subsection{Radiative-Capture Crose Section}

In Sec. 2.1, we adopted the 232-mb $2200-\mathrm{m} / \mathrm{sec}$ capture cross section from an unpublished evaluation by Goldman et al. (Go71) and assigned to it a $1 / v$ varlation; as shown 1 in $F 1 g$. 16. The $1 / v$ decrease continues to about $0.1 \mathrm{keV}$, where it meets the wings of the 5.9-keV resonance shown In $\mathrm{FIg} .17$. From 4 to $140 \mathrm{keV}$, we used the data of Block (B168) for the integrated cross seition, taking the widths and actual energles of the resonances from the total-crosssection measurements of Garg et al. (Ga65). Thus, the first resonance comes at $5.906 \mathrm{keV}$ with a peak capture cross section of $1480 \mathrm{mb}$, rather than the $380 \mathrm{mb}$ found with Block's resolution. As shown in Figs. 17 and 18, the result in the low keV region is not drastically different from the ENDF/B(II) evaluation. Most of the difference comes from inproved resolution and more accurate energles.

Figure 19 shows the region from 0.1 to $1 \mathrm{MeV}$. Here we relled malnly on Henkel's work (He5n, He53). Because the cross section is only a few millibarns or less, we did not attempt to follow the fine structure, as did the older ENDF/B evaluation, but instead have averaged rather severely. In Fig. 20, we relled on the measurement of Calv1 et a1. (Ca62) for the croas section from 3.5- to $5-\mathrm{MeV}$, and then arbitrarily assumed a linear rlse through the cluster of

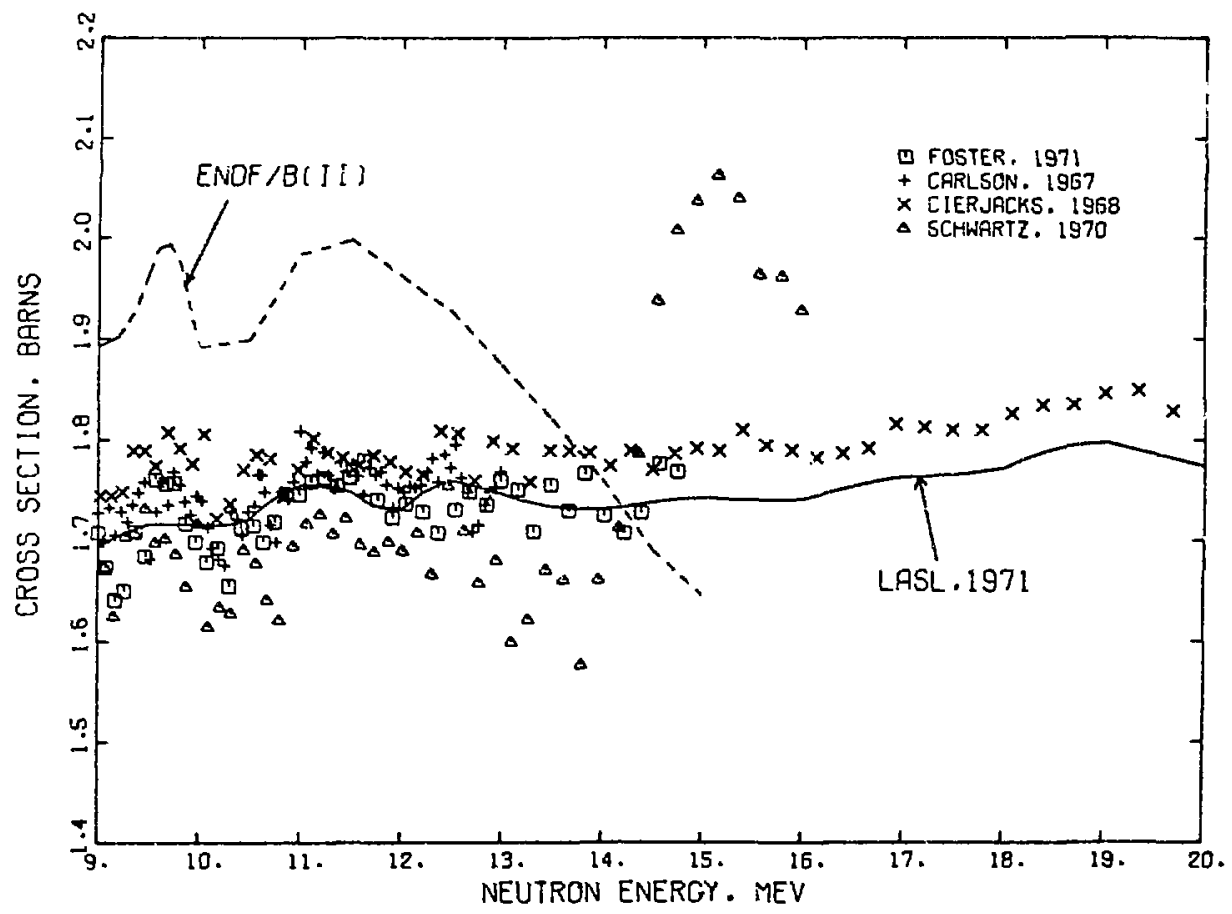

Fig. 8. Measured and evaluated total cross section for ${ }^{27} \mathrm{Al}$ from 9 to $20 \mathrm{MeV}$. The experimental data are averages of 3 points for the Carison (Ca67) results, 8 points for Clerjacks (C168), and 5 points for Schwartz (Sc70). 


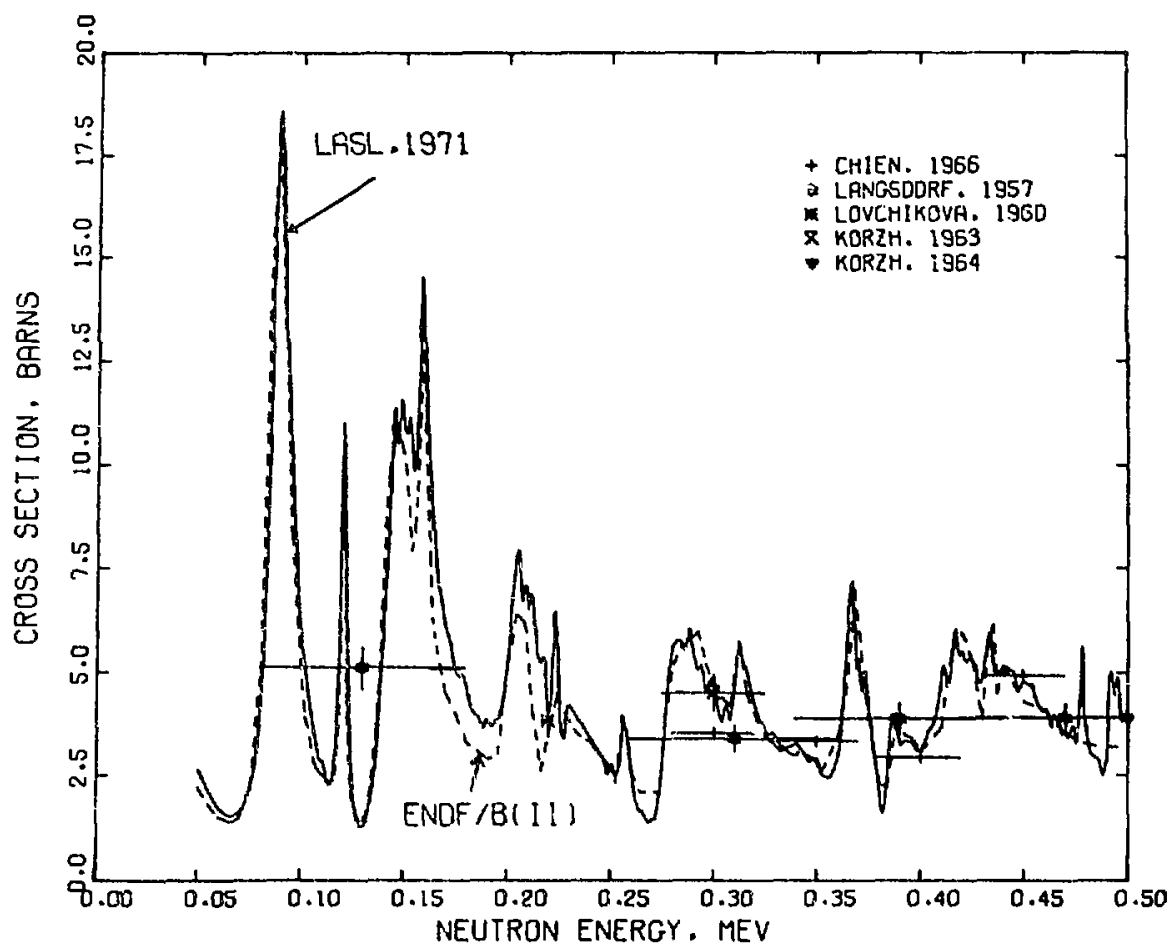

Fig. 9. Measured and evaluated elastic scattarlng cross section for ${ }^{27}$ Al from 0.05 to $0.50 \mathrm{MeV}$.

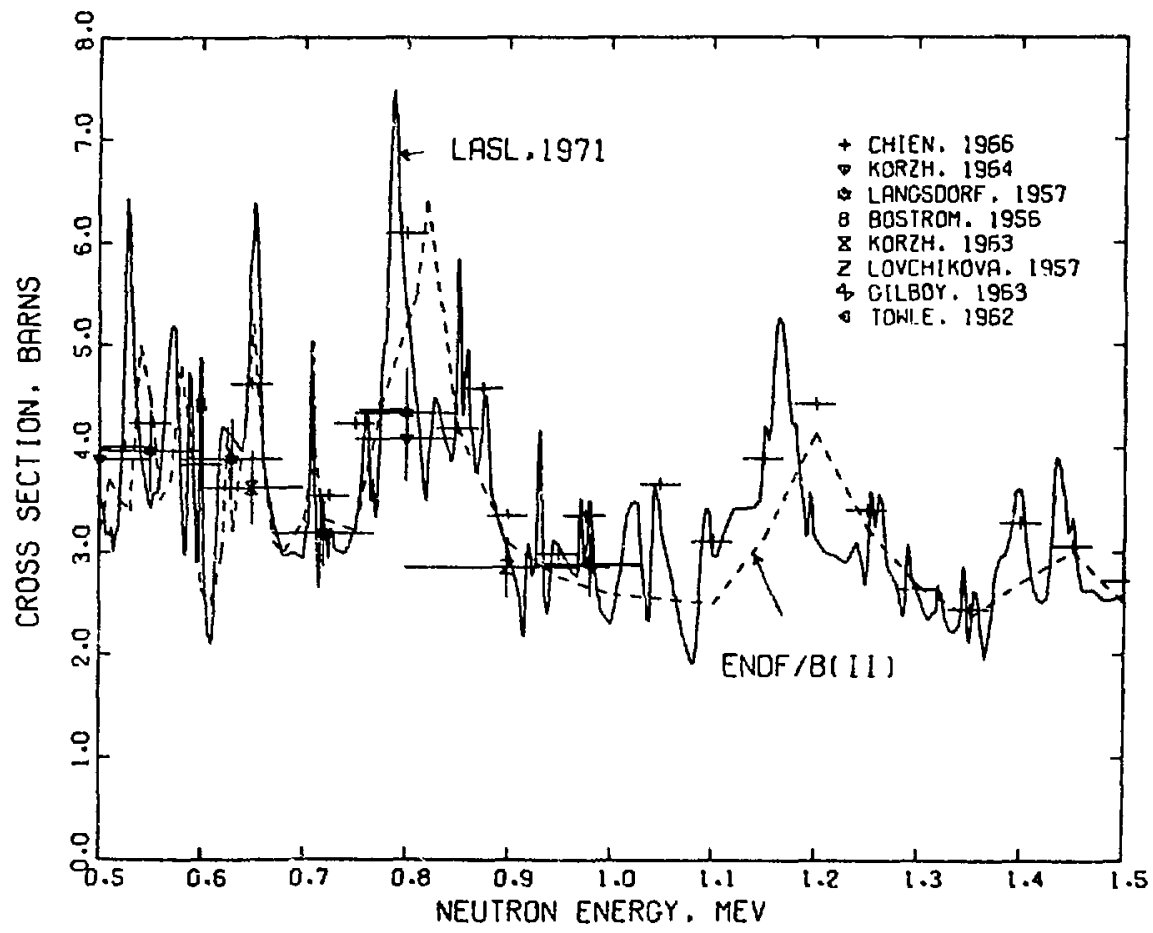

Fig. 10. Measured and evaluated elastic scattering cross section for ${ }^{27}$ Al from 0.5 to $1.5 \mathrm{MeV}$. 



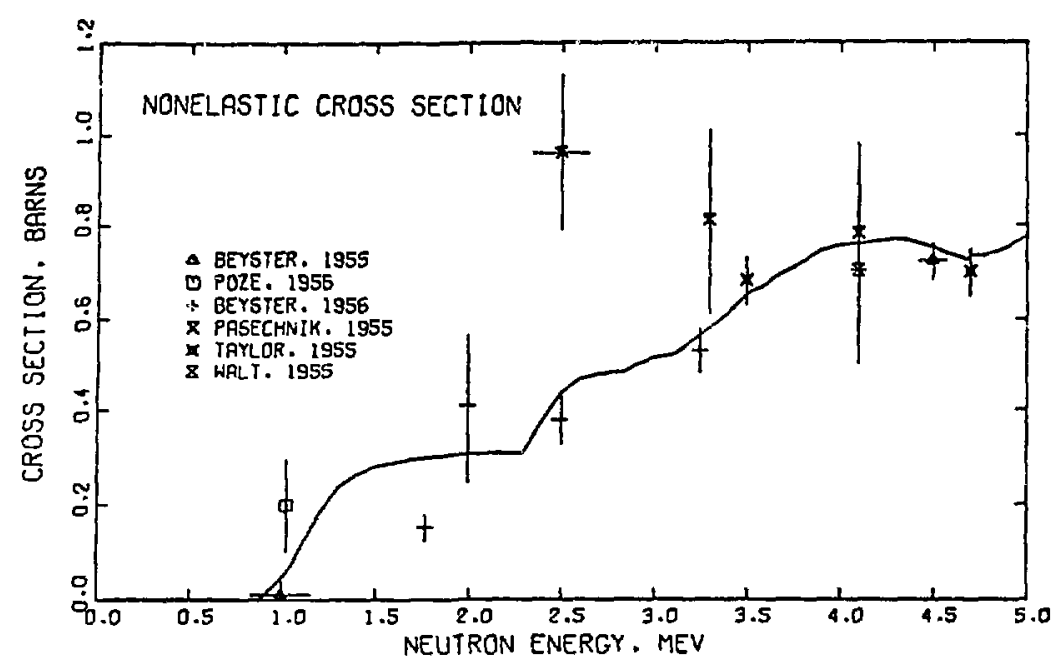

Fig. 13. Measured and evaluated nonelastic cross section for $27 \mathrm{Al}$ from 0.5 to $5.0 \mathrm{MeV}$.

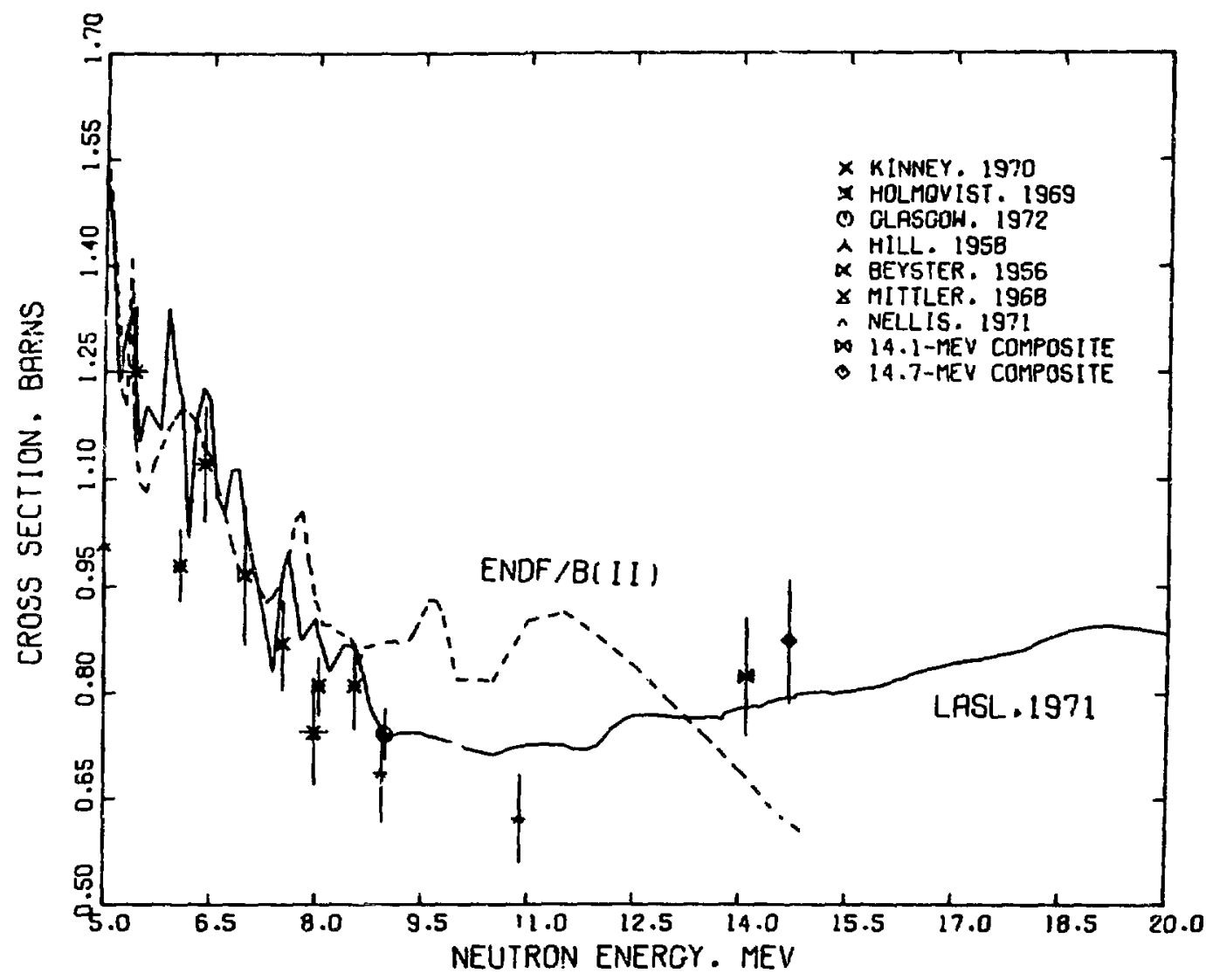

Fig. 14. Measured and evaluated elastic scattering cross section for 27 Al from 5 to 20 MeV. The 14.1-KeV point was obtained by fitting a composite of me urerients near that energy (Bo65a, Co58, Sa59, St65, Yu58); similarly, the 14.7-MeV point results from three measurements near that energy (An59, Be58, Kh58). The composites are shown in F1g. 59. 


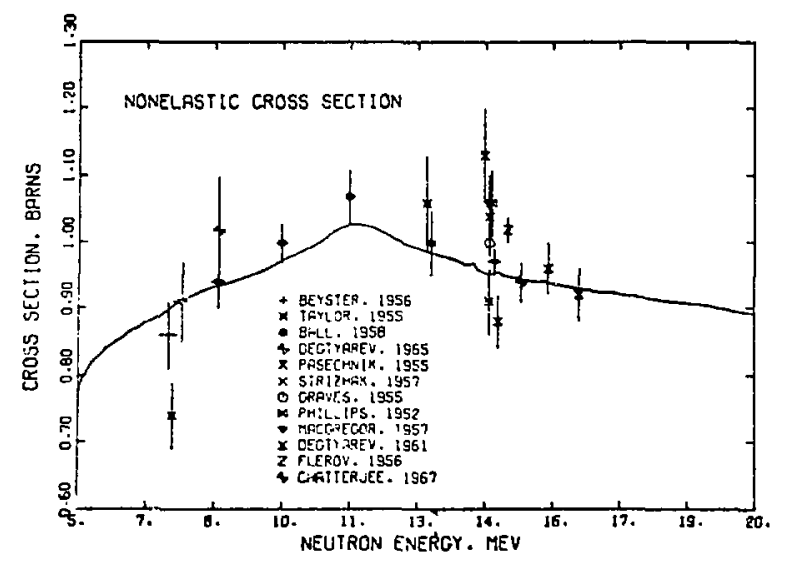

F1g. 15. Measured and evaluated nonelastic cross section for $27 \mathrm{Al}$ from 5 to $20 \mathrm{MeV}$.

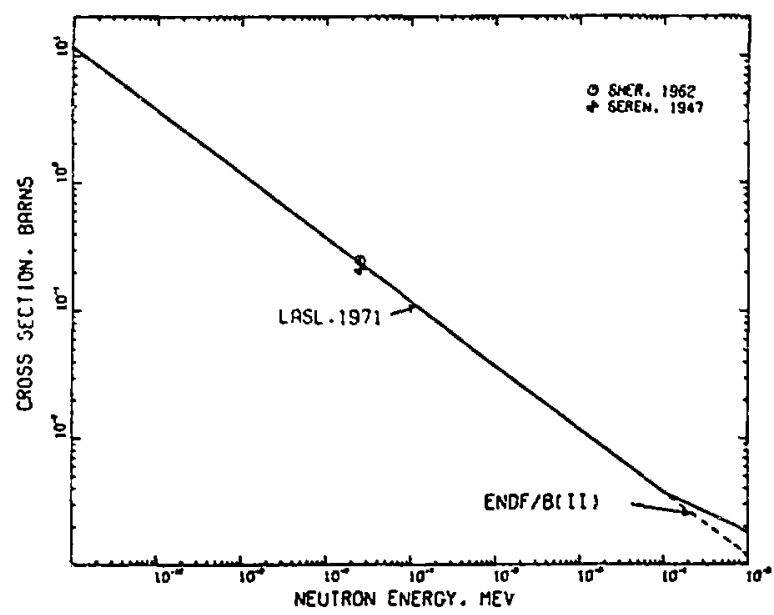

Fig. 16. Messured and evaluated ${ }^{27} \mathrm{Al}(\mathrm{n}, \gamma){ }_{\mathrm{Al}}^{28}$ cross section from $10^{-5} \mathrm{eV}$ to $1 \mathrm{keV}$.

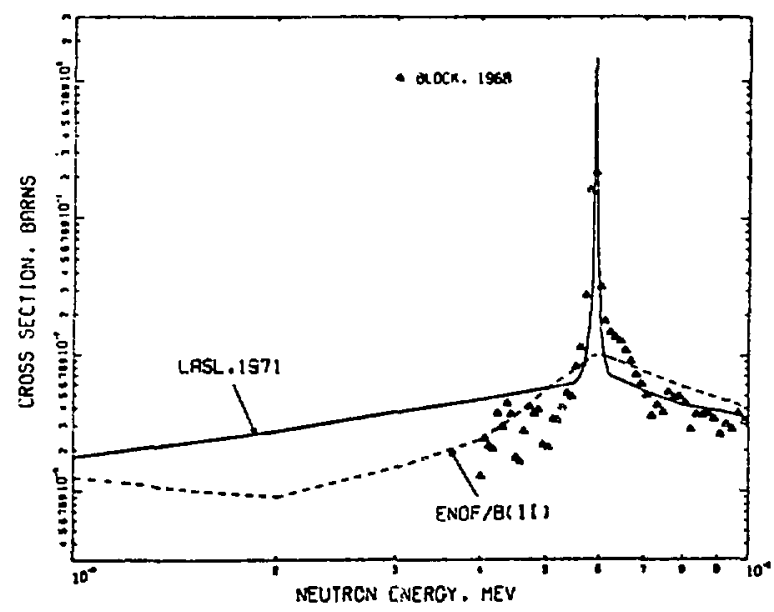

Fig. 17. Measured and evaluated ${ }^{27} \mathrm{Al}(\mathrm{n}, \mathrm{\gamma})^{28 \mathrm{Al}}$ cross section from 1 to $10 \mathrm{keV}$.

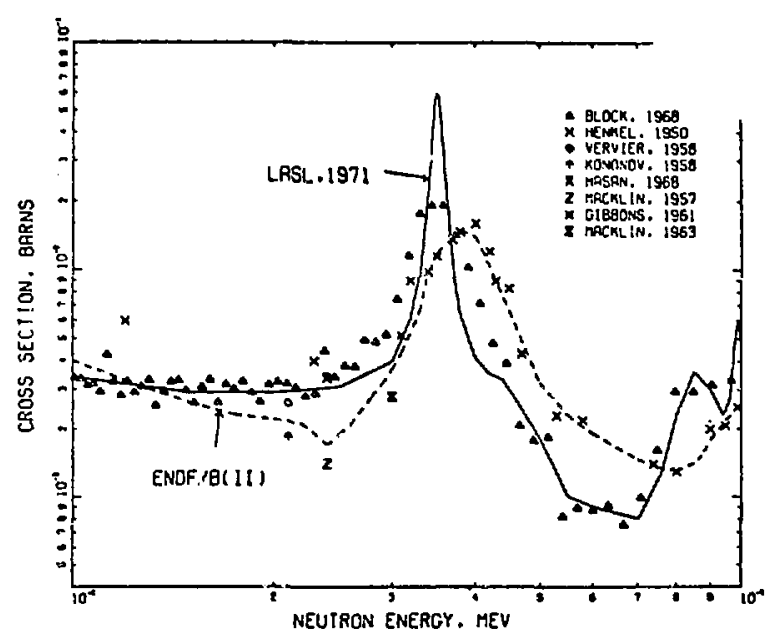

Fig. 18. Measured and evaluated ${ }^{27} \mathrm{~A} 1(n, \gamma){ }^{28} \mathrm{Al}$ cross section from 10 to $100 \mathrm{keV}$.

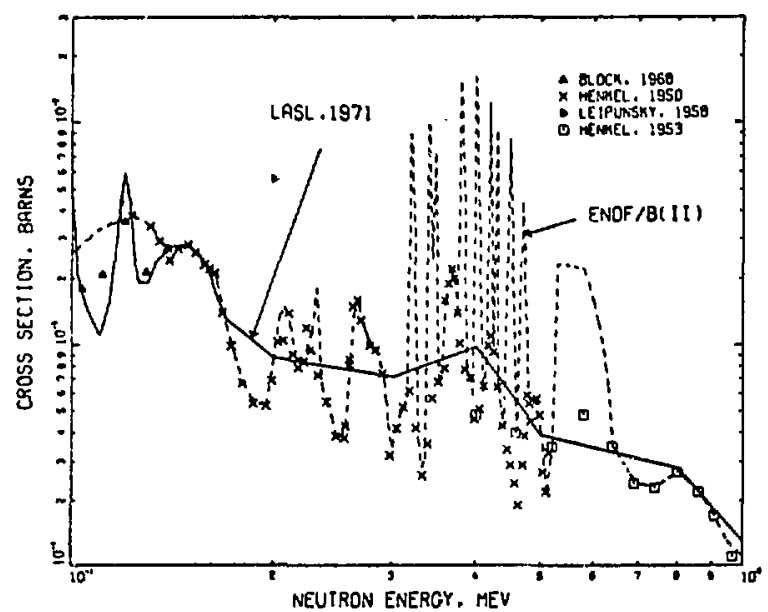

Fig. 19. Measured and evaluated ${ }^{27} \mathrm{Al}(\mathrm{n}, \gamma){ }_{\mathrm{Al}}^{28}$ cross section from 0.1 to $1.0 \mathrm{MeV}$.

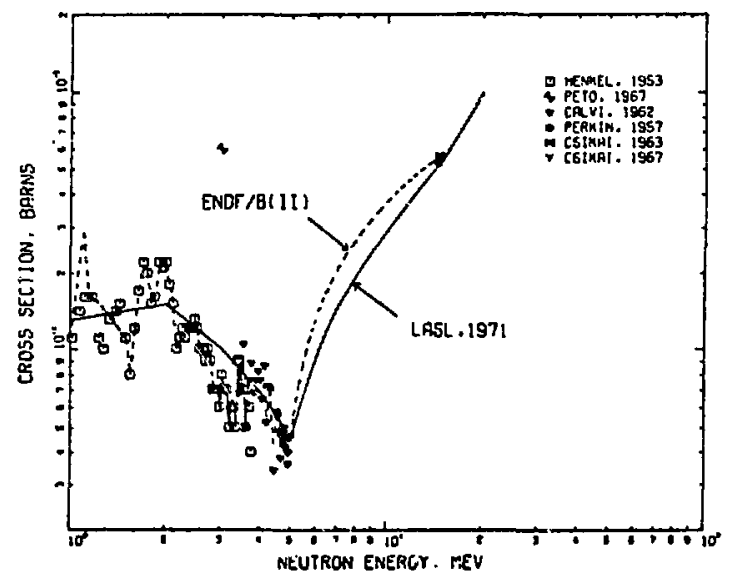

Fig. 20. Measured and evaluated ${ }^{27} \mathrm{Al}(\mathrm{n}, \mathrm{y})^{28} \mathrm{Al}$ cross section from 1 to $20 \mathrm{MeV}$. 
14-MeV measurements (Pe57, Cs63, Cs67), which exhibit the beginning of the inverse photonuclear giant resonance.

\subsection{Inelastic Scattering Cross Sections}

Experimental data provide the basis for the inelastic cross-section evaluation, although we used simple model calculations to supplement the measurements in certain regions. All inelastic data are given in the ENDF/B files as $\left(n, n^{\prime}\right)$ reactions tc discrete states; the $\left(n, n^{\prime}\right)$ cross sections to the first 13 excited states of ${ }^{27} \mathrm{Al}$ with $E_{x}<5 \mathrm{MeV}$ are given explicitly, whereas the data for $E_{x}>5 \mathrm{MeV}$ are grouped into 27 excitation-energy bins with bin widths of either 0.5 or $0.75 \mathrm{MeV}$.

$\frac{2.4 .1 \text { The }{ }^{27} \mathrm{Al}\left(\mathrm{n}, \mathrm{n}^{\prime}\right) \text { Cross Sections for } \mathrm{E}_{x}\left({ }^{27} \mathrm{Al}\right)<}{5 \mathrm{MeV} \text {. }}$

The level structure of ${ }^{27} \mathrm{Al}$ below an excitation energy of $5 \mathrm{MeV}$ is well determined and is given in Fig. 21, together with the photon branching ratios. The information in Fig. 21 was obtained mainly from the measurements of van der Leun et al. (Va67),
E11lott et a1. (E168), Häusser et al. (Ha68a), Röpke et a1. (Ro68, Ro69), and Huang and Ophel (Hu69), together with the 1967 compllation by Endt and van der Leun (E:a67).

The evaluation by Dickens (Di71) of the $\left(n, n^{\prime}\right)$ cross sections to the first 13 excited states of ${ }^{27} \mathrm{Al}$, which is based on several $\left(n, n^{\prime}\right)$ and $\left(n, n^{\prime} \gamma\right)$ measurements, was adopted in our evaluation for the 5- to 9-MeV energy region. For $E_{n}<5 \mathrm{MeV}$, we mainly used the $\left(n, n^{\prime}\right)$ measurements of Towle and Gilboy (To62) and Tsukada et al. (Ts61), and the ( $n, n^{\prime} \gamma$ ) measurements of Chung et al. (Ch68) and Mathur et al. (Ma65) to determine the cross sections. For the neutron energy region from 9 to $20 \mathrm{MeV}$, we used a smooth extrapolation of the lower energy results that passed through the $14-\mathrm{MeV}$ measurements of Stelson et al.

(St65) and Bonazzola et al. (Bo65a). Because the Information obtained in the $14 \mathrm{-MeV}$ experiments (St65, Bo65a) mainly concerns states below 3-MeV excitation, we assumed roughly similar shapes for the cross sections to states with excitation energy between 3.5 and $5 \mathrm{MeV}$.

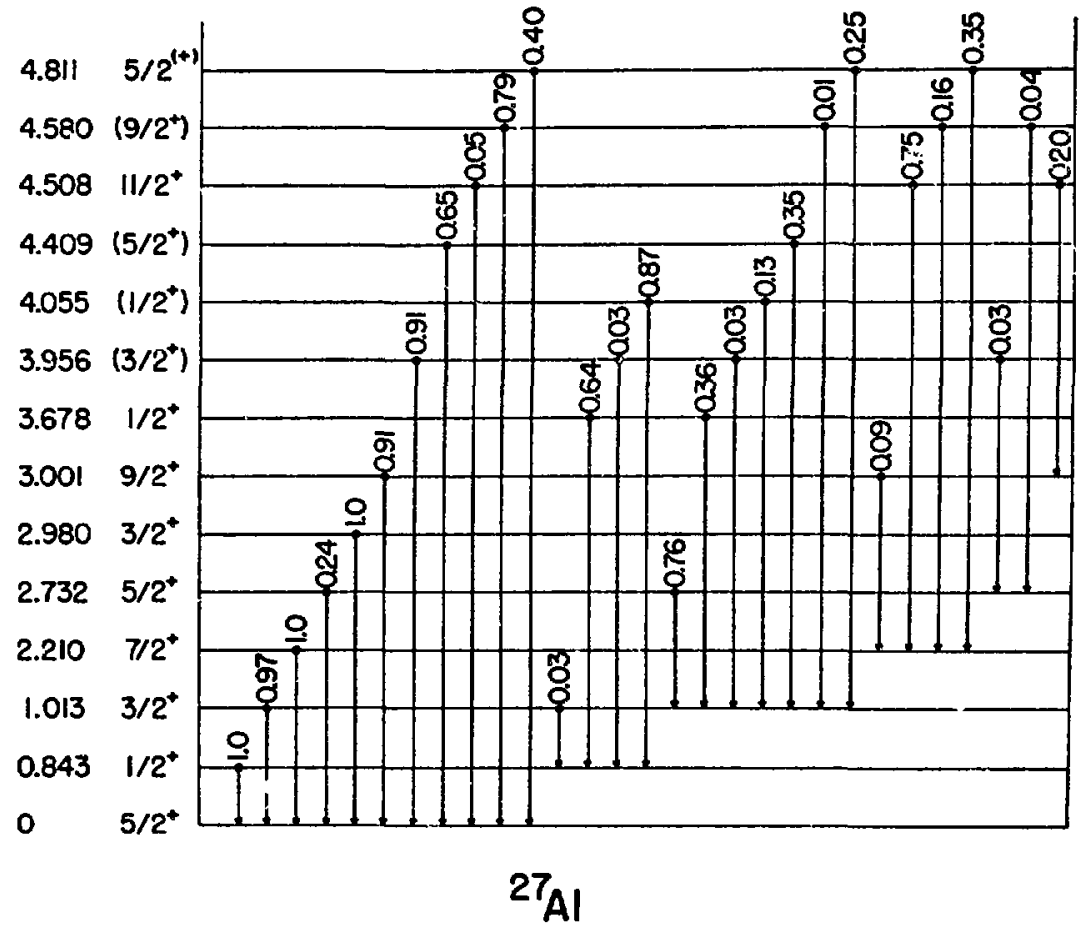

Fig. 21. Energy-level decay scheme for ${ }^{27} \mathrm{Al}$. Note that the erergy scale is distorted. 
The $\left(n, n^{\prime}\right)$ excitation cross sections that resulted from this analysis and much of the available experimental data are shown In FIgs. 22-31. Because some of the levels are too closely spaced to be clearly resolved in the measurements, we comblned the excltation cross section to nearby levels in several of the figures. In all cases the shapes of the curves near threshold are based on Hauser-Feshbach calculations. The related $\left(n, n^{\prime} \gamma\right)$ measurements are described in $\sec , 3.2$.

\section{$\frac{\left.2.4 .2 \text { The }{ }^{27} \mathrm{Al}\left(\mathrm{n}, \mathrm{n}^{\prime}\right) \text { Cross Sections for } \mathrm{E} \times{ }^{27} \mathrm{Al}\right) \geq}{5 \mathrm{MeV} .}$}

The $\left(n, n^{\prime}\right)$ cross sections to states in 27 Al with $E_{x}>5 \mathrm{MeV}$ were obtalned in several steps. First, the total inelastic cross section for neutron energies above $5 \mathrm{MeV}$ was estimated from direct measurements at $7 \mathrm{MeV}$ by Thomson (Th63) and Towle and Owens (To67), from measurements of the ground state $\left(n, n^{\prime} \gamma\right)$ trans1tions between 5 and $9 \mathrm{MeV}$ by Dickens (D171), and by subtraction of the evaluated elastic, $(n, \gamma),(n, p)$, $(n, d),(n, t),(n, \alpha)$, and $(n, 2 n)$ cross sections from the evaluated total cross section. The resulting total lirelastic cross section, which includes the ( $n, n p)$ and $(n, n \alpha)$ reactions, is given in FIg. 32 . The portion of the inelastic cross section due to states with $\mathrm{E}_{\mathrm{x}}>5 \mathrm{MeV}$ was then determined by subtracting the component from states with $\mathrm{E}_{x}<5 \mathrm{MeV}$ (Sec. 2.4.1), and the remainder was distributed among the states in ${ }^{27} \mathrm{Al}$ with $\mathrm{E}_{\mathrm{x}}>5 \mathrm{MeV}$ by using a simple evaporation model. In this calculation, the cross section was assumed to have the form

$$
\sigma\left(E_{x}\right) \propto\left(E_{n}^{\prime}-E_{x}\right) \exp \left(E_{x} / T\right)
$$

where $E_{n}^{\prime}$ is the total center-of-mass energy ava11able.

The nuclear temperatures used in the calculations are based approximately on $\left(n, n^{\prime}\right)$ measurements by Thomson (Th63) at $7 \mathrm{MeV}$ and Graves and Rcsen

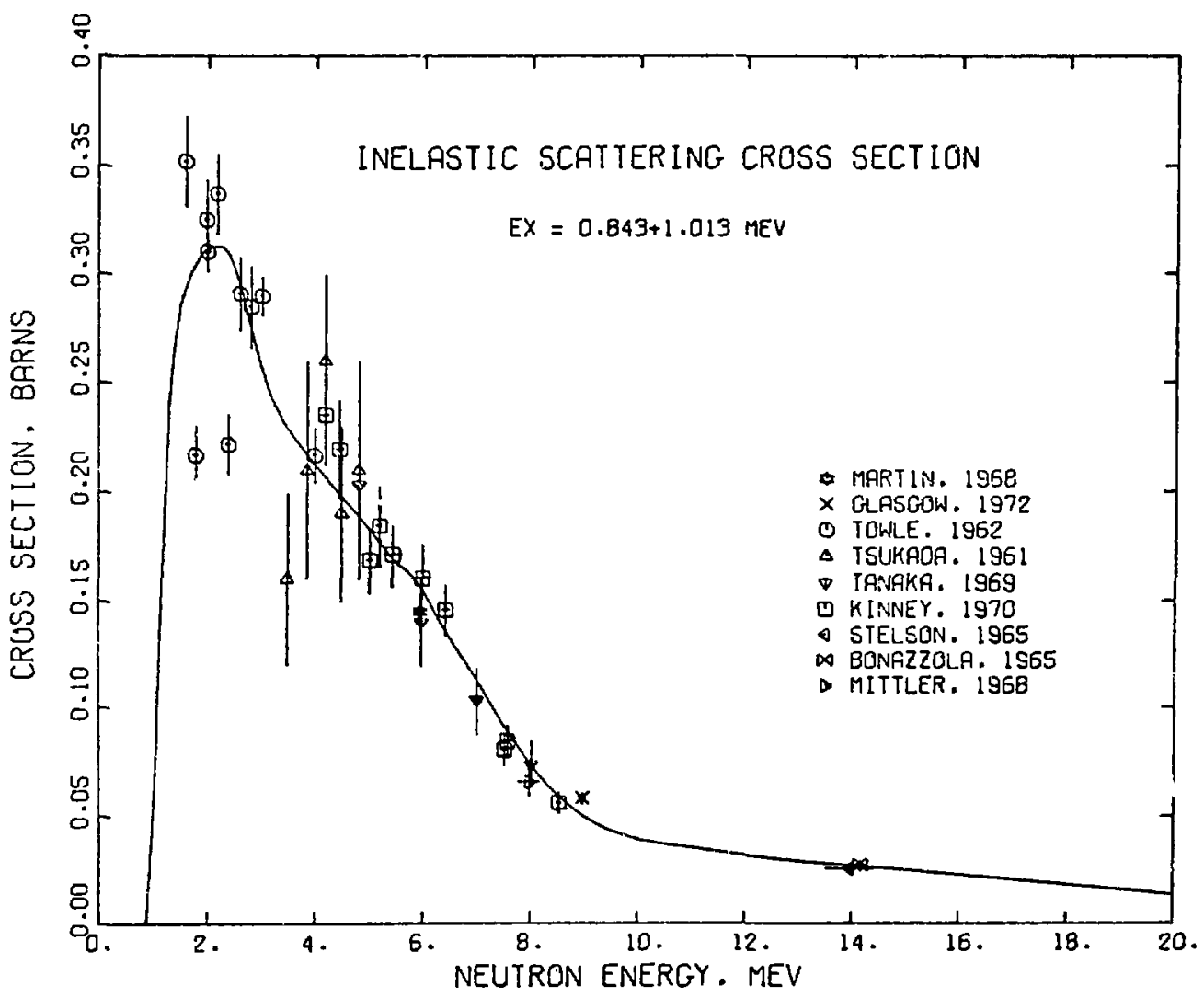

Fig. 22. Measured and evaluated inelastic-scattering cross section to the combined $0.843-$ and $1.013 \cdot-$ MeV levels of $27 \mathrm{Al}$. 
(Gr53) at $14 \mathrm{MeV}$, and are given by the expression

$$
T=0.52 \mathrm{E}_{\mathrm{n}}^{0.265}(\mathrm{MeV}),
$$

where $E_{n}$ is the laboratory neutron energy in MeV. This choice of temperature also agrees with an inelastic neutron-spectrum measurement by Schectman and Anderson (Sc66) at $14 \mathrm{MeV}$ for outgoing neutron energles between 1.3 and $4 \mathrm{MeV}$. If, however, the schectman and Anderson analysis is weighted toward slightly higher secondary neutron energies, a significantly higher temperature (1.9 MeV) results, Indicating that the simple evaporation model used here might underestimate the cross section for higher energy inelastic neutrons.

The $\left(n, n^{\prime}\right)$ cross sections for $E_{x}>5 \mathrm{MeV}$ that resulted from the above analysis are represented in the ENDF/B files as excitation cross sections to $27 \mathrm{fic}-$ titious levels in ${ }^{27}$ Al with excitation energies between 5.25 and $18.875 \mathrm{MeV}$. Each of these "levels" represents a bin or group of levels over a range of excitation energies. Bin widths of $0.5 \mathrm{MeV}$ are used for $E_{x}<17 \mathrm{MeV}$ and widths of $0.75 \mathrm{MeV}$ for higher ex- citation energies. This treatment as quasi-discrete levels allows the energy-angle relationships of outgoing neutrons to be preserved in a very simple manner; In particular, it preserves the forward peaking in the laboratory system of the lower-energy secondary neutrons caused by center-of-mass motion.

2.5 The ${ }^{27} \mathrm{Al}(\mathrm{n}, \mathrm{np})^{26} \mathrm{Mg},{ }^{27} \mathrm{Al}(\mathrm{n}, \mathrm{n} \alpha)^{23} \mathrm{Na}$, and ${ }^{27} \mathrm{Al}(\mathrm{n}, 2 \mathrm{n})^{26} \mathrm{A1}$ Cross Sections

The thresholds for the $(n, n p),(n, n \alpha)$, and $(n, 2 n)$ reactions on ${ }^{27} \mathrm{~A} 1$ are $8.58,10.48$, and 13.54 $\mathrm{MeV}$, respectively. Very little information is avallable on these reactions, and the evaluated curves described here are little more than rough estimates in some regions.

Measured values of the $(n, n p)$ cross section near $14 \mathrm{MeV}$ vary from $17 \mathrm{mb}$ (Ha62) to $200 \mathrm{mb}$ (G161), with several intermediate results (A157, Al61). Information on this cross section is also avaljable from gamna-ray production measurements for the $1.809-\mathrm{MeV}$ photon, which results from de-excitation of the first exclted state in ${ }^{26} \mathrm{Mg}$. Many of the higher states in

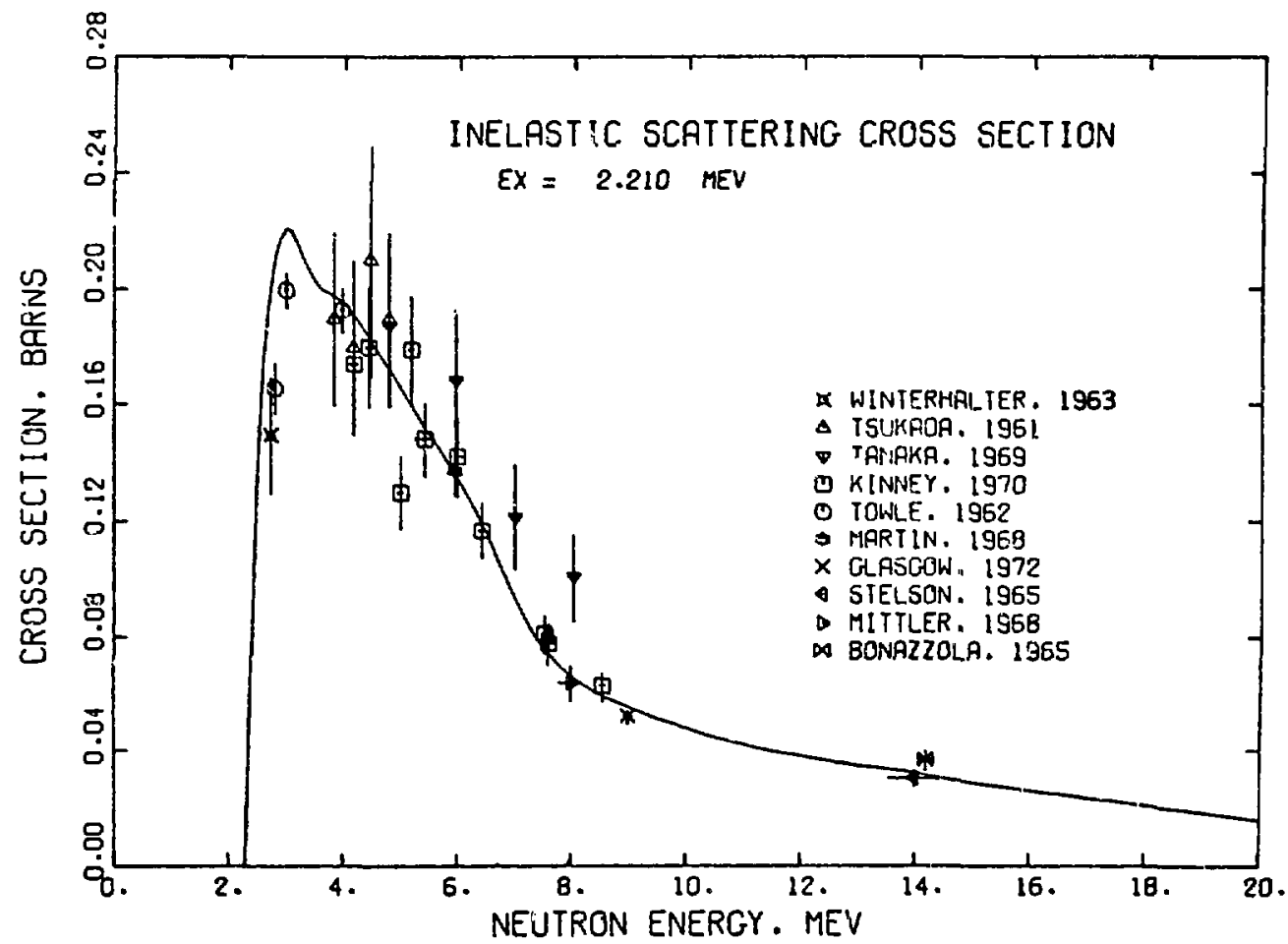

Fig. 23. Measured ani evaluated inelastic-scattering cross section to the $2.210-\mathrm{MeV} 1$ evel of ${ }^{27} \mathrm{Al}$. 
${ }^{26} \mathrm{Mg}$ cascade through the $1.809-\mathrm{MeV}$ level, as is shown in the level diagram of Fig. 33 (En67), so that the production cross section for the $1.809-\mathrm{MeV}$ photon gives a lower limt for the $(n, n p)$ cross section, after correction for the $(n, d)$ reaction. The evaluated $(n, x y)$ cross section for the $1.809-\mathrm{MeV}$ photon is $112 \mathrm{mb}$ at $14 \mathrm{MeV}$, as is described in Sec. 3.2.1. Our evaluated ( $n, a p)$ cross section at that energy is approximately $160 \mathrm{mb}$.

The $(n, n p)$ and $(n, n \alpha)$ cross sections, together with the total $\left(n, n^{\prime}\right)$, tha $\left(n, n_{\gamma}\right)$, and the $(n, 2 n)$ cross sections are shown in Fig. 34. The $\left(n, n^{\prime}{ }^{\prime}\right)$ cross section is the sum of $\left(n, n^{\prime}\right)$ reactions to states in ${ }^{27} \mathrm{Al}$ that decay by gamma emission, and the total $\left(n, n^{\prime}\right)$ is the sum of the $\left(n, n_{\gamma}\right),\left(n, n_{p}\right)$, and $(n, n \alpha)$ cross sections. Because there is no experimental information available on the $(n, n x)$ cross section, the curve in Fig. 54 is only a rough estimate.

The only direct infermation on the $(n, 2 n)$ cross section comes from activation measurements (Ma60, Cs63) Involving the isomeric first exclted stare of ${ }^{26} \mathrm{Al}$ at excitation energ; $229 \mathrm{keV}$. Because many photon transitions in ${ }^{26} A 1$ bypass this state (En67), the activation measurements furnish only a lower limit for the $(n, 2 n)$ cross section. The evaluated curve shown in Fig. 34 is basid roughly on the assumption that highly-excited states in ${ }^{27}$ Al decay $50 \%$ by neutron enission. The $(n, 2 n)$ cross section that results at $20 \mathrm{MeV}$ is slightly more than twice the measured

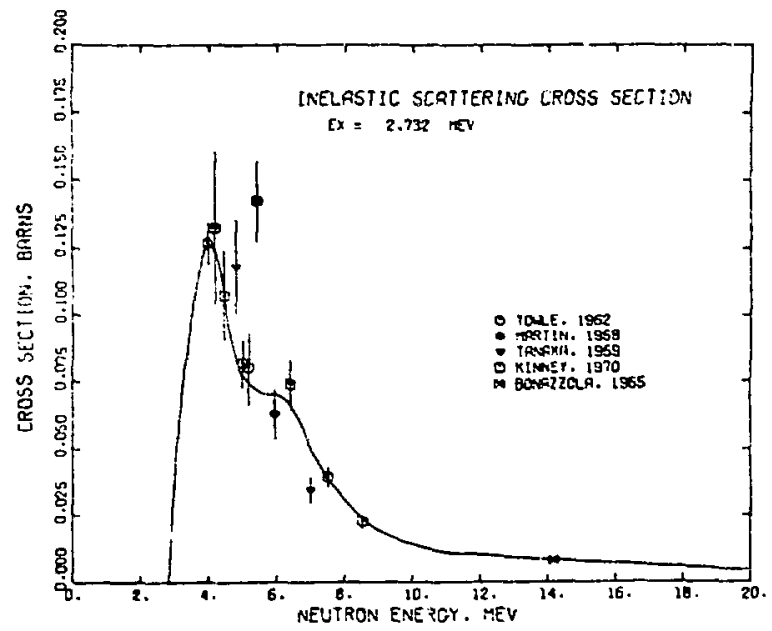

Fig. 24. Measured and evaluated inelastic-scattering cross section to the $2.732 \mathrm{MeV}$ level of $27_{\mathrm{A} 1}$. value for production of the metastable state. This value appears reasonable, but it is only a rough estimate.

The evaluated $(n, 2 n)$ cross section is entered as a separate reaction in the ENDF/B f1les. The $(n, n p)$ and $(n, n \alpha)$ cross sections are not entered explicitly, but are included by flagging the $\left(n, n^{\prime}\right)$

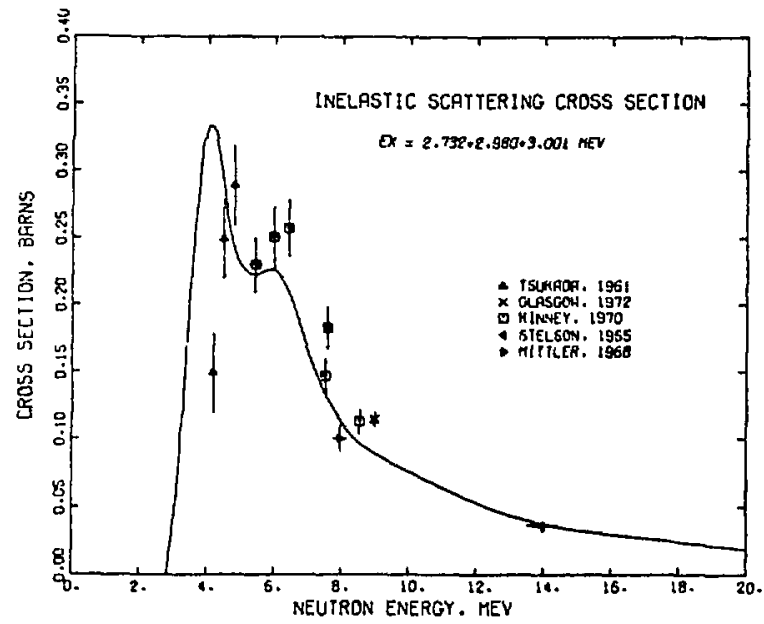

Fig. 25. Measured and evaluated inelastic-scattering cross section to the combined 2.732-, 2.980 and $3.001-\mathrm{MeV}$ levels of $27_{\mathrm{Al}}$.

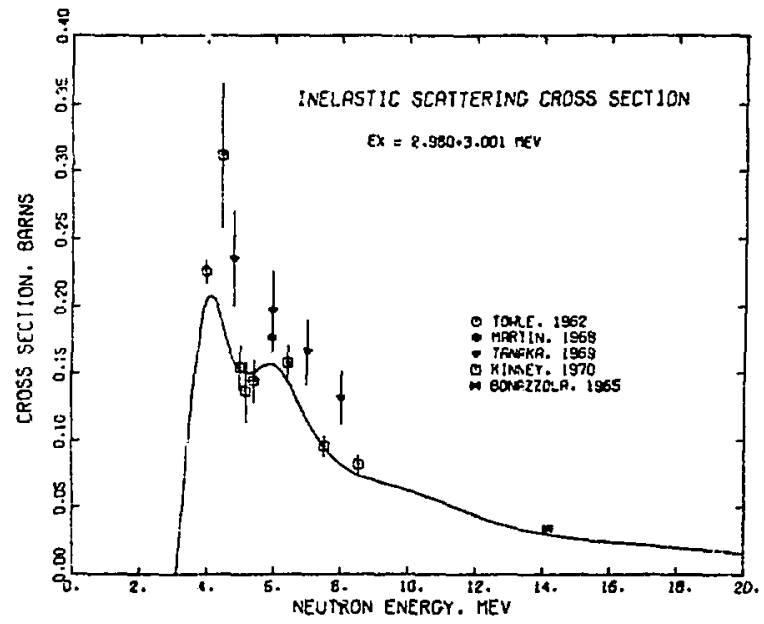

Fig. 26. Measured and evaluated inelastic-scattering cross section to the comlined 2.980 - and 3.0 $0 \mathrm{~d} 1-\mathrm{MeV}$ levels of $27 \mathrm{Al}$. 


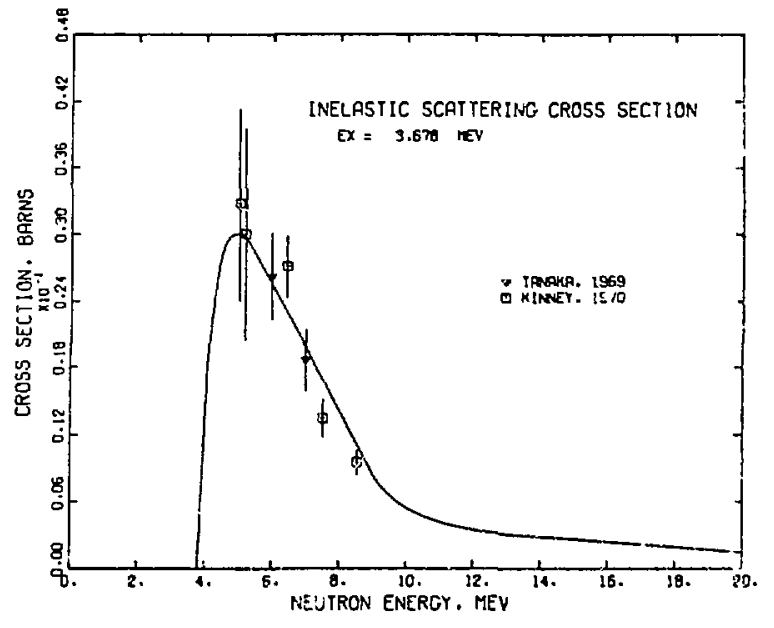

Fig. 27. Measured and evaluated inelastic-scatter ing cross section to the $3.678 \mathrm{MeV}$ level of $" 7 \mathrm{Al}$.

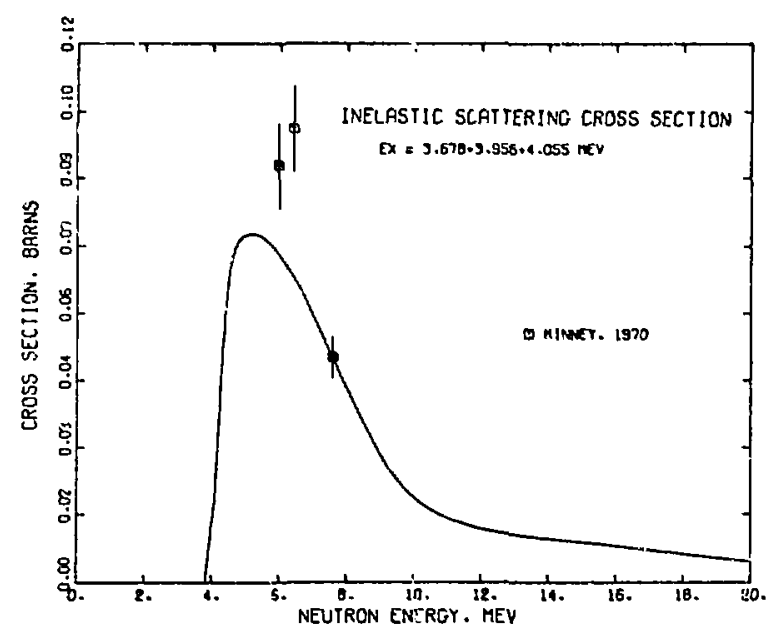

Fig. 28. Measured and evaluated inelastic-scattering cross section to the combined 3,678-., $3.956-$, and $4.055-\mathrm{MeV}$ levels of $27_{\mathrm{Al}}$.

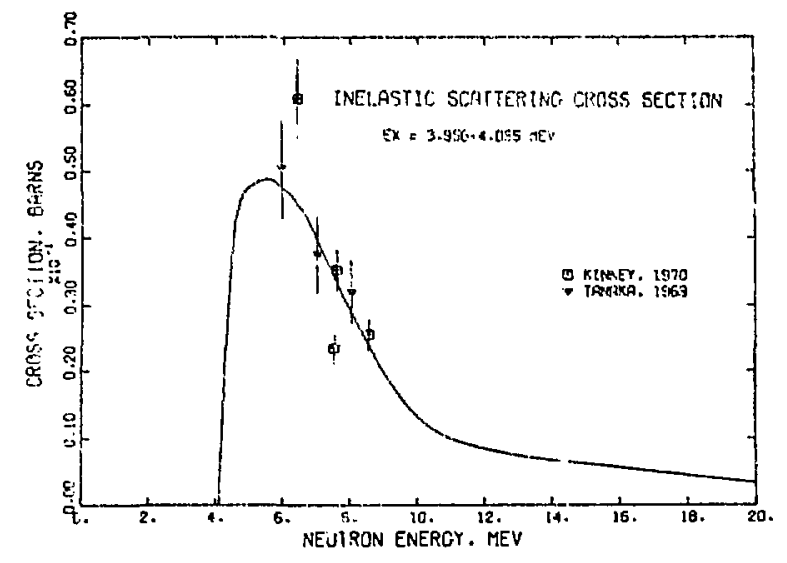

Fig. 29. Measured and evaluated inelastic-sca,tering cross section to the combined 3.956and $4.0 .55-\mathrm{MeV}$ levels of $2 \overline{\mathrm{A}} \mathrm{A}$.

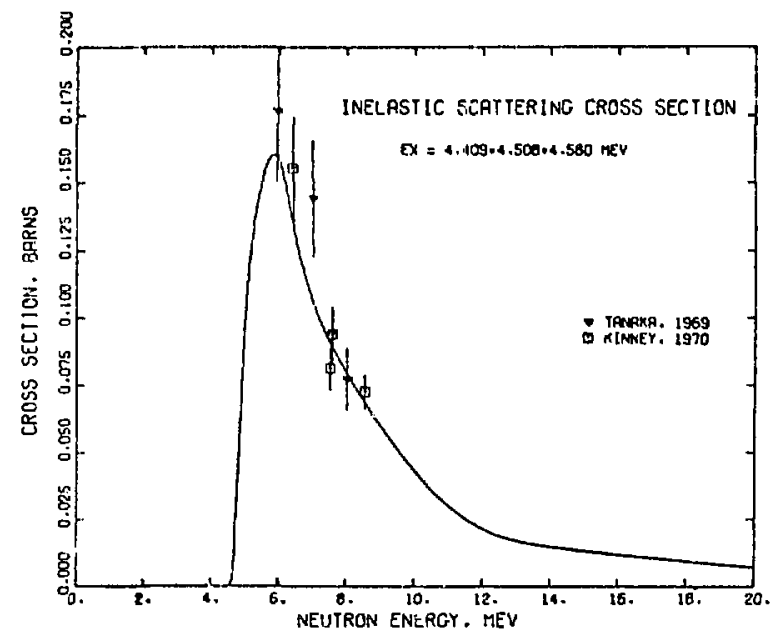

F1g. 30. Measured and evaluated inelastic-scattering cross section to the combined 4.409-, $4.508-$, and $4.580-\mathrm{MeV}$ levels of $27 \mathrm{Al}$.

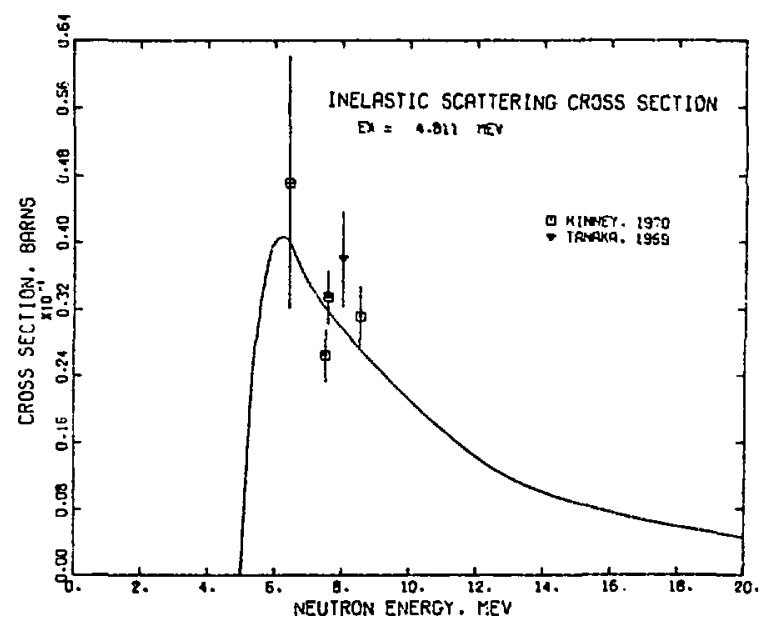

Fig. 31. Measured and evaluated inelastic-scattering cross section to the $4.811-\mathrm{MeV}$ level of ${ }^{27} \mathrm{Al}$. 


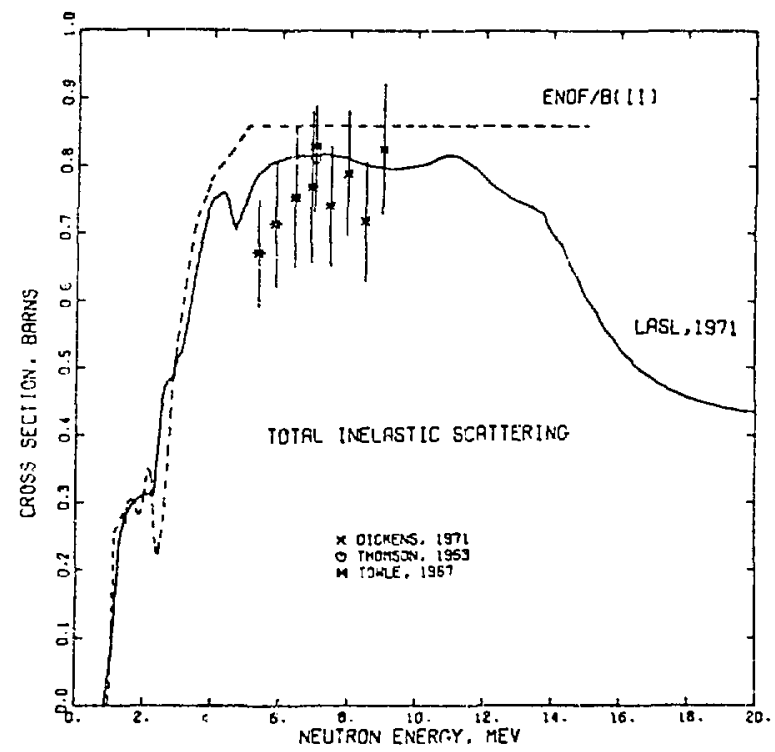

Fig. 32. Measured and evaluated total inelasticscattering cross section for $27 \mathrm{Al}$. The $(n, n p)$ and $(n, n \alpha)$ reactions are lncluded.

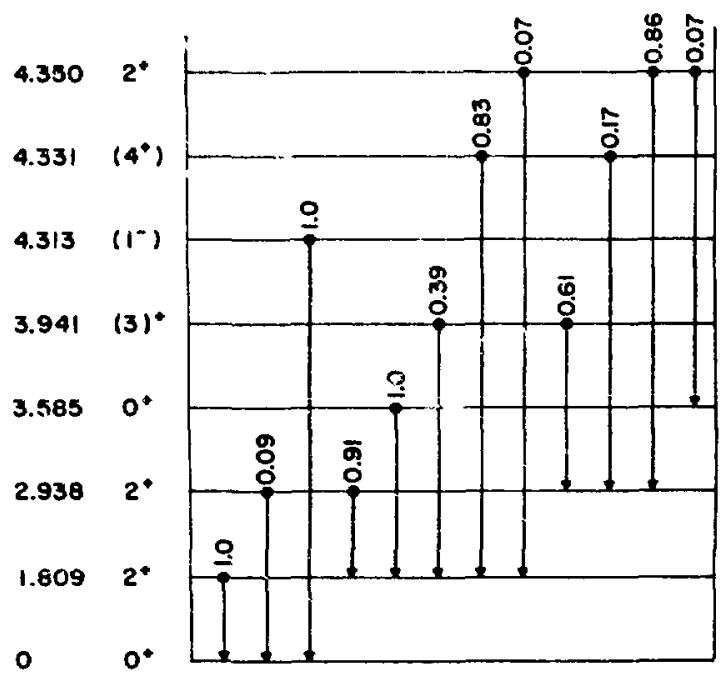

${ }^{26} \mathrm{Mg}$

Fig. 33. Energy-level secay scheme for ${ }^{26} \mathrm{Mg}$. Note that the energy scale is distorted.

reactions to certain higher-excication states in ${ }^{27} \mathrm{Al}$ as decaying by proton or alpha emisston. This representation assumes a sequence in the reactions that is on $y$ partially true; however, it should cause no difficulty in most practical problems, and it allows the energy-angle relationship of secondary neutrons so be better preserved in the laboratory system.

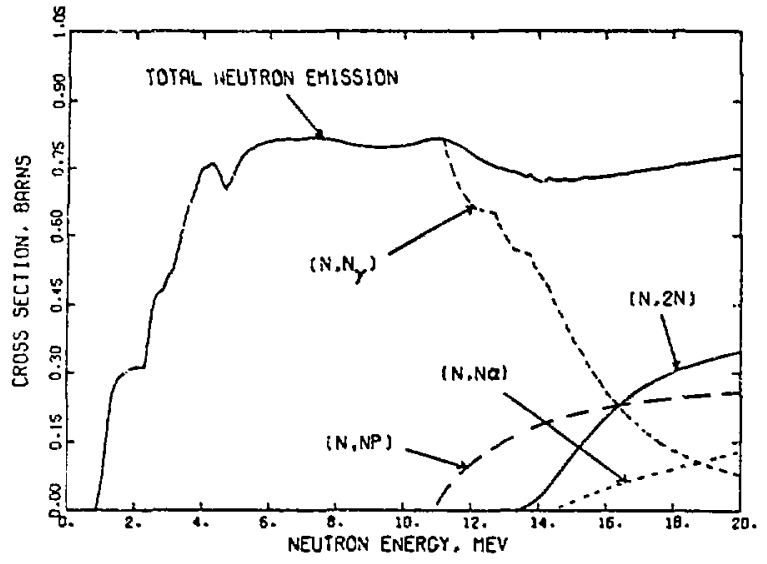

Fig. 34. The total neutron-emission cross section compared to its constituent $\left(n, n_{\gamma}\right),(n, n p)$, $(n, n \alpha)$, and $(n, 2 n)$ reactions. The $\left(n, n_{\gamma}\right)$ curve is defined as that part of the $\left(n, n^{\prime}\right)$ cross section which results in photon emission.

\subsection{The ${ }^{27} \mathrm{Al}(\mathrm{n}, \mathrm{p})^{27} \mathrm{Mg}$ Cross Section}

The threshold for the $(n, p)$ reaction with ${ }^{27}{ }_{A 1}$ occurs at $1.90 \mathrm{MeV}$. For neutron energles below $5 \mathrm{MeV}$, we adopted an earlier evaluation by .Toanou and Stevens (Jo64), which was alco used for ENDF/B(II). Above $5 \mathrm{MeV}$, the recommended curve Is based on measurements that use the $9.5-m i n B^{-}$activity of ${ }^{27} \mathrm{Mg}$.

The evaluated curve is compared to the avallable measurements between threshold and $7 \mathrm{MeV}$ in Fig. 35, between 7 and $13 \mathrm{MeV}$ in $\mathrm{Fig}$. 36, and between 13 and $20 \mathrm{MeV}$ in Fig. 37. The results of Ferguson and A1bergotti (Fe67), which are substantlally lower thar the evaluation in Figs. 36 and 37, are from a relative measurement that was normalized to a value of 55 mb near $13 \mathrm{MeV}$. Similarly, absolute data were obtained at only one energy (50 mb at $14.4 \mathrm{MeV}$ ) In the Gabbard and Kern measuremen; (Ga62), which also 11 es well below the evaluation, and the remaining Gabbard points were normalized to that value. Therefore, because the preponderance of experimental data near $14 \mathrm{MeV}$ suggest a substantlally higher $(n, p)$ cross section, we chose the evaluated curve to follow approximately the measurements of Mani (Ma60), resulting in a cross section of $77 \mathrm{mb}$ at $14.1 \mathrm{MeV}$.

\subsection{The ${ }^{27} \mathrm{Al}(\mathrm{n}, \mathrm{d})^{26} \mathrm{Mg}$ and ${ }^{27} \mathrm{Al}(\mathrm{n}, \mathrm{t})^{25} \mathrm{Mg}$ Cross Sections The thresholds for the ${ }^{27} \mathrm{Al}(\mathrm{n}, \mathrm{d})$ and ${ }^{27} \mathrm{Al}(\mathrm{n}, \mathrm{t})$ reactions are 6.27 and $11.29 \mathrm{MeV}$, respectively. Be- cause only one measurement is avaflable for the $(n, d)$ reaction, we assumed that the cross section has about the same shape as the $(n, p)$ cross section. The re-}




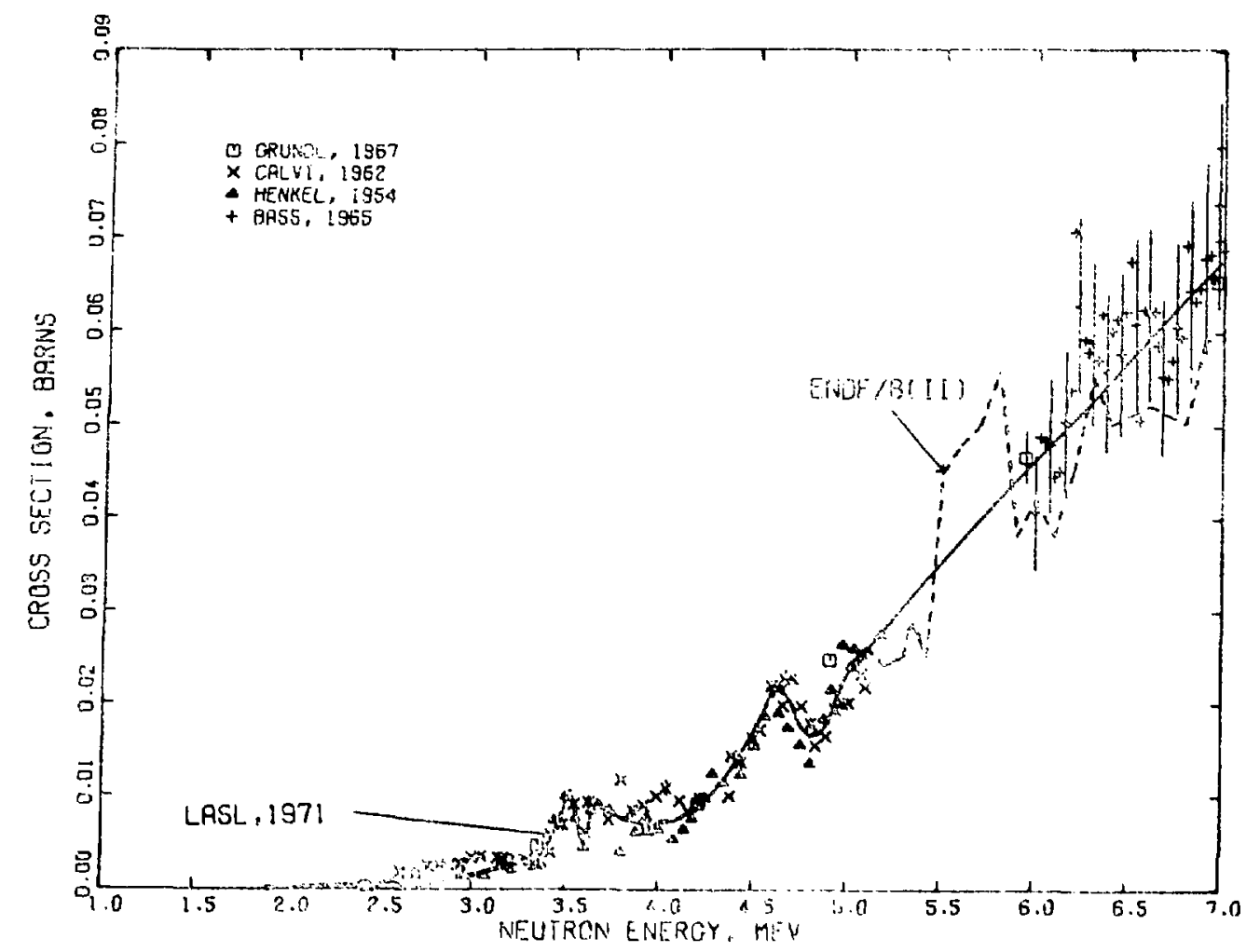

Fig. 35. Mensuret ari evaluated ${ }^{27} \mathrm{~A}:(n, F){ }^{27} \mathrm{Mg}$ eross section from 1 to $7 \mathrm{MeV}$.

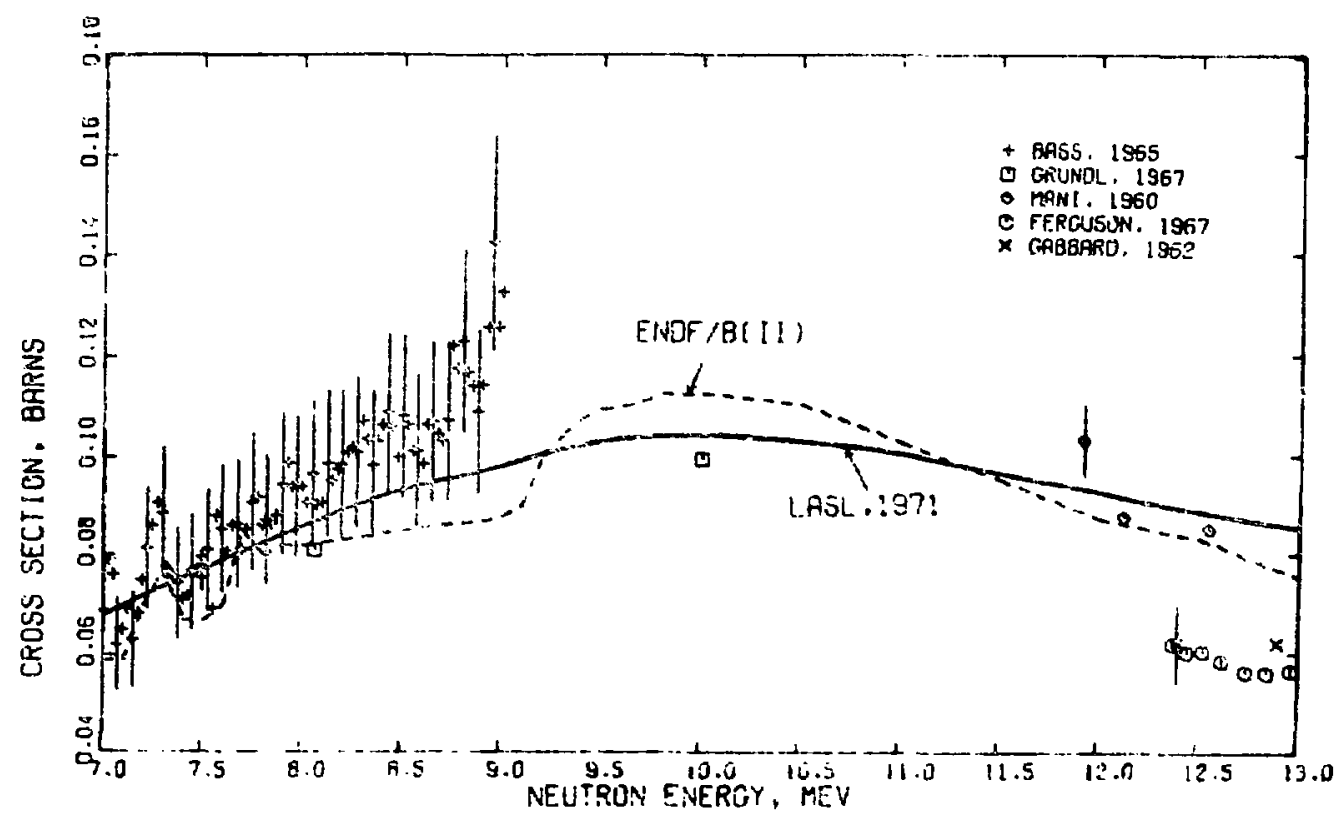

Fig. 36. Measured and evaiuated ${ }^{27} \mathrm{Al}(\mathrm{n}, \mathrm{p})^{27} \mathrm{Xg}$ cross section from 7 to 13 MeV. 


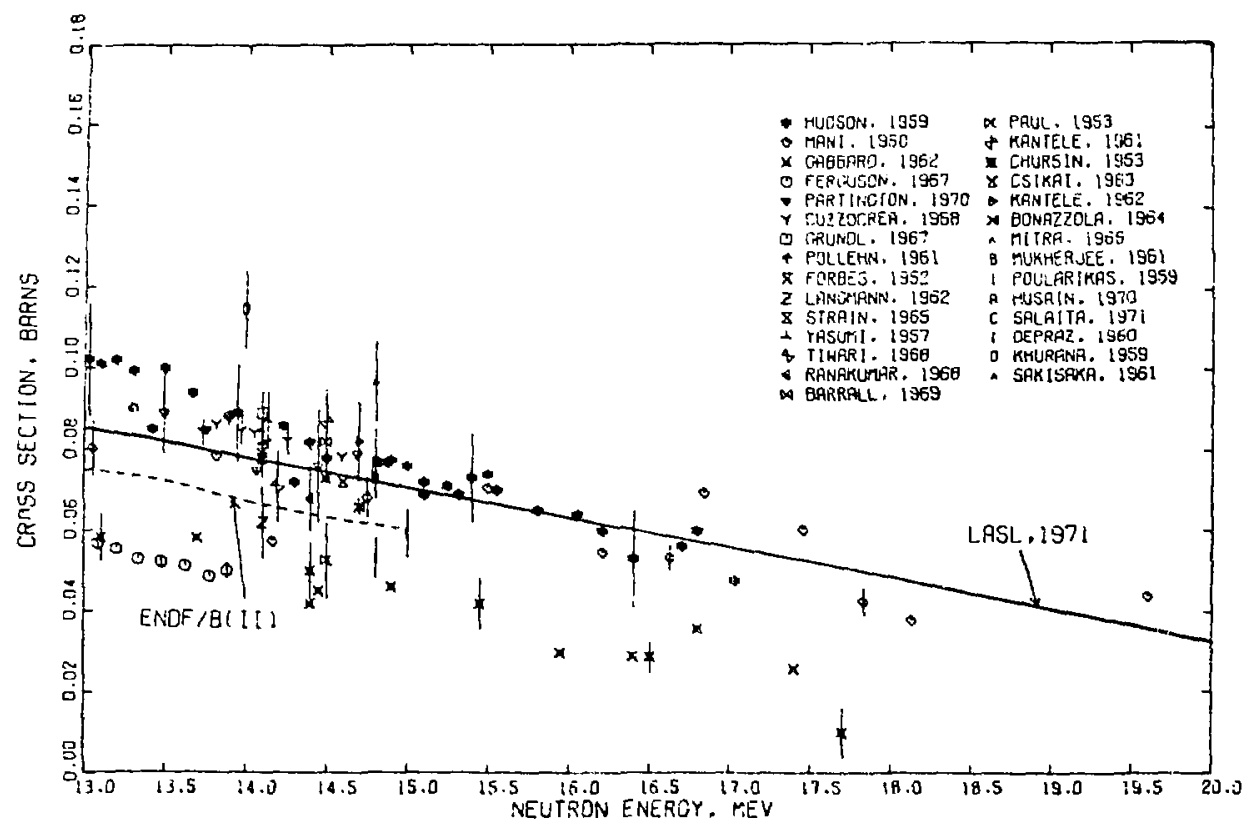

Fig. 37. Measured and evaluated ${ }^{27} \Lambda 1(n, p){ }^{27} \mathrm{Mg}$ cross section from 13 to $20 \mathrm{MeV}$.

sulting curve was normalized to the lone measurement by Glover and Weigold (G161) at $14.8 \mathrm{MeV}$, as shown in Fig. 38. There are no measurements available for the $(n, t)$ reaction: so we assumed the same shape for the $(n, t)$ cross section as was used for the $(n, d)$ cross section, with an appropriate shift in energy. The evaluated $(n, t)$ curve, also shown in Fig. 38, reaches a maximum of $15 \mathrm{mb}$ at $20 \mathrm{MeV}$.

\subsection{The ${ }^{27} \mathrm{Al}(\mathrm{n}, a)^{24} \mathrm{Na}$ Cross Section} The ${ }^{27} \mathrm{Al}(\mathrm{n}, \infty)$ reaction forms ${ }^{24} \mathrm{Na}$ which $B^{-}$decays to ${ }^{24} \mathrm{Mg}$ with a 15-h half-life. Consequently, a large number of cross-section measurements are avaflable from activation studies. Although the threshold for the reaction is $3.25 \mathrm{MeV}$, the cross section does not become important unt1l above $6 \mathrm{MeV}$. The evaiuated curve between 5 and $12.5 \mathrm{MeV}$ is compared to the avallable measurenents and to the ENDF/B(II) curve in Fig. 39. Our results 1te below the ENDF/B(II) data at these energies and represent somewhat of a compromise between the neasurements of Butler and Santry (Bu63) and rewe: et al. (Te60). It is interesting to note that if the Tewes data are renoralized by a factor of 1.37 , very good agreement with the Butler data is obtained.

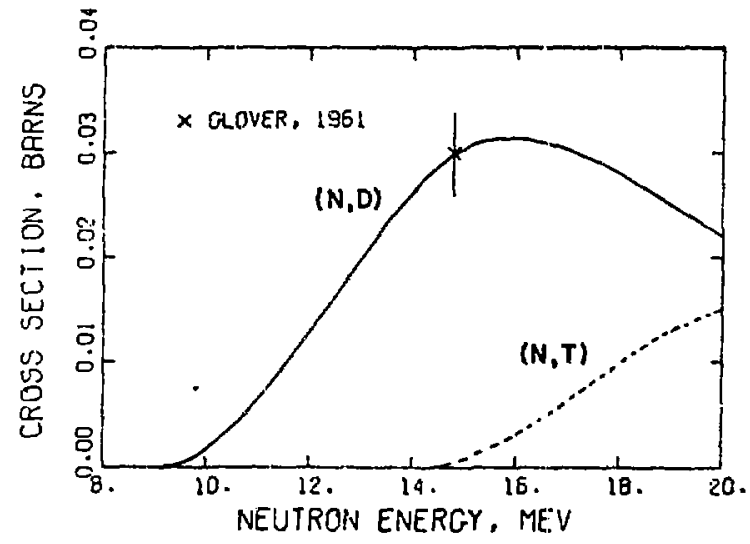

Fig. 39. Evaluated ${ }^{27} \mathrm{Al}(\mathrm{n}, \mathrm{d}){ }^{26} \mathrm{Mg}$ and ${ }^{27} \mathrm{Al}(\mathrm{n}, \mathrm{t}){ }^{25} \mathrm{Mg}$ cross sectlons compared to the $(n, d)$ measurement by Glover (G161).

Figure 40 shows the measured and evaluated $(n, \alpha)$ cross section from 12.5 to $20 \mathrm{MeV}$. The evaluated re-

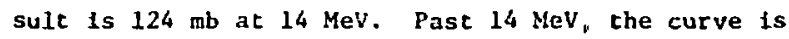
well determined and is based mainly on the data of Butler and Santry (Bu63) and Paulsen and LIskien (Pa65). 


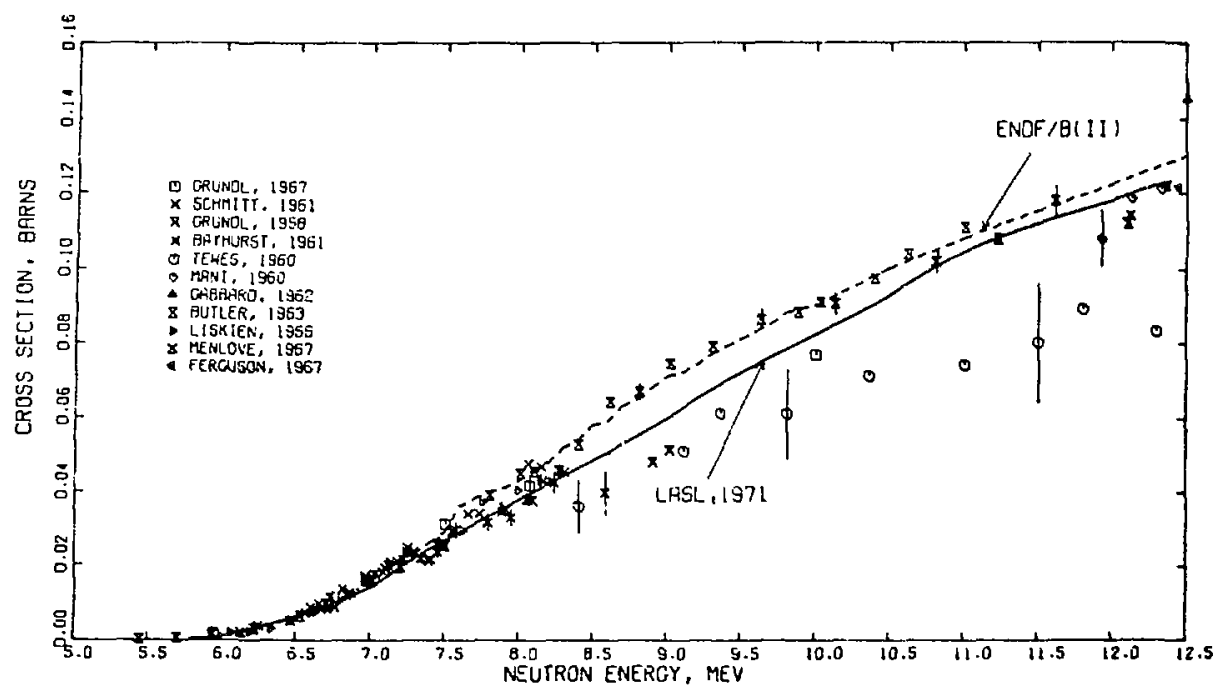

Fig. 39. Measured and evaluated ${ }^{27} \mathrm{Al}(\mathrm{n}, \alpha)^{24} \mathrm{Na}$ cross section from $5 . \mathrm{C}$ to $12.5 \mathrm{MeV}$.

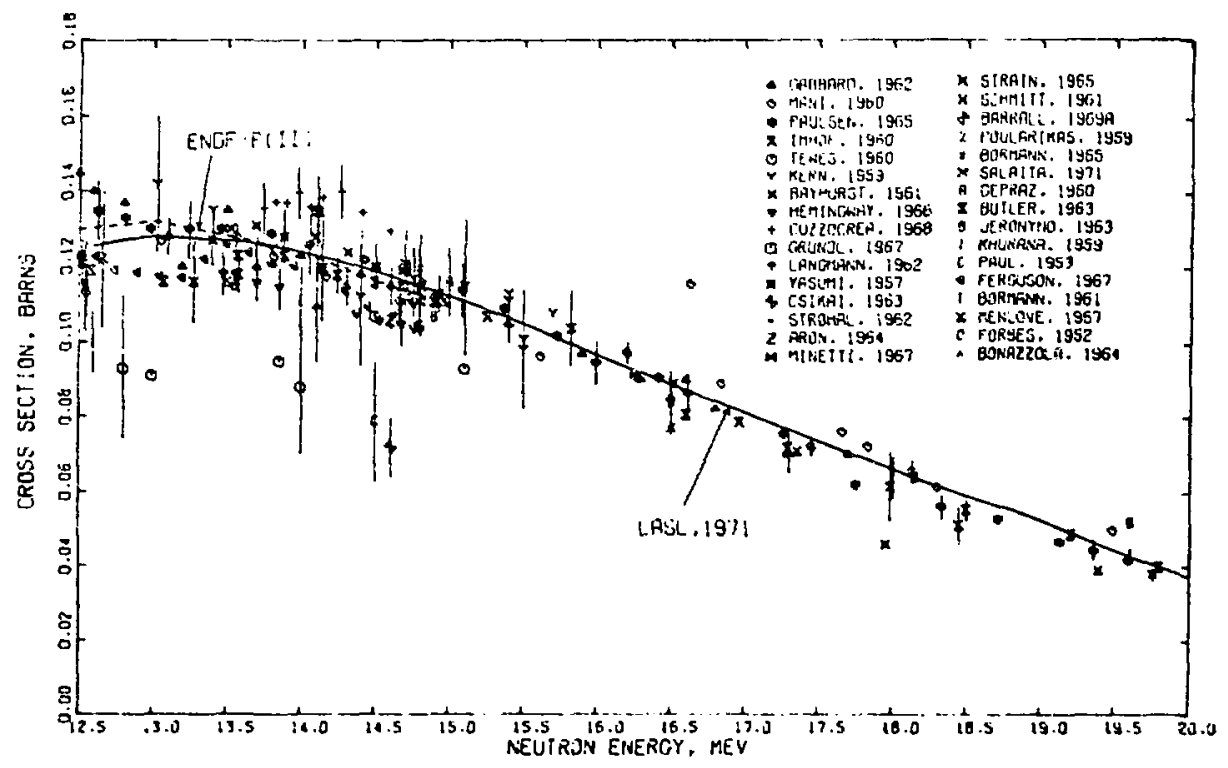

Fig. 40. Neasured and evaluated ${ }^{27} \mathrm{Al}(n, a){ }^{24} \mathrm{Na}$ cross section from 12.5 to $20 \mathrm{MeV}$.

3. PHOTON-PRODUCIION CROSS SECTIONS AND ENERGY SPECTRA

\subsection{Photon Production from the ${ }^{27} \Lambda(n, \gamma)^{28} \wedge 1$ Reaction}

In the absence of data at epithermal neutron energies, we assumed that the photon energy spectrum resulting from zadiative capture of thermal neutrons applies at all neutron energies for the $(n, y)$ reac- tion. In evaluating the thermal spectrum, we took the energies of the prominent photons primarily from the geisurements of Orphan et a1. (Or70), and relied mainly on the compllation by Bartholomew et al. (Ba67) for the photon intensities. Preliminary low-background measurements on a very pure sample by Jurney (Ju71) were also used in evaluating the intensities. 
The Jurney results indicate that several of Orphan's strong lines below $1 \mathrm{MeV}$ are spurlous, and consequently these were omitted from the evaluation.

In addition to the strong lines, a continuum of gamma rays was included in the evaluation based on the weak lines and unresolved continuum given by orphan et al. $(0 r 70)$. The intensicy of the continuum was normalized to bring the total energy pex capture up to the binding energy of ${ }^{28} \mathrm{Al}$. Table II lists the composite photon spectrum (lines plus continuum) ६rouped into 0.5-MeV hins, together with spentra measured by seven previous authors. The total photon multiplicity for the evaluatei spectrum is 2.035 photons/capture. The last four colums is Table II agree semi-quantitatively except at the lowest energies. The large multiplictiy in the lowest energy bin for the evaluation results mainly from the extremely intense $30.6-\mathrm{keV}$ photon from the first ex cited state of ${ }^{28} \mathrm{Al}(\mathrm{Ju} 71)$. Unfortunately, we did not become aware of the aeasurement by Hardell et al. (Ha69) given in Table II unthl afcer the evaluation. We plan to incorporate those results intc thi evaluation at a future date.
3.2. Photon Production from ${ }^{27} \mathrm{Al}(\mathrm{n}, x y)$ Reactions

Inelastic scattaring is the dominant source of phctons in the MeV neutron energy region. The thre. classes of inelastic gama rays that we conside:er. are discrete phucons resulting fron excitation of states in ${ }^{27} \mathrm{Al}$ with $E_{\mathrm{X}}<5 \mathrm{MeV}$, discrete photons resulting from cascades to levels below $5 \mathrm{MeV}$ from higher states in a continuum or unresolved reglon, and transitions comple: $y$ wittin the continuur itgion, defined here to ir ates in 27 with $E_{x}>5$ sti. Contribution frot zine first two classes of transitions are described in suc, 3.2.l asd the thinc class is described in Sec. 3.2.2. In addition to photons f.oin inelasti: scattoring, photons fron (n,pr). $(n, n p \gamma)$, and $(n, 2 \pi y)$ reactions are also inciuded in the evaluation.

\subsubsection{Discrece Phorons from ${ }^{27}$ Al $(n, x y)$ Reactions}

The photons from inelastic scattering to levels in ${ }^{27}$ Al with $E_{x}$ - 5 sinel are Included explicitly in the evaluation. The ross section for these discrete photons was calculated below $E_{i 1}=5 \mathrm{MeV}$ from the evaluated ( $n, n^{\prime}$ ? exritarion cross sections, cugether

TABLE II

CAPTURE GANMA-RAi SPECTRUM OF 27 AI FOK THERMAL NEUTRONS IN PHOTONS/100 CAPTURES

\begin{tabular}{|c|c|c|c|c|c|c|c|c|}
\hline $\begin{array}{c}\text { Photon Energy } \\
\text { Bin (MeV) } \\
\end{array}$ & $\begin{array}{c}\text { Bartholomew } \\
1958^{a}\end{array}$ & $\begin{array}{c}\text { Groshev } \\
1959^{a} \\
\end{array}$ & $\begin{array}{r}\text { Draper } \\
1963^{\mathrm{a}} \\
\end{array}$ & $\begin{array}{c}\text { Greenwood } \\
1965^{\circ} \\
\end{array}$ & $\begin{array}{c}\text { liardel1 } \\
1969 \\
\end{array}$ & $\begin{array}{c}\text { Maerker } \\
1969 \\
\end{array}$ & $\begin{array}{c}\text { Orphan } \\
1970 \\
\end{array}$ & $\begin{array}{l}\text { Present } \\
\text { Results }\end{array}$ \\
\hline $\begin{array}{r}0-0.5 \\
0.5-1.0 \\
1.0-1.5 \\
1.5-2.0 \\
2.0-2.5 \\
2.5-3.0 \\
3.0-3.5 \\
3.5-4.0 \\
4.0-4.5 \\
4.5-5.0 \\
5.0-5.5 \\
5.5-6.0 \\
6.0-6.5 \\
6.5-7.0 \\
7.0-7.5 \\
7.5-8.0\end{array}$ & $\begin{array}{r}4.5 \\
13.5 \\
6.9 \\
10.7 \\
7.6 \\
3.3 \\
2.5 \\
3.4 \\
1.5 \\
0.5 \\
20.0\end{array}$ & $\begin{array}{r}8.1 \\
15.0 \\
10.9 \\
11.8 \\
13.1 \\
15.4 \\
5.5 \\
0.8 \\
5.3 \\
1.7 \\
24.0\end{array}$ & $\begin{array}{r}7.7 \\
5.4 \\
13.0 \\
10.0 \\
17.0 \\
7.0 \\
15.0 \\
16.0\end{array}$ & $\begin{array}{l}9.2 \\
4.9 \\
4.3 \\
8.8\end{array}$ & $\begin{array}{r}0.5 \\
2.3 \\
3.3 \\
7.0 \\
10.8 \\
20.0 \\
17.3 \\
13.6 \\
16.3 \\
18.8 \\
6.5 \\
2.3 \\
6.4 \\
1.5 \\
0.1 \\
33.0\end{array}$ & $\begin{array}{r}6.1 \\
12.5 \\
10.4 \\
13.1 \\
20.5 \\
15.9 \\
14.3 \\
16.1 \\
17.6 \\
6.8 \\
2.8 \\
6.0 \\
2.2 \\
0.7 \\
32.4\end{array}$ & $\begin{array}{r}12.6 \\
10.5 \\
0.8 \\
6.5 \\
12.9 \\
13.4 \\
10.7 \\
11.1 \\
15.0 \\
16.1 \\
5.4 \\
1.3 \\
4.5 \\
4.0 \\
2.7 \\
29.7\end{array}$ & $\begin{array}{r}27.5 \\
10.3 \\
2.5 \\
7.9 \\
12.8 \\
18.6 \\
13.9 \\
16.5 \\
19.5 \\
20.3 \\
9.5 \\
1.7 \\
7.9 \\
5.3 \\
3.0 \\
26.5\end{array}$ \\
\hline $\begin{array}{l}z \text { Binding } \\
\text { Energy }\end{array}$ & 50 & 69 & 71 & 42 & 93 & 96 & 84 & 100 \\
\hline
\end{tabular}

Taken from the compilation by Bartholomew et al. (Ba67). 
with the level decay scheme given in FIg. 21 (Sec. $2 \cdot 4 \cdot 1)$. Above $E_{n}=5 \mathrm{MeV}$, however, the second and third classes of transitions described above berome possible, and a calculation based on statistical theory was made to estimate these continuum contributions. The calculation yielded estimates of continuous photon-energy spectra ( $g$ iven in Sec. 3.2.2) as well as contributions from the continuum states to the discrete photons that are associated with the resolved states below $\mathrm{E}_{\mathrm{x}}=5 \mathrm{MeV}$.

The statistical theory calculations were performed with the code SPECTIO, using a method similar to that described by Troubetzkoy ( $\operatorname{Tr} 61$ ). For a given incident neutron energy, the probability of exclting states of excitation energy $E_{x}$ in the residual nucleus $\left({ }^{27} \mathrm{Al}\right)$ by neutron emission from the compound state $\left({ }^{28} \mathrm{Al}\right)$ was assumed to have the form

$$
N_{n} \Delta E_{x} \propto\left(E_{\max }-E_{x}\right) \sigma_{\text {Inv }}\left(E_{x}\right) \rho\left(E_{x}\right),
$$

where $E_{\max }$ is the maximum energy available in th: center-of-mass system, $\sigma_{\text {inv }}\left(E_{x}\right)$ is the inverse cross section for the trangition, and $\rho\left(E_{x}\right)$ is the density of states at energy $E_{x}$ in the residual nucleus. The decay by photon emission of states in the residui.l nucieus was assumed to be described by

$$
N_{Y}\left(E_{X}, E_{X}^{\prime}\right) \Delta E_{X} \propto\left(E_{X}-E_{X}^{\prime}\right)^{2 \ell+1} \rho\left(E_{X}^{\prime}\right)
$$

where $E_{X}$ and $E_{X}^{\prime}$ are the excitation energies of the Intilal and finel states, respectively, and $l$ is the multipole order of the transition.

For the $\left(n, n^{\prime} Y\right)$ calculations, a level density expression of the form

$$
\rho\left(E_{x}\right) \propto \exp \left(E_{x} / T\right)
$$

was included with the ane temperatures, $T$, as were used in the $\left(n, n^{\prime}\right)$ cross section evaluation in Eq. (2), Sec. 2.4.2. The Inverse cross section was taken to be constant, and pure dipole transitions $(l=1)$ were assumed. We determined the normalization of the calculations by the total inelastic cross section. Transitions entirely within the continuum region were assumed to be independent of spin. However, in calsulating the population of discrete levels due to transictons from the continum region, the number of states of spin $J$ at a particular energy in the con- tinuum was assumed proportional to (2J+1) $\exp \left(-J(J+1) / 2 \sigma^{2}\right)$, where $\sigma$ is a spin cutoff factor related to the excitation energy and nuclear moment of inertsa. Transitions from states in the continuum were allowed to proceed by dipole radiation to the eligible discrete states, and the discrete states were de-excited by the decay scheme shown in Fig. 21. A summary of the discrete photon transitions from $\left(n, n^{\prime}\right)$ reactions that were included in the evaluation is given in Table III. These transitions are from ${ }^{27} \mathrm{Al}$ states with $\mathrm{E}_{x}<5 \mathrm{MeV}$ and result from the decay scheme shown in Fig. 21. The evaluated curves for a selection of discrete gamma rays are compared to the available experimental data in Figs. 41-50. Anisotropies in the plioton angular distributions are small (Sec. 5.3). Often the experimental results at a single angle $(\omega-\cos \theta)$ have simply teen multiplied by $4 \pi$ steradians for the comparisons shown in Figs. 41-50. Where integral results are available, the " $\mu$ " entry in the figures is left blank.

TABLE III

GAMA RAYS FROM INELASTIC SCATTERING

\begin{tabular}{lll}
$\begin{array}{c}E_{Y} \\
(\mathrm{MeV})\end{array}$ & \multicolumn{1}{c}{$E_{1}$} & \multicolumn{1}{c}{$E_{f}$} \\
4.811 & $\frac{M e V)}{(M e V)}$ & 0. \\
4.580 & 4.811 & 0. \\
4.508 & 4.580 & 0. \\
4.409 & 4.508 & 0. \\
3.956 & 4.409 & 0. \\
3.798 & 3.956 & 1.013 \\
3.567 & 4.811 & 1.013 \\
3.396 & 4.580 & 1.013 \\
3.212 & 4.409 & 0.843 \\
3.113 & 4.055 & 0.843 \\
3.042 & 3.956 & 1.013 \\
3.001 & 4.055 & 0. \\
2.980 & 3.001 & 0. \\
2.943 & 2.980 & 1.013 \\
2.835 & 3.956 & 0.843 \\
2.732 & 3.678 & 0. \\
2.665 & 2.732 & 1.013 \\
2.601 & 3.678 & 2.210 \\
2.370 & 4.811 & 2.210 \\
2.298 & 4.580 & 2.210 \\
2.210 & 4.508 & 0. \\
1.848 & 2.210 & 2.732 \\
1.719 & 4.580 & 1.013 \\
1.507 & 2.732 & 3.001 \\
1.224 & 4.508 & 2.732 \\
1.013 & 3.956 & 0. \\
0.843 & 1.013 & 0. \\
0.791 & 0.843 & 2.210 \\
0.170 & 3.001 & 0.843
\end{tabular}




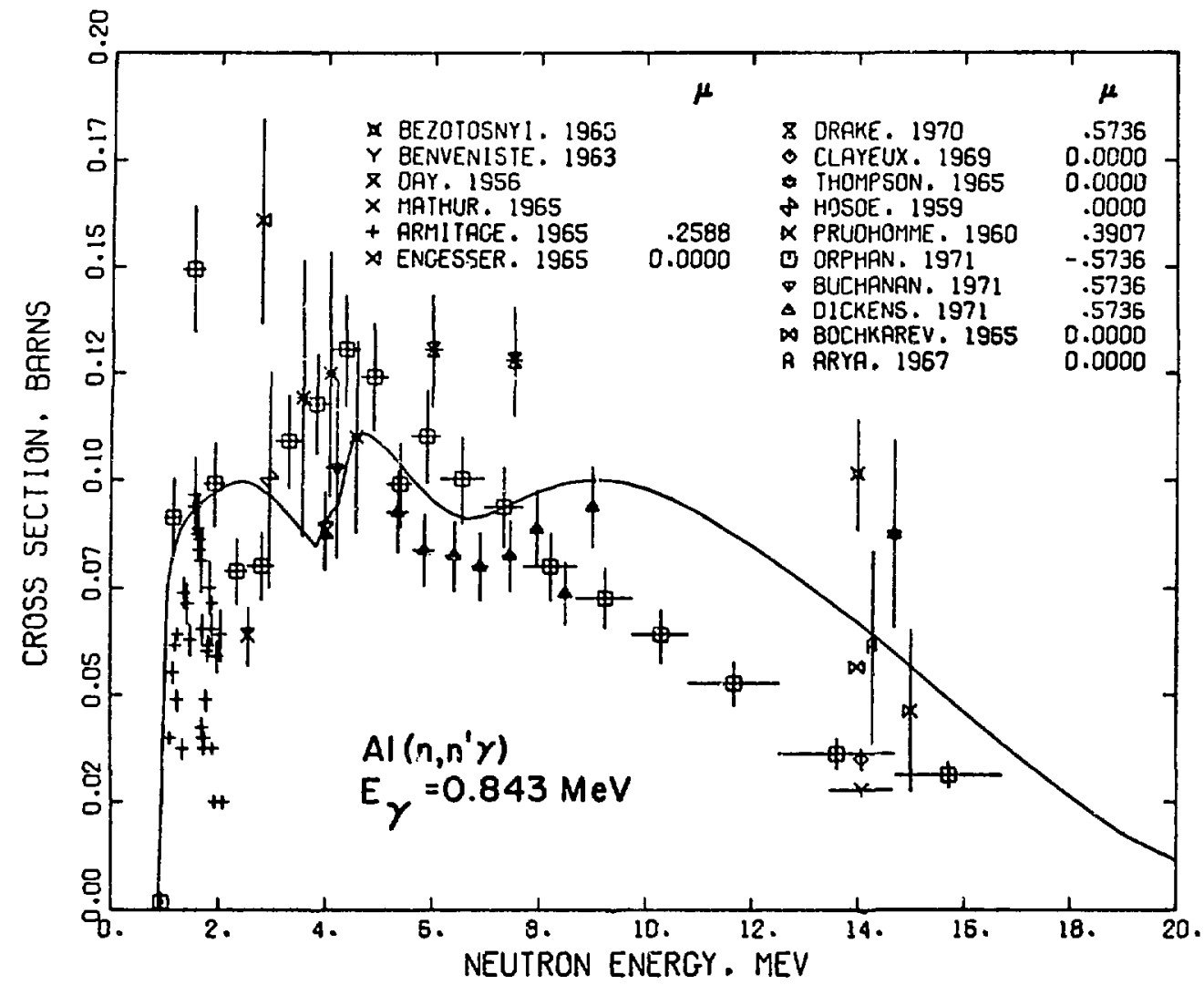

F18. 41. Measured and evaluated ${ }^{27} \mathrm{Al}\left(\mathrm{n}_{,} \mathrm{n}^{\prime} \mathrm{Y}\right)$ cross sectio: for the $0.843-\mathrm{MeV}$ photon from the $0.843 \rightarrow 0-\mathrm{MeV}$ transition in $27_{\mathrm{Al}}$.

The measurements by Dickens (D171), Orphan and Hoot (Or71), Buchanan et al. (Bu71), Nyberg et al. (Ny69), Clayeux and Grenier (C169), and Chung et al. (Ch68) were made with $\mathrm{Ge}(\mathrm{Li})$ detectors and have much better energy resolution than the older measurements that were made with scintillation detectors, mainly NaI. In FIgs. 45-47, only $\mathrm{Ge}(\mathrm{LI})$ measuremencs are shown because a nearby gamna ray was not resolved In the NaI measurements. Similarly, the sum of the 2.980- and 3.0\%-MeV photons that is shown in Fig. 48 is compared only to scintillation detector measurements, which did not resolve these gamma rays.

As described earlier, the photon-production cross sectlons below $\sim 5 \mathrm{MeV}$ are based on the $\left(n, n^{\prime}\right)$ level-excitation cross sections. Above $5 \mathrm{MeV}$, the cross sections contaln calculated contributions from levels with $E_{x}>5 \mathrm{MeV}$. We adjusted the calculated contributions for the 0.843-, 2.732-, 2.980-, $3.001-, 3.965-$, and $4.055-\mathrm{HeV}$ levels to produce bet- ter agreement with the measurements by Dickene (D171) from 5 to $9 \mathrm{MeV}$ and with several $14-\mathrm{MeV}$ results (Ar67, Be63, Be66, Bo65, C169, Ny69, Pr60, Th65). The measurements by Orphan and Hoot (or71) at Gulf Radlation Technology (GRT) that are Included in Figs. 41-50 did not become avallable until after the evaluacion was completed. There is significant disagreement between the evaluated curves and the orphan data for several of the rhotons, with the evaluation generally being too high in the 8- to $14-\mathrm{MeV}$ region. However, the GRT results are also lower than several of the $14-\mathrm{MeV}$ measurements, which partially accounts for the discrepancy with the evaluation. The results of Figs. 41-50 Indicate that the siaple calculation described above generally over-estimates the contribution from unresolved states to the discrete-phocon cross sections.

The thresholds for the ${ }^{27} \mathrm{Al}$ (n,npy) and ${ }^{27} \mathrm{Al}(\mathrm{n}, 2 \mathrm{n} \gamma)$ reactions are 10.46 and $13.98 \mathrm{MeV}$, respectively. The 


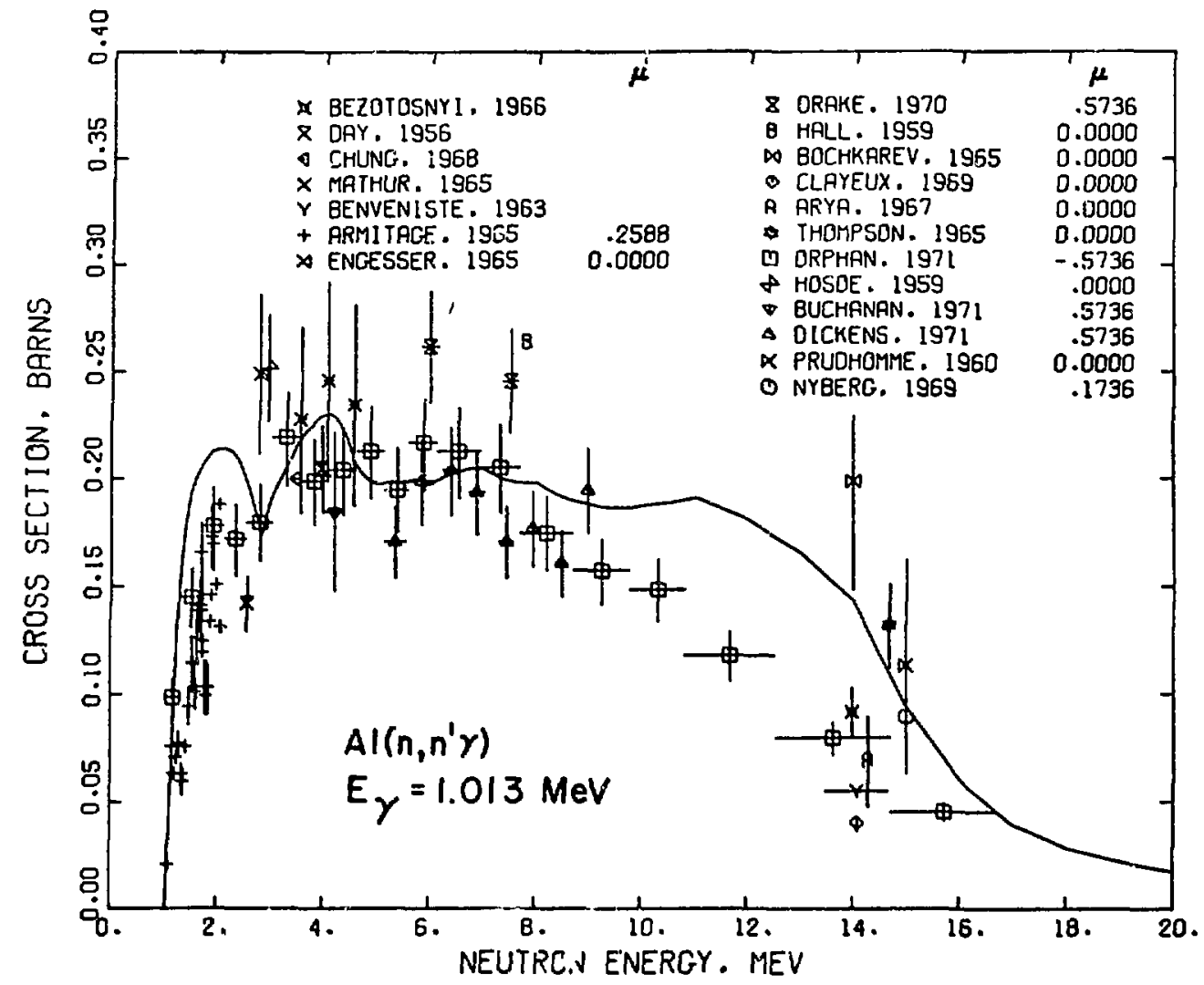

Fig. 42. Measured and evaluated ${ }^{27} \mathrm{Al}\left(\mathrm{n}, \mathrm{n}^{\prime} \gamma\right)$ cross section for the $1.013-\mathrm{MeV}$ photon from the 1.013 $\rightarrow 0-\mathrm{MeV}$ transition in $27_{\mathrm{Al}}$.

photon-production cross sections and energy spectra from these reactions were also estimated in the statistical theory calculations described above. These estimates were made by assuming that states in ${ }^{27} \mathrm{Al}$ above the threshold for particle emission (8.271 MeV) decay predominantly by particle emission. For the $(n, n p)$ reaction, rough account of penetrability effects on the outgolng proton was taken using the $\sigma_{\text {inv }}$ factor in $\varepsilon_{q}$. (3). Above the threshold for the $(n, 2 n)$ reaction, the additional assumption was made that states in ${ }^{27} \mathrm{Al}$ at high excltation energy decay $50 \%$ by proton emission and $50 \pi$ by neutron emission. The calculated cross sections and energy spectra from the $(n, n p \gamma)$ and $(n, 2 n \gamma)$ reactlons were approprlately normalized with the evaluated $(n, n p)$ and $(n, 2 n)$ cross sections.

Because the threshold for the $(n, 2 n \gamma)$ reaction is very high and the cross section so uncertain, we combined our estimates for this reaction with the $\left(n, n^{\prime} \gamma\right)$ data in the ENDF/B files. However, the evaluated photon-production cross sections for the ${ }^{27} \mathrm{Al}(\mathrm{n}, \mathrm{np}){ }^{26} \mathrm{Mg}$ reaction are included explicitly, and a summary of the discrete photons from this source is given in Table IV. The decay scheme for 2.5 ig is given in Fig. 33. The evaluated curve for the $1.809-\mathrm{MeV}$ photon from the first excited state of ${ }^{26} \mathrm{~kg}$ is shown in $\mathrm{F} / \mathrm{g}$. 51 . The $(\mathrm{n}, \mathrm{np})$ crosa section was adjusted as noted in Sec. 2.5 to produce agreement with the experiments shown in FIg. 51. In FIg. 52 , the sum of the evaluated curves for the 1.719and $1.809-\mathrm{MeV}$ photons is compared to the measurements near $14-\mathrm{MeV}$, which did not resolve the two photons. Below $10 \mathrm{MeV}$, the curve is due entirely to the 1.719MeV transition, which results from inelastic scattering.

Estimates of the production cross sections for four photons excited in the ${ }^{27} \mathrm{Al}(\mathrm{n}, \mathrm{p}){ }^{27} \mathrm{Mg}$ reaction are also included in the evaluation. These transi- 


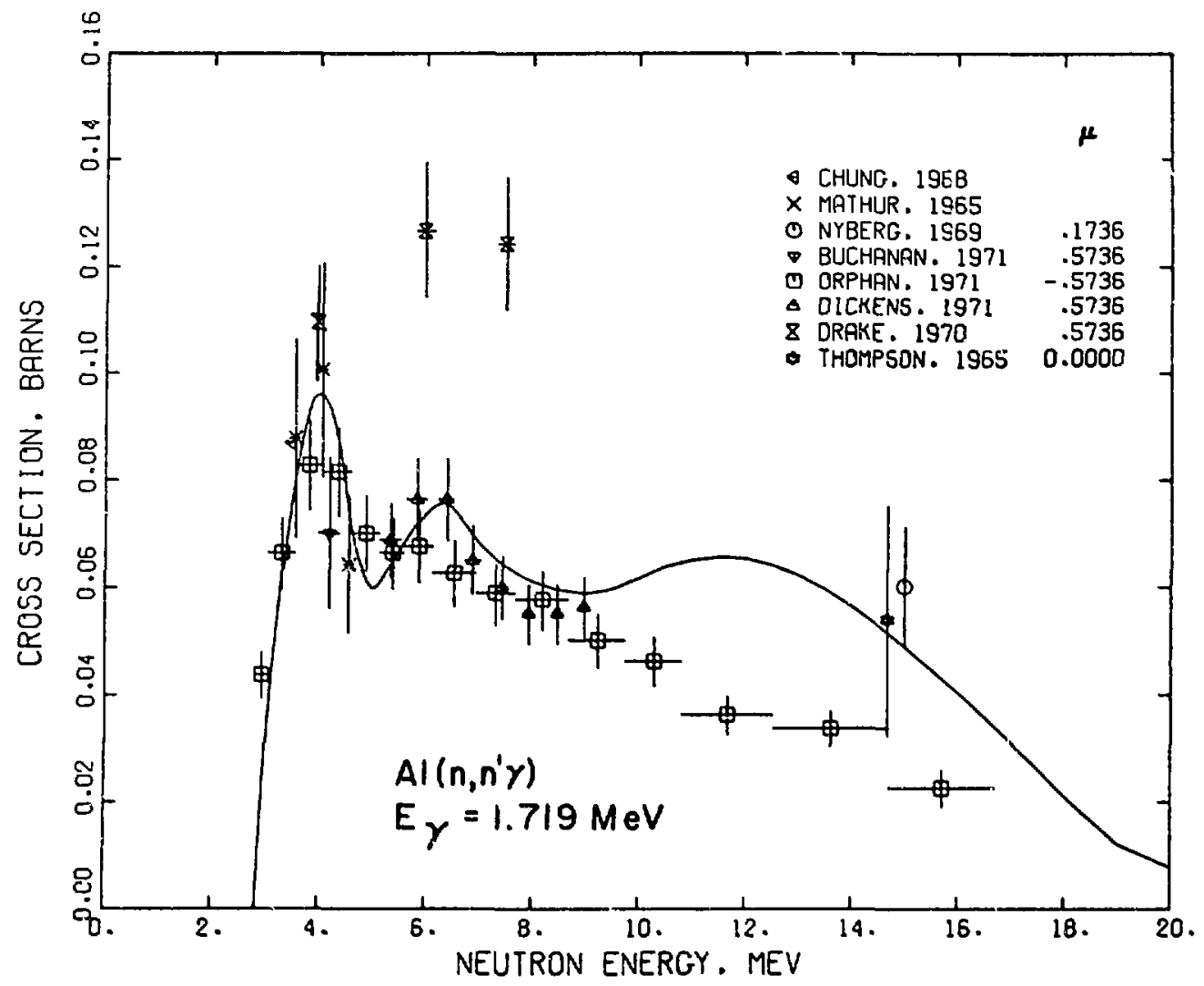

F1g. 43. Measured and evaluated ${ }^{27} \mathrm{Al}\left(\mathrm{n}, \mathrm{n}^{\prime} \mathrm{\gamma}\right)$ cross section for the 1.719-MeV photon from the $2.732 \rightarrow 1.013-$ MeV transition in 27 A

TABLE IV

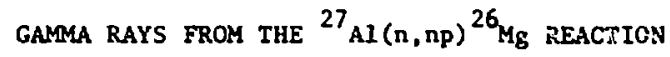

\begin{tabular}{|c|c|c|}
\hline $\begin{array}{c}\mathrm{E}_{\mathrm{Y}} \\
(\mathrm{MeV}) \\
\end{array}$ & $\begin{array}{c}E_{1} \\
(\mathrm{MeV}) \\
\end{array}$ & $\begin{array}{c}E_{f} \\
(\mathrm{MeV}) \\
\end{array}$ \\
\hline 4.313 & 4.313 & 0. \\
\hline 2.938 & 2.938 & 0. \\
\hline 2.522 & $\left\{\begin{array}{l}4.331 \\
4.350\end{array}\right.$ & $\left.\begin{array}{l}1.809 \\
1.809\end{array}\right\}$ \\
\hline 2.132 & 3.941 & 0. \\
\hline 1.809 & $\left\{\begin{array}{l}1.809 \\
3.585\end{array}\right.$ & $\left.\begin{array}{l}0 . \\
1.809\end{array}\right\}$ \\
\hline 1.40 & $\left\{\begin{array}{l}4.350 \\
4.331\end{array}\right.$ & $\left.\begin{array}{l}2.938 \\
2.938\end{array}\right\}$ \\
\hline 1.129 & 2.938 & 1.809 \\
\hline 1.003 & $\left\{\begin{array}{l}3.941 \\
4.350\end{array}\right.$ & $\begin{array}{l}2.9381 \\
3.5851\end{array}$ \\
\hline
\end{tabular}

tIons are summarized in Table $v$. The results are based entirely on the Dickens measurements (D171), with a smooth extrapolation to $20 \mathrm{MeV}$.

\section{TABLE $V$} GAMMA RAYS FROY THE ${ }^{27}$ Al $(n, p){ }^{27} M_{B}$ REACTION

$\begin{array}{lll}\begin{array}{c}E_{Y} \\ (\mathrm{MeV})\end{array} & \begin{array}{c}E_{i} \\ (\mathrm{MeV})\end{array} & \begin{array}{c}E_{\mathrm{f}} \\ (\mathrm{MeV})\end{array} \\ 1.936 & 1.936 & 0 . \\ 1.692 & 1.692 & 0 . \\ 0.984 & 0.984 & 0 . \\ 0.952 & 1.936 & 0.984\end{array}$




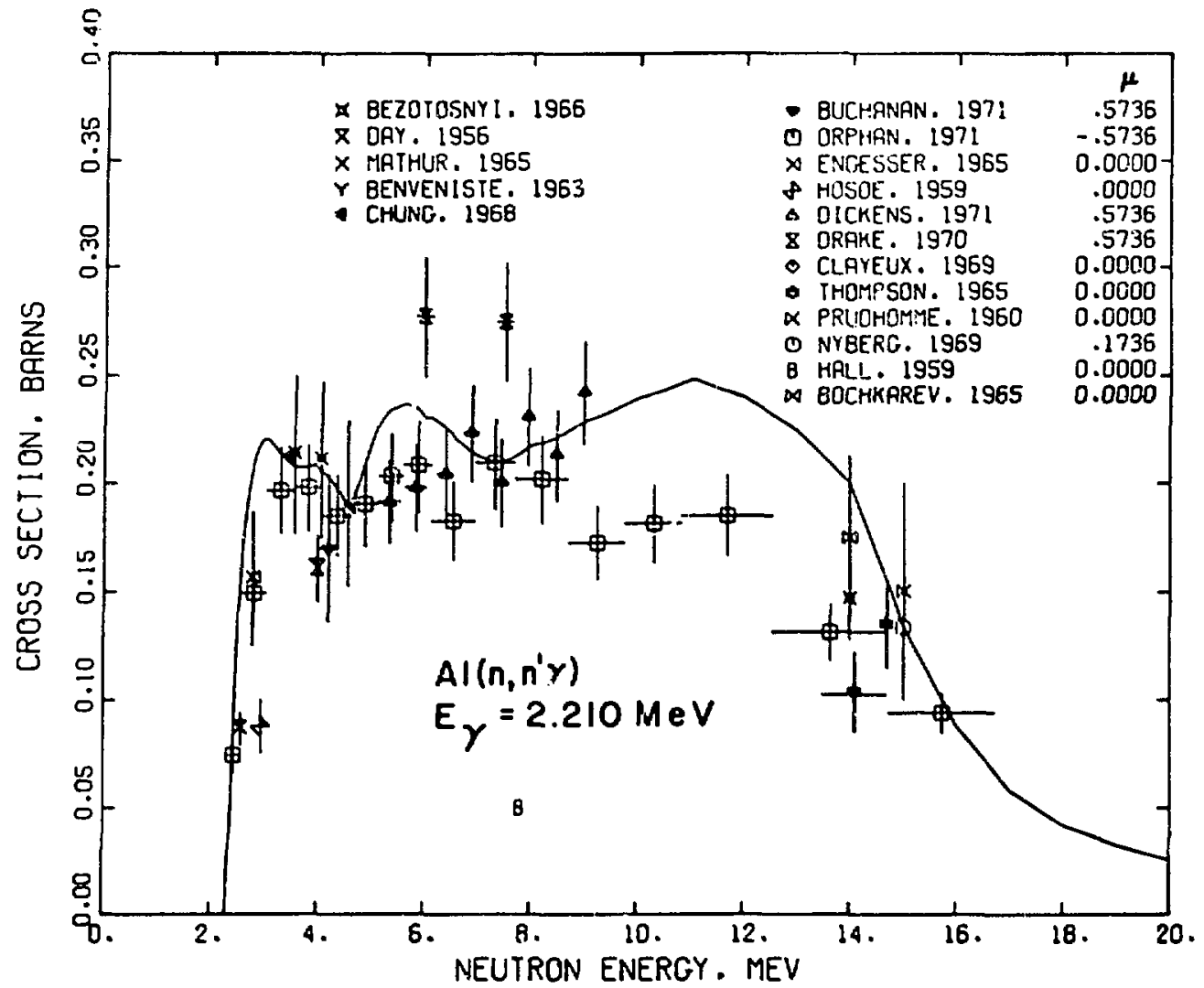

Fig. 44. Measured and evaluated ${ }^{27} A 1\left(n, n^{\prime} Y\right)$ cross section for the $2.210-$ MeV photon from the $2.210 \rightarrow 0-$ HeV cransition in $27 \mathrm{Al}$.

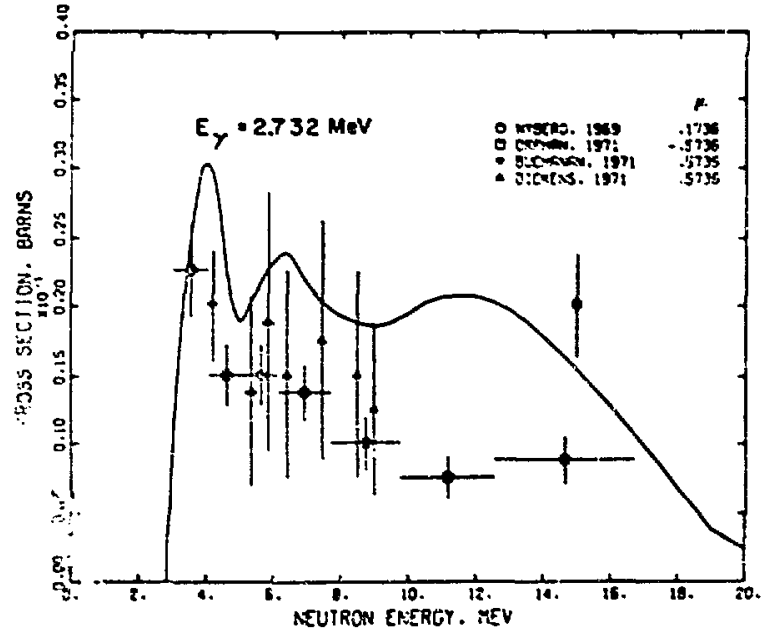

Fig. 4.5. Measured and evaluated $27 \mathrm{Al}\left(\mathrm{n}, \mathrm{n}^{\prime} \mathrm{Y}\right)$ cross rection for the $2.732-\mathrm{MeV}$ photon from the $2,732 \rightarrow 0-M e V$ transition in $27 \mathrm{Al}$.

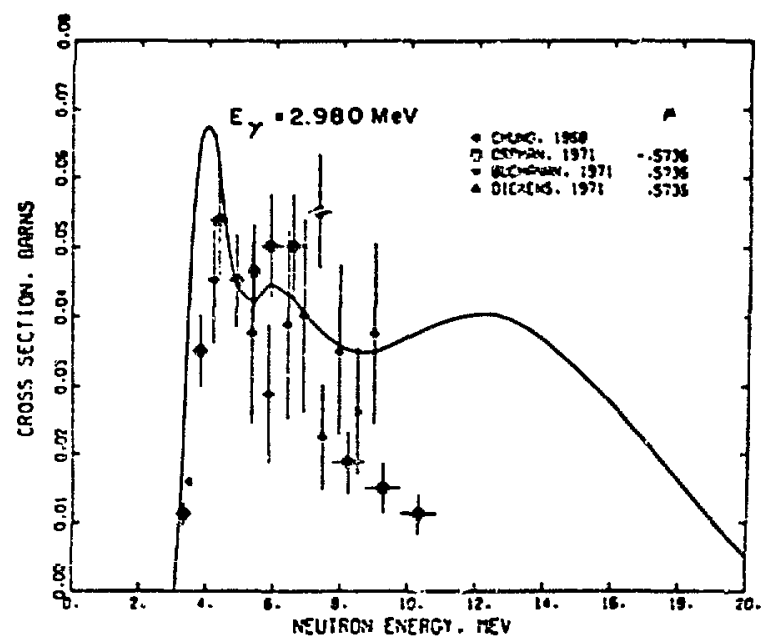

Fig. 46. Measured and evaluated ${ }^{27} \mathrm{Al}\left(\mathrm{n}, \mathrm{n}^{\prime} \mathrm{Y}\right)$ cross seccion for the 2.980-Mev photon from the $2.980 \rightarrow 0-\mathrm{MeV}$ transition in $27 \mathrm{Al}$. 


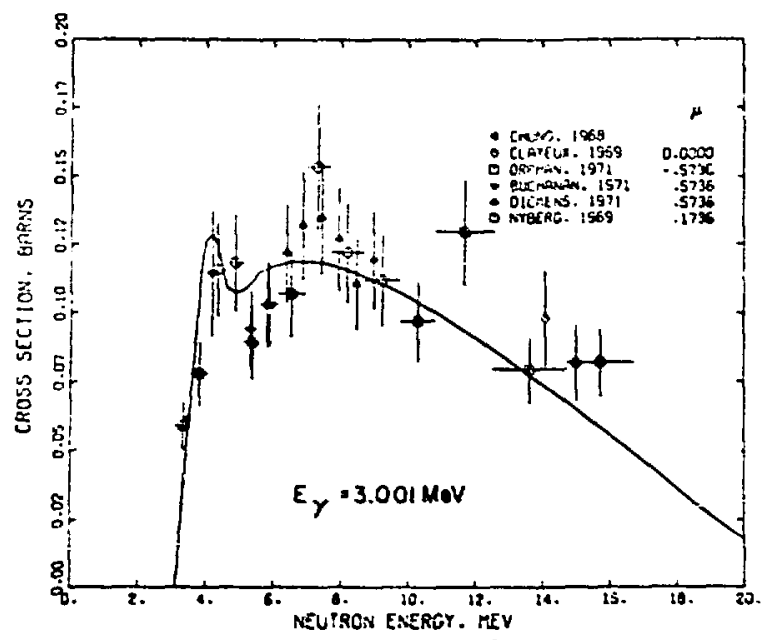

Fig. 47. Measured and evaluated ${ }^{27} \mathrm{Al}\left(\mathrm{n}, \mathrm{n}^{\prime} \mathrm{\gamma}\right)$ cross section for the $3.001-\mathrm{MeV}$ photon from the $3.001 \rightarrow \mathrm{C}-\mathrm{MeV}$ transition in $27 \mathrm{Al}$.

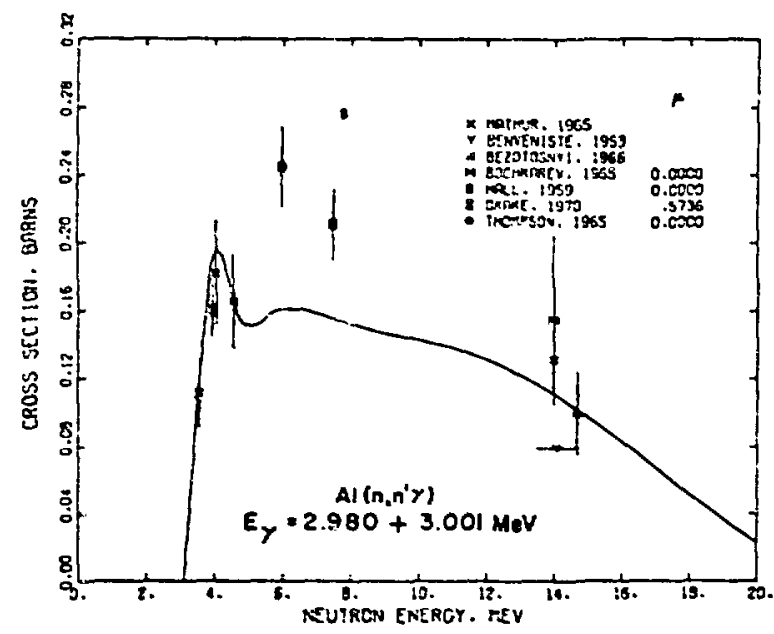

F1 . 49. Measured and evaluated $27 \mathrm{Al}\left(\mathrm{n}, \mathrm{n}^{\prime} \gamma\right)$ cross section sumed for the $2.980-$ and $3.001-$ MeV photons.

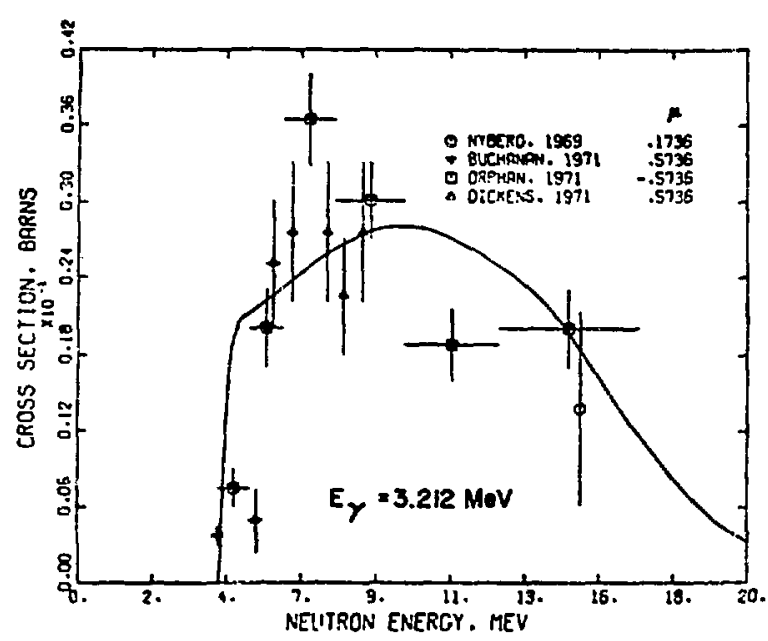

Fig. 49. Measured and evaluated ${ }^{27} \mathrm{Al}\left(\mathrm{n}, \mathrm{n}^{\prime} \mathrm{Y}\right)$ cross section for the 3.212-MeV photon friom the $4.055 \rightarrow 0.843-\mathrm{MeV}$ transition in $27 \mathrm{hl}$.

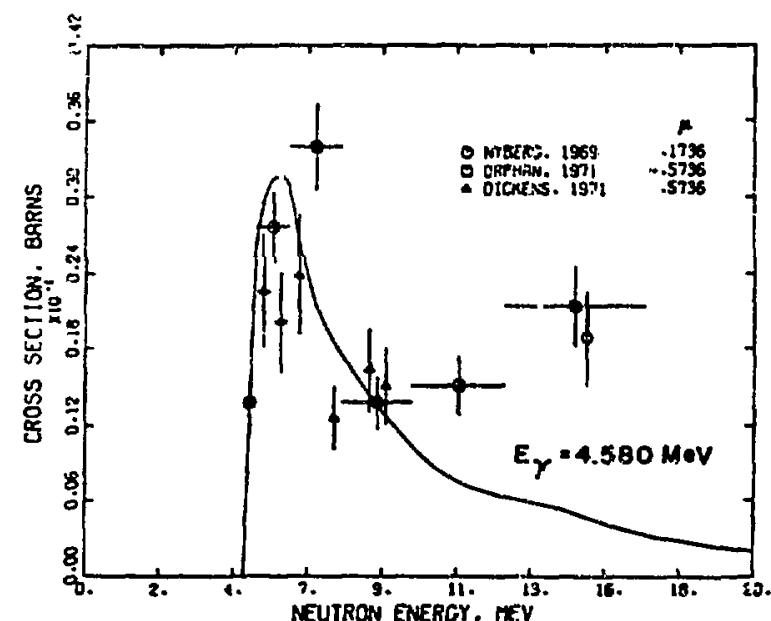

F1g. 50. Measured and evaluated ${ }^{27} \mathrm{Al}\left(n, n^{\prime} \gamma\right)$ cross section for the $4.580 \mathrm{MeV}$ photon from the $4.580 \rightarrow 0-$ Mev transition in $27_{\mathrm{Al}}$.

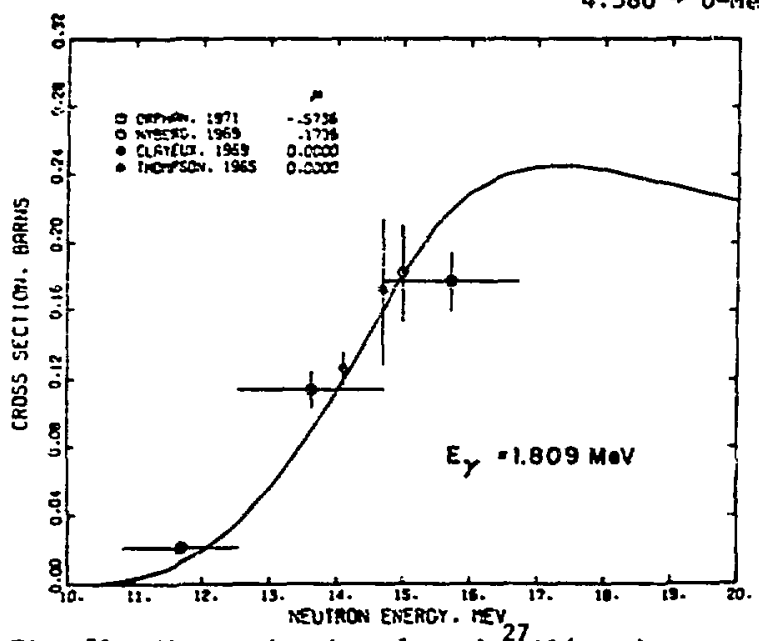

F1g. 51. Heasured and evaluated $27 \mathrm{Al}(\mathrm{a}, \mathrm{x} y)$ cross section for the $1.809-\mathrm{MeV}$ photon from the $1.809+0-\mathrm{MeV}$ transition in $26 \mathrm{Mg}_{8}$. 


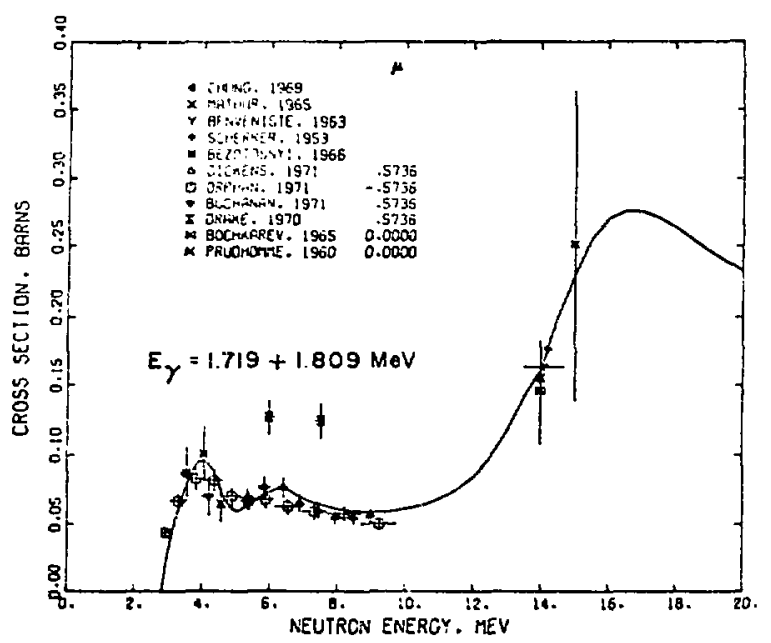

Fig. 52. Combined ${ }^{27} \mathrm{Al}(\mathrm{n}, \mathrm{x} \gamma)$ cross section for the $1.719-$ and $1.809-\mathrm{MeV}$ photons, corresponding to the $2.732 \rightarrow 1.01 .3-\mathrm{MeV}$ transition in $27 \mathrm{Al}$ and the $1.809 \rightarrow 0-\mathrm{lleV}$ transition in $26 \mathrm{Mg}$, respectively.

\subsubsection{Continuum Photons from ${ }^{27} \mathrm{Al}(\mathrm{n}, \mathrm{xy})$ Reactions}

At neutron energies above $5 \mathrm{MeV}$, an important component of the photon-production cross section results from transitions originating with levels in ${ }^{27}$ Al having $E_{X}>5 \mathrm{MeV}$, either to other continuum levels or down to levels with $E_{x}<5 \mathrm{MeV}$. To measure the cross sections for these unresolved photons, unfolding techniques are necessary that require highquality data having good statistics and low background. Consequently, little information (Pe64, Dr70) of this nature existed until recently. For this evaluation, photon-energy speitra from continuum states formed in $\left(n, n^{\prime}\right),(n, n p)$, and $(n, 2 n)$ reactions were estimated from the statistical-theory calculations described in Sec. 3.2.1.

Comparisons are glven in Figs. 53 and 54 tetween the evaluated photon spectra for all processes (including the resolved lines of Sec. 3.2.1) and the experimental results of Drake et al. (Dr70) at 7.5 $\mathrm{MeV}$ (Fig. 53) and the measurements of Orphan and Hoot (0r71) over two higher neutron-energy regions (Fig. 54). " The Orphan results in Fig. 54 did not become avaflable until after the evaluation was completed. The unresolved photons from the calculations appear at ali photon energies in the figures; above $E_{Y} \sim 5 \mathrm{MeV}$, however, the evaluated curve is due en-

"The comparisons given in Fig. 54 were provided by M. Fricke of GRT. tirely to the calculated unresolsed photon spectrum. The agdeement between the evaluation and Drake's results shown in Fig. 53 is poor, particularly because unresolved photons with $E_{\gamma}>4.5 \mathrm{MeV}$ were not observed in the measurements. The evaluated results are in better agreement with orphan's measurements in Fig. 54, particularly for higher photon energles.

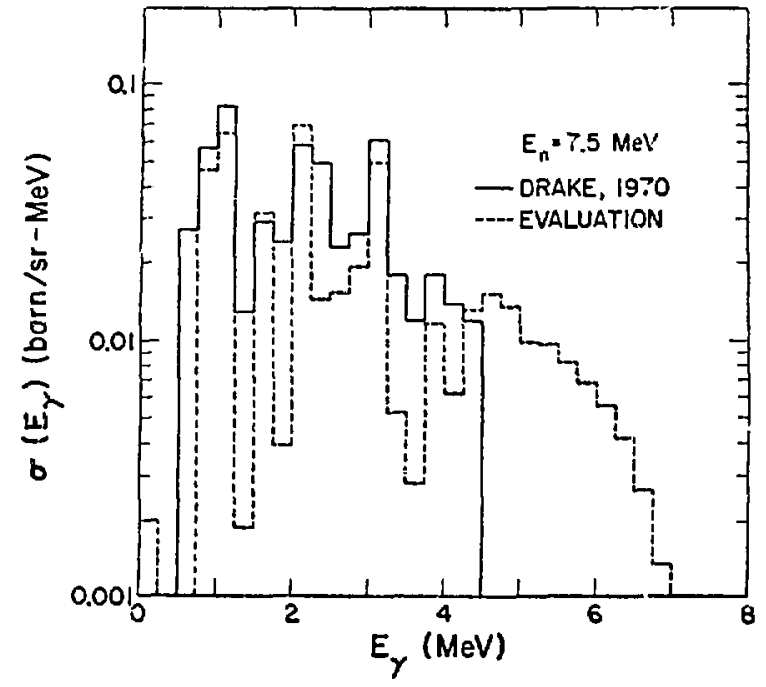

Fig. 53. Heasured and evaluated photon energy spectra from all reactions at $E_{n}=7.5 \mathrm{MeV}$.

In Fig. 55 we compare the total gamma-ray production cross section measured by Orphan and Hoot (or71) to the evaluated curve. The data in Fig. 55 Include all photons from all reactions. The evaluated curve appears to be somewhat low in the 5- to 9-MeV region, although it is generally within $20 \%$ of the measured values. The dip in the curve above 13 $\mathrm{MeV}$ results mainly from the onset of the $(n, 2 n)$ reaction.

\section{NEUTRON ENERGY DISTRIBUTIONS}

The $\left(n, n^{\prime}\right),(n, n p)$, and $(n, n \alpha)$ reactions were treated as $\left(n, n^{\prime}\right)$ reactions to levels or groups of levels (Secs. 2.4 and 2.5) that decay by emission of photons, protons, or alpha particles. The energy distributions of secondary neutrons from these processes are implictt in this representation, and no further information is required.

The threshold for the $(n, 2 n)$ reaction 1 s 13.55 $\mathrm{MeV}$, and there are no experimental data available for the energy distribitions of secondary neutrons from that reaction. Therefore, the neutron spectra 


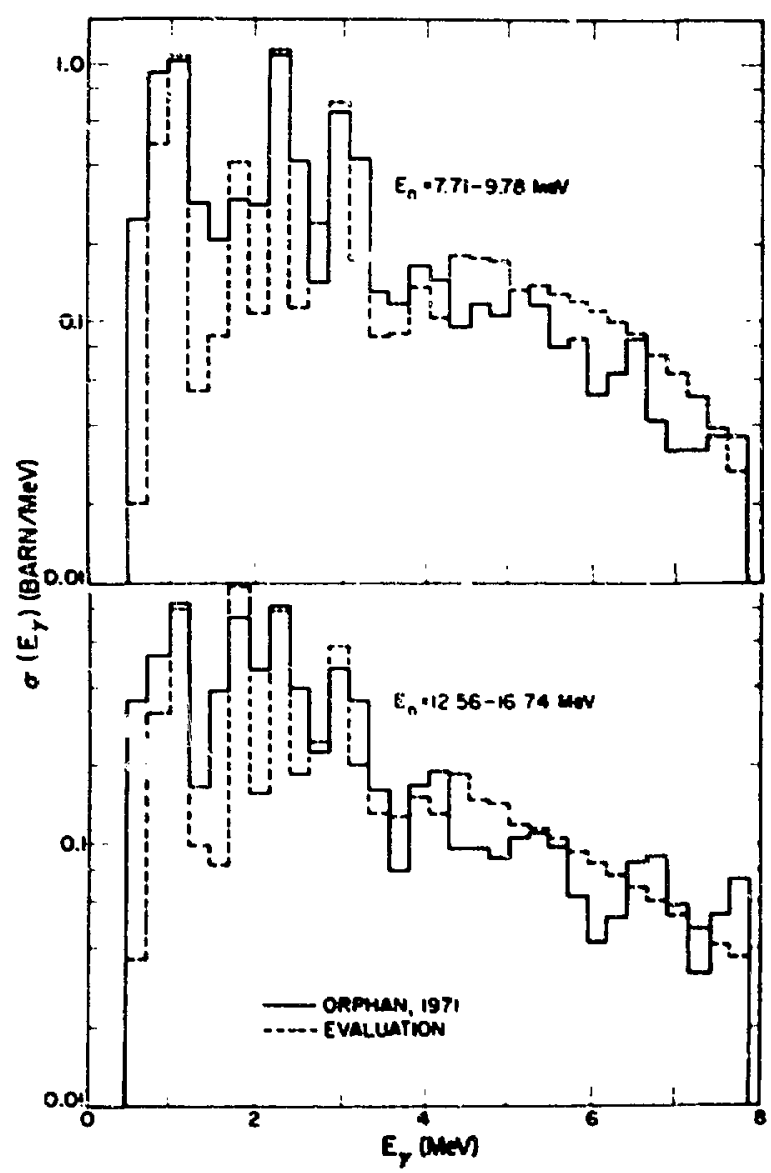

Fig. 54. Yleasured and evaluaced photon energy spectra frum all reactions averaged ovar the neutron energy regions 7.71-9.78 $\mathrm{NeV}$ and 12.56-16.74 $\mathrm{seV}$.

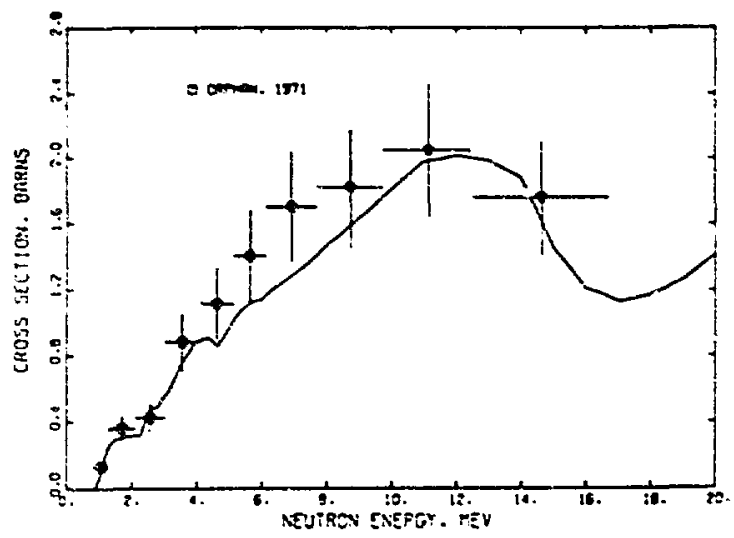

Fig. 55. Measured and evaluated total photon-production cross section from al: $2 \bar{j}_{A l}(n, x y)$ reactions. fron the $(n, 2 n)$ reaction were estimated from the statistical-cheory calculations described in Sec.

3.2 .1 . In the calculations, the $(n, 2 n)$ reaction was assumed to proceed in the sequence

$$
27 \mathrm{Al}+\mathrm{n} \cdot{ }^{28} \mathrm{Al}{ }^{\star} \cdot{ }^{27}{ }^{\star}+\mathrm{n} \cdot{ }^{26} \mathrm{Al}+2 \mathrm{2n} .
$$

The decay of ${ }^{28} A 1^{*}$ and $27{ }^{*}$ by neutron ealssion was assutsed to follow Eq. (3), with the additional assumption of equal branching for proton and natron enission from ${ }^{27} \mathrm{Al}$. We used Eq. (5) to express the level density. The nuclear temporature defined by Eq. (2) was used fer ${ }^{28} \mathrm{M}^{*}$ and ${ }^{27} \mathrm{M}{ }^{*}$, with an appropriate adjustment made for the $(n, 2 n)$ Q-value in the lacter case.

\section{s. ANGULAR DISTRI BUTIONS}

\subsection{Elastic Neutron Angular Distr fbutiors}

The anfular distributions of neutrons fros elastic scatcaring were taken as lootropic below $100 \mathrm{keV}$, and no atteapt was made to include anisotropy near the large resonances. From 0.1 :0 $8 \mathrm{MeV}$, Legendre coefficlents were derived from all avallable data sets that were complete enough to fit (mainly La57, Ch66, To62, I561, K170, and Be58). The soof flcienes used for the evaluation were ubtained by drawing stooth curves through plots of the fleted values. thus complately averaging over the resonance struccure. The resulting coefflclents for $\$>0$ uere increased enpirically by up to 207 between 2.5 and 5 YeV to avold violating Wick's linit (H149). Represantat lve comparisons between the neasured and evalwaicd angular distributions at neutron energies below $8 \mathrm{MeV}$ are given in Figs. 56-58.

To obtain the distributions at higher energies, optical-model culculaticns, using the Agee-Rosen parameters (Ag66), were compared to the ciuster of teasurentents between 14 and $15 \mathrm{MeV}$, and to the 24-IfV measurement of Stuate et ai. (St62). Hithout atcempting to refine the paramecers, we altered the calculated angular distributions empirically to inprove agrectent with experiment, and new Legendre coefictents were derlved frne the adjusted distributions. A smooth interpolation from 8 to $16 \mathrm{MeV}$ was then made. The Legendre coeff 1 cients that resulted lead to non-r.egative distributions at all neutron energles, and do not vlolate Hick's lower linit (W149) for the $0^{\circ}$ cross section. The result- 


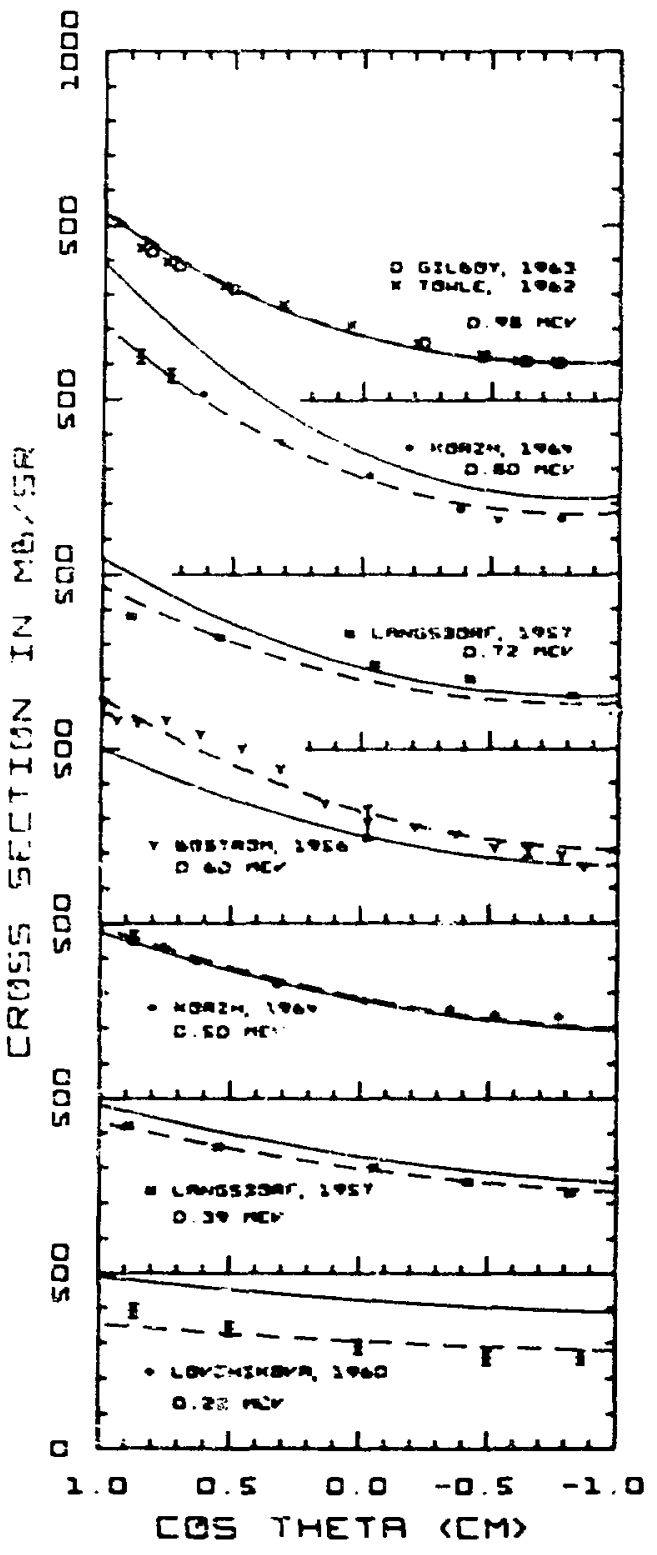

Fig. 56. Measured and evaluated angular distributhons for eiastic scatcerlag fros 0.22 to $0.98 \mathrm{seV}$. The dashed curves represent the evaluaced shapes norealized to the beasurexents: the solid curve glves the sane shapes noralized to the evaluated clastic cross sections.

Ing differential cross sections are cospared to the pessureents betveen 8 and 15 MeV ha Fis. 59.

\section{5.?. Nonelastic Neveron Anular Distributions}

The angular distributions of secondary neutrans frosi all $\left(r, n^{\prime}\right)$ reactions, Inrelusing $(n, n p)$ and $(n, n a)$. are asfuned to be isotropic in the centerof mass systen. The extensive comperisons given by

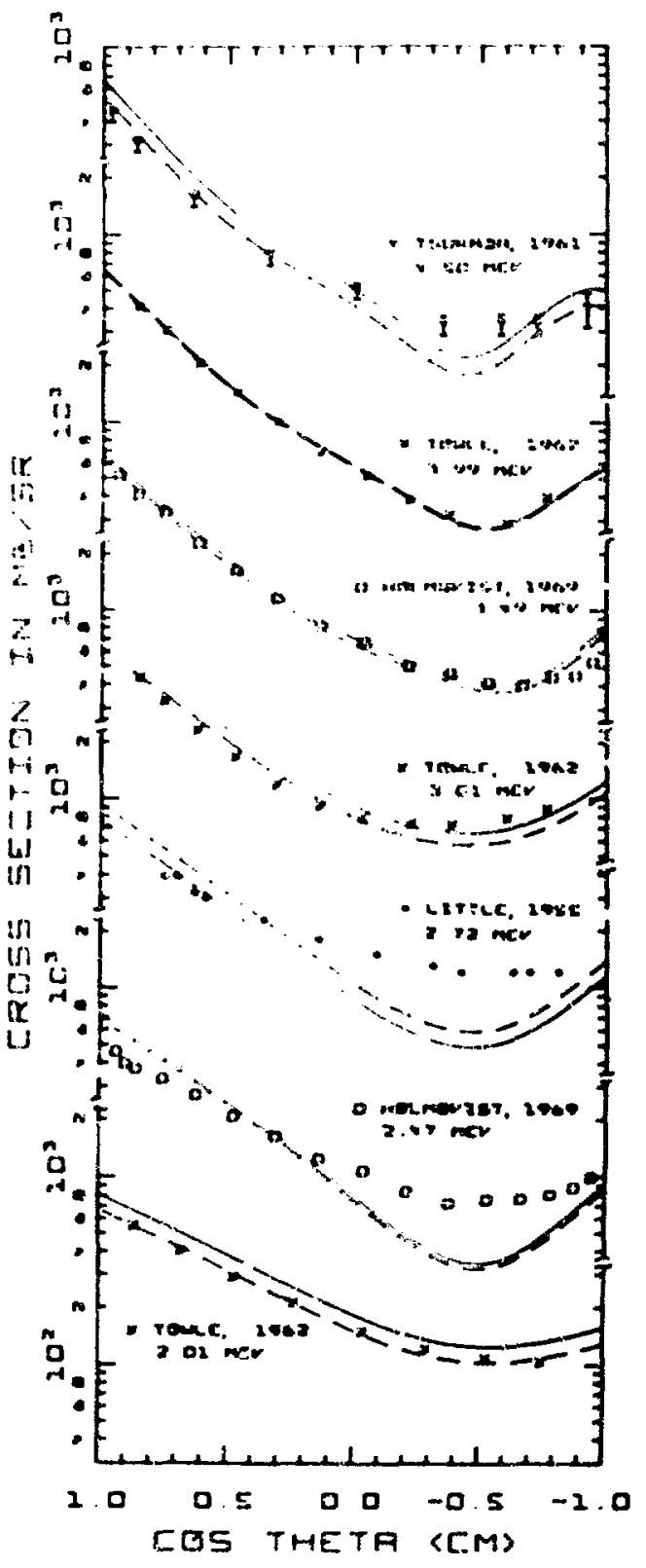

15. 37. Measured and ovaluaced angular discribubutluns log tastic scectering fron 2.01 10 \&.50 Mey. Ser caption to Flä. 56 for derall:.

Kinney and Peroy (X170) of theif inslaxtic angular distribution ecssuresents vith the gesulew of ocher authors Indicate that ixotropy is usually a reasona able assumption. There are exasples, of course, where isocropy doeg not hold but the devistons are generally not soo severe. 


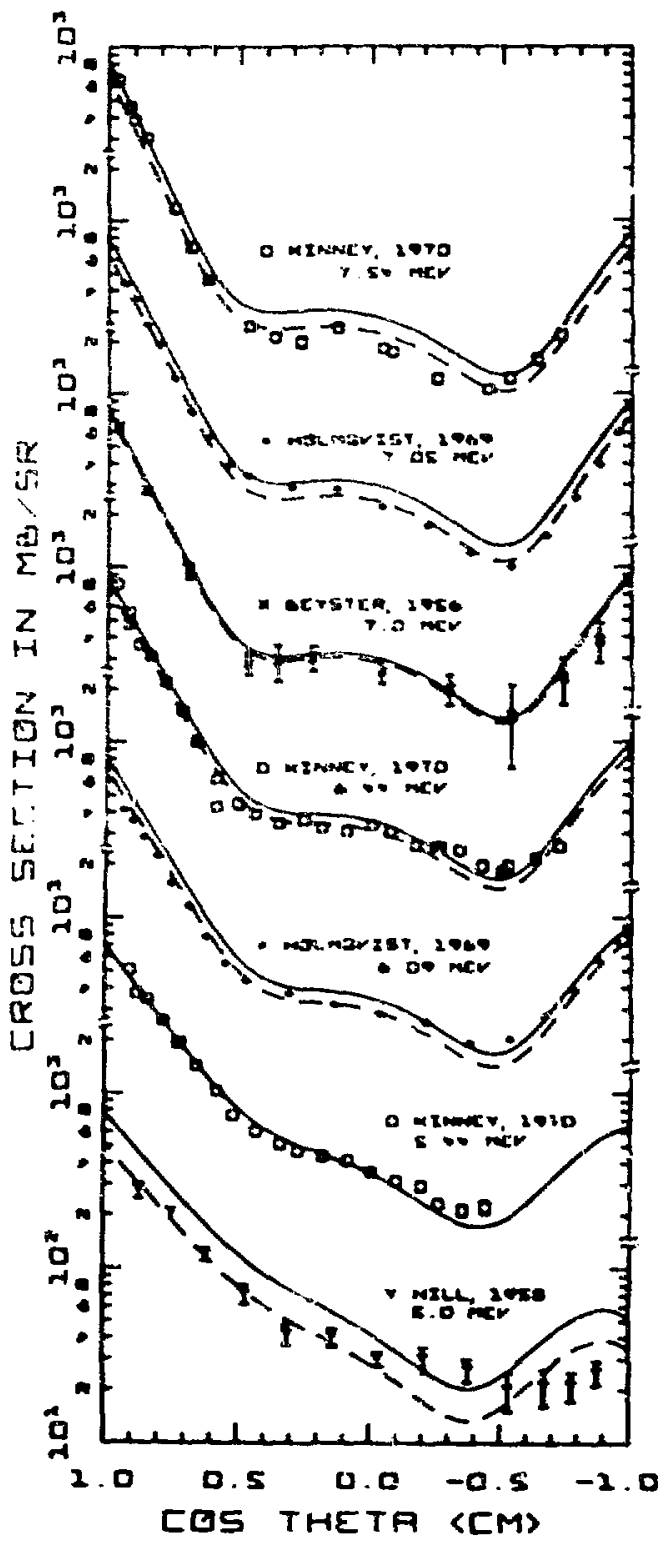

Fig. SB. Teasured and evaluaced angular distribuclons for elastlc scatcering fran 5.0 to $7.56 \mathrm{MaV}$. See caption to Fis. 56 for decalls.

lio daes are avallable for the angular distributions of neutront from the $(n, 2 n)$ reaction. For chis evaluation leboratory angular dletributlone wero provided for thw $(n, 2 n)$ eoerey specte dlscusand in Sec. 4. These distributlors ware obeslned by asouning lsotropic enission of a dineveron is the

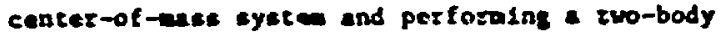

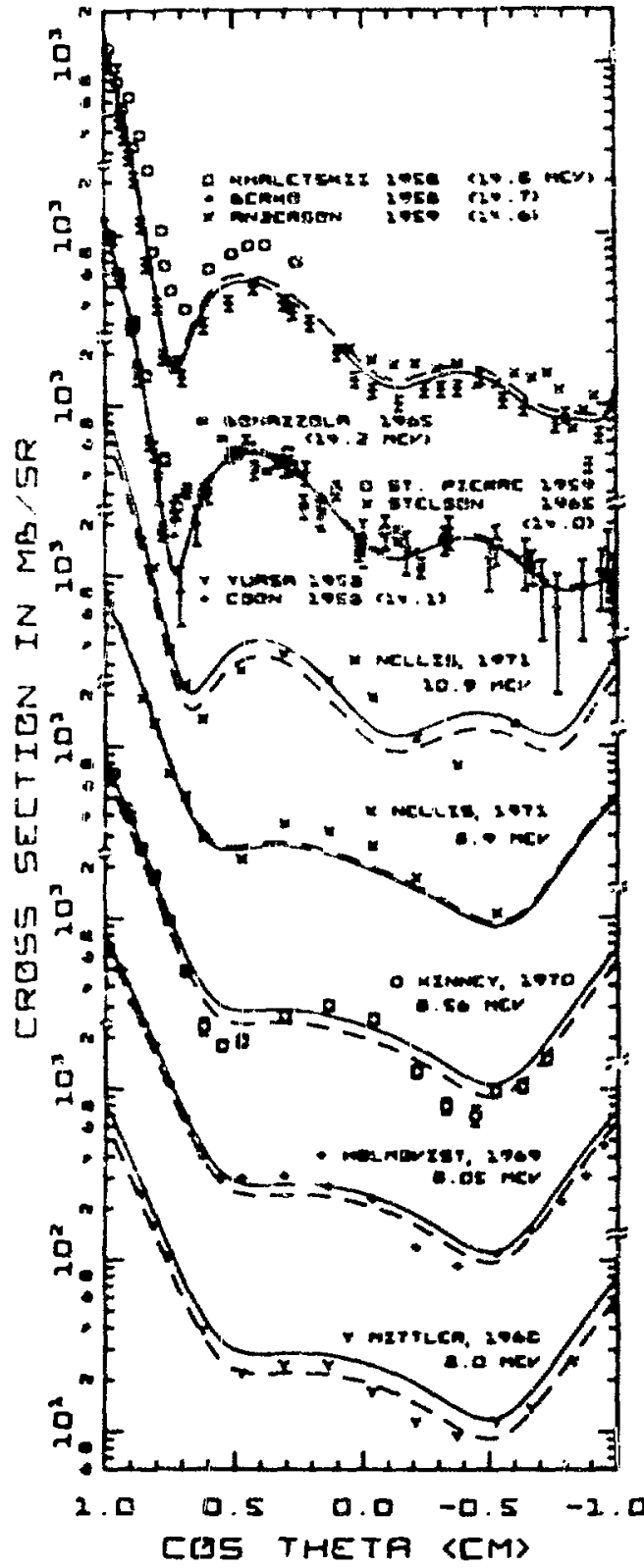

Fig. 59. Yeasured and evelisated anguler distributlons for lasele seatering from 8.0 to 14.8 tiev. See caption to tis. 56 for detalls.

tranaformation to the laboratory syate. At sach Incident nejtron enersy, average Q-values that veze obtalned fron the energy spectra vere used in the celculetions.

\subsection{Secondary Photon Ansular Dletribuclong}

Al secondaxy photone fron both $(n, y)$ and $(n, x y)$ rantetons are assuned in the evaluation to be 1so- 
eroplc in the labozatory systen. For the $(n, y)$ reaction, no data are avallable on the angular distributlons, but the assumption of 1 sotropy would cerzainly be valid at lot neutron energies where s-waye capture doelnates and where the cross section is largest.

The assumption of 1sotsopy for ${ }^{27} \mathrm{Al}(n, x y)$ reactiens is generally supported by Dickens' geasuremenl:s (D17i) at 55, 75, and 90 . There are exceptions, of course. ' : Eare coxplete angular-distribution measurewents of Chung et al. (Ch68) at $E_{n}=3.5 \mathrm{MeV}$ Ind 1cate significant anisotroples for the $2.210-\mathrm{HeV}$ piro$\operatorname{ton}\left[\sigma\left(0^{\circ}\right) / 0\left(90^{\circ}\right)-1.2\right\}$ and for the 3.001-KeV photon $\left(0\left(0^{\circ}\right) / 0\left(90^{\circ}\right)\right.$. 1.4\}, although less prowounced effects vere observed for these photons by Mathur et a1. (Ha65) between 3.57 and $4.57 \mathrm{MeV}$. The other photons observed in these two measurements (Ch68. Ma65) aro neasly isotropic.

\section{DISCUSSION}

There are sevesad areas in the present evaluation where iaprovezients can ba ande. A better treatment of the resonance structure in the elatic crose sectlons and angular distributions in the keV rogion would be useful, and greater applicacion of model codes should iaprove the elastic results at higher neutron energies. A sore thorough study of the inelastlc cross-section measurements would smprove these data, particularly if greater use were made of theoretical calculations. Further, an extensive new seasurement of neutron energy spectra as a function of angle has been wade by kammerdlener (Ka72) for 14-IleV incident neutrons, and inclusion of these data should 1eprove the inclastic resules at that energy. There are preliminary Indications (Mu72) from calculations of tIme-dependent nettron specisa emerging from aluminum spheres pulsed with 14 -HeV neutrons (Ha70) that the Inslastic data need loprovement at 16-MeV. Better estimates for some of the chargedparticle mission cross sections can be made with recently Itaproved madel codes such as Cosand (Du71). The capture gama-ray energy spectrum can be upgraded on the basis of cxlsting measurements, and the new extenslve results by Orphan and Hoot (Or71) should Improve the $(n, x y)$ crose sections and secondary-photon spectra. Flually, Improvements are possible in the Inelatic-neutron and secondary-photon angular distributions on the basis of existing measurements and nuclear theory.

$A$ sumary of estimated uncertianties in the varlow cross sections 15 included in Table VI. These errors represent order-of-angnitude averages

TABLE VI

ESTIMATFD ERFors IN THE EVALUATED CROSS SECTIONS of ${ }^{27} \mathrm{~A}$

\begin{tabular}{|c|c|c|c|c|c|c|c|c|c|c|c|}
\hline \multirow[b]{2}{*}{ Cross Section } & \multirow{2}{*}{$\begin{array}{l}\text { ENDF/B } \\
\text { Des1manclon }\end{array}$} & \multicolumn{10}{|c|}{ Neutron Energy (MeV) } \\
\hline & & Thermal & 0.01 & $\underline{0.1}$ & 1 & 3 & 5 & 8 & 11 & 14 & 20 \\
\hline Total & $M F=3, M T-1$ & $\pm 5 x$ & $\pm 5 z$ & $\pm 4 \%$ & $\pm 2 \pi$ & $\pm 2 \%$ & $\pm 2 \pi$ & $\pm 2 \%$ & \pm 28 & $\pm 2 z$ & \pm 27 \\
\hline Elastic & $M F=3, M T=2$ & $5 z$ & $5 \%$ & $4 \pi$ & 37 & $5 \%$ & 82 & $12 x$ & $20 \%$ & $15 \%$ & $20 z$ \\
\hline Nonelastec & $\mathrm{MT}-3, \mathrm{MT}-3$ & $4 z$ & $20 \%$ & $20 \%$ & $30 \%$ & $15 \%$ & $10 \mathrm{x}$ & $10 \%$ & 157 & $10 \%$ & $20 \%$ \\
\hline Total $\left(n, n^{\prime}\right)$ & $M F-3, M T=4$ & - & - & - & $30 x$ & $15 \%$ & $10 \%$ & 108 & 153 & 158 & $30 \%$ \\
\hline$(n, 2 n)$ & $M T-3, M T-16$ & - & - & - & - & - & - & - & - & $50 \%$ & $50 z$ \\
\hline $\begin{array}{l}\text { Discrete }\left(n, n^{\circ}\right) \\
E_{x}<5 \text { MeV }\end{array}$ & $M F=3, M T=51-63$ & - & - & - & $30 x$ & $15 x$ & ist & $20 z$ & $25 \%$ & $30 \%$ & 502 \\
\hline $\begin{array}{l}\text { DLscrete }\left(n, n^{\prime}\right) \\
E_{x}>5 \mathrm{MeV} \\
(n, y)\end{array}$ & $\begin{array}{l}\mathrm{MF}=3, \mathrm{MT}=64-90 \\
\mathrm{MF}-3, \mathrm{MT}=102\end{array}$ & -7 & $\begin{array}{c}- \\
20 z\end{array}$ & $\begin{array}{c}- \\
20 z\end{array}$ & $20 z$ & $\begin{array}{c}- \\
20 z\end{array}$ & $\begin{array}{c}- \\
20 z\end{array}$ & $\begin{array}{l}50 z \\
50 z\end{array}$ & $\begin{array}{l}50 z \\
50 z\end{array}$ & $\begin{array}{l}50 x \\
20 x\end{array}$ & $\begin{array}{l}507 \\
x^{2}\end{array}$ \\
\hline$(n, p)$ & $M F-3, M T=103$ & - & - & - & - & $30 z$ & 207 & $20 z$ & 207 & $15 \%$ & 207 \\
\hline$(n, d)$ & $M F=3, M T=104$ & - & - & - & - & - & - & - & $50 \%$ & $50 \%$ & 507 \\
\hline$(n, t)$ & $M F-3, \mathrm{MT}-105$ & - & - & - & - & - & - & - & - & - & $50 \pi$ \\
\hline$(n, a)$ & $\mathrm{MF}=3, \mathrm{MT}=107$ & - & - & - & - & - & - & $15 \%$ & $15 \pi$ & $10 \%$ & $10 \%$ \\
\hline Totel $(n, x y)$ & $\begin{array}{l}M T=13, \text { Sus of } \\
M T=4,28,103\end{array}$ & - & - & - & $30 x$ & $15 z$ & $15 x$ & $20 z$ & $20 z$ & $20 z$ & $40 \%$ \\
\hline $\begin{array}{l}\text { Individual } \\
(n, x y) \text { LInes }\end{array}$ & $\begin{array}{l}M F=13 \\
M T=4,28,103\end{array}$ & - & - & - & $30 \%$ & $15 \bar{x}$ & 157 & $20 z$ & $25 \%$ & $30 \%$ & $50 \%$ \\
\hline
\end{tabular}


over broad energy groups and are not expected to hold true in detall. In addition, we mo no attempt to estimate the errors due to unknown structure in the cross sections. The accuracy of the elastic angular distributions is expected to be generally $\pm 15 \%$, alehough larger errors will certainly occur in regions of structure.

\section{ACKNOWLEDGMENTS}

We wish to thank D. M. McClellan, C. I. Baxman, and $N$. Whit temore for thelr help with the many clerical lasks required for this work and E. T. Jurney for his many useful comments. Finally, we gratefully acknowledge the many authors who provided us with their experimental results in advance of publication.

\section{MEFERENCES}

Ag66 F. P. Agee and L. Rosen, "Calculations of Neutron Cross Sections Using a Local Optical Potential with Average Parameters," Los Alamos Scientific Laboratory report LA-3538-NS (1966).

A157 c. L. Allan, "Protons from the Interaction of 14-MeV Neutrons with Medium We1ght Nucle1," Proc. Phys. Soc. (London) A70, 195 (1957).

Ai61 D. L. Allan, "An Experimental Test of the Statistical Theory of Nuclear Reactlors," Nucl. Phys. 24, 274 (1961).

An59 J. D. Anderson, C. C. Gardner, J. W. MicClure, M. P. Nakada, and C. Wong, "Back-Angle Elistic siattering of $14.6 \mathrm{-MeV}$ Neutrons from Aluminum, Copper, and Z1rconium," Phys. Rev. 115, 1010 (1959).

Ar64 P. M. Aron, S. S. Bugorkov, K. A. Petrzhak, and A. V. Sorokina, "Radio-Chemical Determination of ct.e $\mathrm{Al}^{27}(n, \alpha) \mathrm{Na}^{24}$ Reaction Cross Section for a Neucron Energy of $14.6 \mathrm{MeV}, "$ At. Energlya (trans.) 16, 450 (1954).

Ar65 B. H. Armitage, J. H. Montague, N. Nath, A. K. H. Siddiq, and D. C. Stupegla, "Production Cross Sections of Gama Rays by Inelustic Neutron Scattering from $27_{\mathrm{Al}}$," proceedings of the Internaticnal Conference on the Study of Nuclear Structure with Neutrons, Antwerp, 1965 (North Holland Publishing Co., Ampterdam, 1966) p. 503.

Ar67 A. P. Arya, D. L. Campbell, and R. D. Wilson, "Y Yield from 14.3-MeV Neutron Inelastic Scattering and Compazison with Quadrupole Transitions," Bull, Am. Phys. Soc. 12, 124 (1967).

Ba58 W. P. Ball, M. MacGregor, and R. Booth, "Neutron Nonelast1c Cross Sections from 7 to 14 Mev," Phys. Rev. 110, 1392 (1958).

Bas8a G. A. Bartholomew and L. A. Higgs, "Compilation of Thermal-Neutron Capture Gama Rays," Atomic Energy of Canada Ltd. report AECL-669 (1958).
Ba61 B. P. Bayhurst and R. J. Prestwood, " $(n, 2 n)$, $(n, p)$, and $(n, \alpha)$ Excitation Functions of Several Nuclel from 7.0 to $19.8 \mathrm{MeV}$," Los Alamos Sct.entific Laboratory report LA-2493 (1961); R. J. Prestiwood and B. P. Bayhurst, " $(n, 2 n)$ Exc1tation Functions of Several Nuclel from 12.0 to 19.8 MeV," Phys. Rev. 12i, 1438 (1961).

Ba65 R. Bass, P. Haug, K. Krüger, and B. Staginnus, "Fast Neutron Excitation Functions by Activation Techniques," European-American Nuclear Data Combltee report EANDC(E) $-66 \mathrm{U}$ (1966) p. 64, and private communication from R. Bass (1971).

Ba67 G. A. Bartholomew, A. Dovelka, K. M. Eastwood, S. Monaro, L. V. Groshev, A. M. DemIdov, V. I. Palekhov, and L. L. Sokolovsk11, "Compendium of Themal-Neutron-Capture $\gamma$-Ray Measurements, Part I, $2 \leqslant 46, "$ Nucl. Data A3, 367 (1967).

Ba69 R. C. Barrall, M. S1lbergeld, and D. G. Gardner, "Cross Sections of some Reactions of Al, S, Mn, $\mathrm{Fe}, \mathrm{N} 1$, In, and I with $14.8 \mathrm{HeV}$ Neutrons," Nucl. Phys. ㅅ․ 38, 387 (1969).

Be55 J. R. Beyster, R. L. Henkel, R. A. Nobles, and J. M. KIster, "Inelastic Collision Crous Sectlons at 1.0- 4.0-, and 4.5-MeV Neutron Energies," Phy, . Rev. 98, 1216 (1955).

Be56 J. R. Beyster, M. Walt, and E. W. Salm1, "Interaction of $1.0-, 1.77-, 2.5-, 3.25-$, and $7.0 \mathrm{MeV}$ Neutrons with Nucle1," Phys, Rev, 104, 1319 (1956).

Be58 S. Berko, W. D. Whitehead, and B. C. Groseclose, "Angular Distribution of Elastically Scattered 14.7-MeV Neutrons," Nuc1. Phys. 6, 210 (1958).

Be63 J. Benventste, N. Chazan, and A. Mitchell, "Spectra of Continuum Gamma Rays Resulting from 14-MeV Neutron Interactions with Several Elecuents, "University of California Radiation Laboratory report UCRL-7440 (UCID-461.9) (1963).

Be66 V. M. Bezotosny1, V. G. Vershinin, L. M. Surov, and M. S. Shvetsov, "Cross Sections for the Production of Gamma Quanta in Inelastic Interaction Between 14-MeV Neutrons and $\mathrm{C}, 0, \mathrm{Al}, \mathrm{Fe}$, and Pb Nucle1," Sov. J. Nucl. Phys. 3, 632 (1966).

B168 R. C. Block, private communication to R. J. Howerton (1968).

Bo56 N. A. Bostrom and I. L. Morgan, private communication to Sigma Center, Brookhaven National Laboratory (1956).

Bo61 M. Bormann, S. Cierjacks, R, Langkau, H. Neuert, and $H$. Pollehn, "Mesure de quelques Segtions Efficaces $(n, \alpha)$ dans 1 'Intervalle des Eniergfes des Neutrons 12 a $19.6 \mathrm{MeV}, "$ J. Phys. Radfum 22, 602 (1961.).

Bo64 G. C. Bonazzola, P. Brovetto, E. Chiavasisa, R. Spinoglio, and A. Pasquarelli, "The Measurement by Activation of Cross Sections for $14.7 \mathrm{MeV}$ Neutrons," Nucl. Phys. 51, 337 (1964). 
Bo65 V. N. Bochkarev and V. V. Nefedov, "Y Radiation frow the Inelastic Interaction of $14-\mathrm{MeV}$ Neutrons with Magnesium, Aluminum, and Sulfur Nuclei," Sov. J. Nucl. Phys. 1, 574 (1965).

Bo65a G. C. Bonazzola, E. Chiayassa, and T. Bressant, "Excited-Core Model in $\mathrm{Al}^{27}$ and Inelastic Scattering of 14.2-MeV Neutrons," Phys. Rev. 140, B835 (1965).

Bo65b M. Bormann, E. Fretwurst. P. Schehka, G. Wrege, H. Büttner, A. Lindner, and H. Meldner, "Some Excitation Functions of Neutron-Induced Reactions in the Energy Range 12.6-19.6 McV," Nuc1. Phys. 63, 438 (1965).

Br64 D. J. Bredin, "Scattering and Polarization of Neutrons from $\mathrm{Al}, \mathrm{Si}, \mathrm{Fe}$, and $\mathrm{Co}$ at $2 \mathrm{MeV}, "$ Phys. Rev. 135, B412 (1964).

Bu63 J. F. Butler and D. C. Santry "Excitation Curves for the Reactions $\mathrm{Al}^{27}(n, \alpha) \mathrm{Na}^{24}$ and $\mathrm{Mg}^{24}(n, p)$ Na.4," Can. J. Phys. 41, 372 (1963).

Bu71 P. S. Buchanan, D. O. Nellis, and W. E. Tucker, "A Compilation of Cross Sections and Angular Distributions of Gamma Rays Produced by Neutron Bombardment of Various Nuclei," Texas Nuclear Corporation report 0R0-2791-32 (1971).

Ca62 G. Calvi, R. Potenza, R. Ricamo, and D. Vinciquerra, "Neutron Reactions in A1 from 2.5 to 5 MeV," Nucl. Phys. 39, 621 (1962).

Ca67 A. D. Carlson and H. H. Barschall, "Fluctuations in Neutron Total Cross Sections," Phys. Rev. 158, 1142 (1967).

Ch63 G. P. Chursin, V. Yu. Gonchar, I. 1. Zalyubovski1, and A. P. Klyucharev, "Cross Sections for $(n, p)$ Reactions on Tin Isotopes for $14.5-\mathrm{MeV}$ Neutrons," Sov. Phys. -JETP 17, 321 (1963).

Ch66 J. P. Chien and A. B. Smith, "Fast Neutron Scattering from Beryllium, Sodium, and Aluminum," Nuc1. Sc1. Eng. 26, 500 (1966).

Ch67 A. Chatterfee and A. M. Ghose, "Nonelastic Cross Sections of Nuclei for 14.8-MeV Neutrons," Phys. Rev. 161, 1181 (1967).

Ch68 K. C. Chung, D. E. Velkley, J. D. Brandenberger, and M. T. MCEllistrem, "2 $7_{\mathrm{Al}}\left(n, n^{\prime} \gamma\right)$ Reactions and the 3002-keV Level," NucI. Phys. Al15, 476 (1968).

Ci68 S. Cierjacks, P. Fort1, D. Kopsch, L. Kropp, J. Nebe, and H. Unseld, "High Resolution Total Neutron Cross Sectlons between 0.5 and $30 \mathrm{MeV}, "$ Kernforschungszentrus Karlsruhe report KFK-1000, Karlsruhe, Germany (1968).

C169 G. Clayeux and G. Grenler, "Spectres de Renvol des Gammas Produits par des Neutrons de 14.1 $\mathrm{MeV}$," Centre d'Etudes de Limell report CEA-R-3807, Lime11, France (1969).

Co58 J. H. Coon, R. W. Davis, H. E. Felthauser, and D. B. Nicodemus, "Scattering of 14.5-MeV Neutrons by Complex iluclei," Phys. Rev. 111, 250 (1958), and private communication to $\bar{R}$. J. Howerton (1959).
Cs63 J. Csikai, B. Gyarmati, and $\frac{I}{2}$. Hunyadi, "Activation Cross-Sections for $\mathrm{Na}^{2}$ and $\mathrm{Al}^{2}{ }^{2}$ with 14-MeV Neutrons," Nuc1. Phys. 46, 141 (1963).

Cs67 J. Csikai, G. Petö, M. Buczkó, Z. Miligy, and N. A. Eissa, "Radiative Capture Cross Sections for 14.7-MeV Neutrons," Nuc1. Phys. A95, 229 (1967).

Cu68 P. Cuzzocrea, E. Perillo, and S. Notarrigo, "Some Excitation Functions of Neutron-Induced Reactions around $14 \mathrm{MeV}, "$ Nuovo CImento B54, 53 (1968).

Da5ó R. B. Day, "Gamma Rays from Neutron Inelastic Scattering," Phys. Rev. 102, 767 (1956).

De60 M. J. DePraz, G. Legros, and M. R. Salln, "Mesure des Sections Efficaces de quelques Reactions $(n, p),(n, \alpha),(n, 2 n), " J$. Phys. Radium 21, 377 (1960).

De61 Yu. G. Degtyarev and V. G. Nadtoch11, "Measurement of the Cross Sections for Inelastic Interaction of Neutrons with an Energy of 13 to 20 NeV Using Certain Isotopes," Sov. J. At. Energy 11, 1043 (1961).

De65 Yu. G. Degtyarev, "Non-Elastic Interaction Cross Sections of Neutrons with $7 \mathrm{Li}, 12 \mathrm{C}, 14 \mathrm{~N}$, $27 \mathrm{Al}, 56 \mathrm{Fe}, \mathrm{Cu}, \mathrm{Pb}, 235 \mathrm{U}, 238 \mathrm{U}$, and $239 \mathrm{Pu}, " \mathrm{~J}$. Nuc1. Energy 20, 818 (1965).

Di71 J. K. Dickens, "Al $(n, x y)$ Reactions for $5.3 \leqslant$ $\mathrm{E}_{\mathrm{n}} \leqslant 9.0 \mathrm{MeV}$," Oak Ridge National Laboratory report ORNL-TM-3284 (1971).

Dr63 J. E. Draper and C. 0. Bostrom, "Transition Intensities from Thermal $(n, \gamma)$ in $\mathrm{Be}, \mathrm{A} 1, \mathrm{Cl}$, $S c$, and $T 1, "$ Nucl. Phys. 47, 108 (1963).

Dr70 D. M. Drake, J, C. Hopkins, C. S. Young, and H. Condé, "Gamma-Ray-Production Cross Sections for Fast-Neutron Interactions with Several Elements," Nuc1. Sc1. Eng. 40, 294 (1970).

Du71 C. L. Dunford, private communication (1971); see also C. L. Dunford, "A Unified Model for Analysis of Compound Nucleus Reactions," Atomics International report AI-AEC-12931 (1970).

E168 R. V. Elliott, T. R. Ophel, and R. H. Spear, "Branching Ratios of $27 \mathrm{Al}$ Bound States," Nucl. Phys. Al15, 673 (1968).

En65 F. C. Engesser and W. E. Thompson, "Gamma Rays from $\left(n, n^{\prime} y\right)$ Interactions of $2.8-\mathrm{MeV}$ Neutrons with Magnesium, Aluminum, Silicon, Titanium, and Iron," Naval Radiological Defense Laboratory report USNRDL-TR-916 (1965).

En67 P. M. Endt and C. van der Leun, "Energy Levels of $Z=11-21$ Nuclei (IV)," Nucl. Phys. A105, 1 (1967).

Fe67 J. M. Ferguson and J. C. Albergott1, "Structure in the Total $24 \mathrm{Mg}(n, p),{ }^{27} \mathrm{Al}(n, p)$, and $27_{\mathrm{Al}}(\mathrm{n}, \alpha)$ Cross Sections from 12 to $15 \mathrm{MeV}$," Nucl. Phrs. A98, 65 (1967). 
F156 N. N. Flerov and V. M. Talyzin, "Cross Section for Inelastic Interactions of $14.5-\mathrm{MeV}$ Neutrons with Various Elements," At. Energiya 1, 155 (1956).

Fo52 S. G. Forbes, "Activation Cross Sections for 14-MeV Neutrons," Phys. Rev. 88, 1309 (1952).

Fo71 D. G. Foster, Jr. and D. W. Glasgow, "Neutroa Total Cross Sections, 2.5-15 MeV. I. Experimental," Phys. Rev. C $\underline{3}, 576$ (1971).

Ga62 F. Gabbard and B. D. Kern, "Cross Sectlons for Charged-Particle Reactions lnduced in Medium Weight Nuclei by Neutrons in the Energy Range 12-18 MeV," Phys. Rev. 128, 1276 (1962).

Ga65 J. B. Garg, J. Rainwater, J. S. Petersen, and W. W. Havens, Jr., private communication to $R$. J. Howerton (1965); see also U. N. Singh, J. B. Garg, J. Rainwater, W. W. Havens, Jr., and S. Wynchank, "High Resolution Spectroscopy in the keV Region-F, Al," Bull. Am. Phys. Soc. 16, 495 (1971).

G161 J. H. Glbbons, R. L. Macklin, P. D. Miller, and J. H. Neller, "Average Radiative Capture Cross Sectlons for 7- to 170-keV Neutrons," Phys. Rev. 122, 182 (1961).

Gi63 W. B. Gilboy and J. H. Towle, "Elastic Scattering of $1 \mathrm{MeV}$ Neutrons," Nucl. Phys. 42,86 (1963).

G161 R. N. Glover and E. Welgold, "Protons and Deuterons from $\mathrm{Al} 27$ Bombarded by $14.8 \mathrm{MeV}$ Neutrons," Nuc1. Phys. 24, 630 (1961).

G172 D. W. Glasgow, private communication (1972).

Go71 D. T. Goldman, P. Aline, R. Sher, and J. R. Stehn, unpublished evaluation (1971).

Gr53 E. R. Graves and L. Rosen, "DIstribution In Fnergy of the Neutrons from the Interaction of 14-MeV Neutrons with some Elements," Phys, Rev. 89, 343 (1953).

Gr55 E. R. Graves and R. W. Dav1s, "Cross sections for Nonelastic Interactions of 14-MeV Neutrons with Various Elements," Phys. Rev. 97, 1205 (1955).

Gr58 J. A. Grundl, R. L. Henliel, and B. L. Perkins, "P 31 ( $n, p) S_{1} 31$ and $A 127(n, \infty) \mathrm{Na}^{24}$ Cross Sections," Phys. Rev. 109, 425 (1958).

Gr59 L. V. Groshev, A. M. Demldov, V. N. Lutsenko, and V. I. Pelikhov, Atlas of $y$-Ray Spectra from Radiative Capture of Thermal Neutrons (Pergamon Press, New York, 1959).

Gr65 R. C. Greenwood and J. H. Reed, "Prompt Garma Rays from Radiative Capture of Thermal Neutrons," IIT Research Institute report IITRI-1193-5' (1965), P. 120 .

Gr67 J. A. Grund1, "A Study of Fission-Neutron Spectra with High-Energy Activation Detectors-Part 1. Detector Development and Excitation Measurements," Nucl. Sci. Eng. 30, 39 (1967).
Ha59 H. E. Hall and T. W. Bonner, "Inelastic ScatterIng of Fast Neutrons by $\mathrm{N} 14$ and $\mathrm{Al} 27, "$ United States Atomic Energy Comission report WASH-1021 (1959), P. 52.

Ha62. F. L. Hassler and R. A. Peck, Jr., "NeutronInduced Reactions in Third and Fourth Shell Nuclei," Phys. Rey. 125, 1011 (1962).

Ha68 S. S. Hasan, A. K. Chaubey, and M. L. Sehgal, "Study of the Average Level Spacing from NeutronCapture Cross Section," Nuovo Cimento 58B, 402 (1968).

Ha68a o. Häusser, D. Pelte, and J. F. Sharpey-Schafer, "The 4509-kev Level in $27_{\mathrm{Al}}$," Can. J. Phys. 46, 1145 (1968).

Ha69 R. Hardell, S. O. Idetjärn, and H. Ahlgren, "Thermal-Neutron Capture Gamma Rays from the ${ }^{27} \mathrm{Al}(\mathrm{n}, \mathrm{\gamma}){ }^{28} \mathrm{Al}$ Reaction," Nucl. Phys. Al26, 392 (1969).

Ha70 L. F. Hansen, J. D. Anderson, E. Goldberg, J. Kammerdiener, E. Plechaty, and C. Wong, "Predictions for Neutron Transport in Alr, Based on Integral Measurements In Nitrogen and Oxygen at $14 \mathrm{MeV}$," Nucl. Sc1. Eng. 40, 262 (1970); L. F. Hansen, J. D. Anderson, J. L. Kammerdlener, and C. Wong, "Sensitivity of Monte Carlo Calculations to the Neutron Cross Sections for Neutron Transport in Nitrogen and In Air," Lawrence Livermore Laboratory report UCRL-51031 (1971).

He50 R. L. Henkel and H. H. Barschall, "Capture Cross Sections for Fast Neutrons," Phys. Rev. 80, 145 (1950).

He53 R. L. Henkel, private communication to Sigma Center, Brookhaven National Laboratory (1953).

He54 P. L. Henkel, private communication to Sigma Center, Brookhaven National Laboratory (1954).

He66 J. D. Hemingway, R. H. James, E. B. M. MartIn, and $G$. R. Martin, "The Determination of the Cross Sectlons for the Reactions $27 \mathrm{Al}(\mathrm{n}, \alpha)$ and $56 \mathrm{Fe}(n, p)$ for $14 \mathrm{MeV}$ Neutrons by an Absolute Method," Proc. Roy. Soc. (London) A292, 180 (1966).

H149 C. T. HAbdon and C. O. Muehlhause, "Neutron Cross Sections at $115 \mathrm{eV}$ and $300 \mathrm{eV}-\mathrm{I}, "$ Phys. Rev. 76, 100 (1949).

H158 R. W. HIll, "Angular Distributlons of Elastic Scattering of 5-MeV Neutrons," Phys. Rev. 109, 2105 (1958).

HiS9 C. T. Hibdon, "Distribution of the Angular Momenta, Level Spacings, and Neutron Widths of $\mathrm{Al}^{28}$ " Phys. Rev. 114, 179 (1959).

H164 C. T. Hibdon, private communication to Sigma Center, Brookhaven National Laboratory (1964).

Ho59 M. Hosoe and S. Suzak1, "Gamma Rays from Heutron Inelastic Scattering of Magnesium, Alumtnum, Iron and Blamuth," J. Phys. Soc. Japan 14, 699 (1959). 
Ho69 B. Holmquist and T. Wledling, "Neutron Elastic Scattering Cross Sections; Experimental Data and Optical Model Cross Section Calculations," Akt iebolaget Atomenergi report $A E-366$, Studsvik, Sweden (1969).

Hu59 0. M. Hudson, Jr. and I. L. Morgan, "Fast Neutron Activation of Al," Bull. Am. Phys. Soc. 4 97 (1959).

Hu69 F. C. P. Huang and T. R. Ophel, "Resonances of the ${ }^{26} \mathrm{Mg}(\mathrm{p}, Y)$ React1on between 660 and 1000 kev," Nucl. Phys, Al35, 647 (1969).

Hu?O L. Husa1n, A. Bar1, and P. K. Kuroda, "Neutron A.ctivation Cross Sections at $14.8 \mathrm{MeV}$ for Rubldlum, Strontium, Zircontum, and N1obium," Phys. Rev. C I, 1233 (1970).

Im60 W. L. Imhof, private communication to Sigma Center, Brookhaven National Laboratory (1960).

Je63 J. M. F. Jeronymo, G. S. Mant, J. Olkowsky, A. Sadeghi, and C. F. Williamson, "Absolute CrossSections for Some $(n, p),(n, a)$, and $(n, 2 n)$ Reactions," Nucl. Phys. 47, 157 (1963).

Jo64 G. D. Joanou and C. A. Stevens, "Neutron Cross Sections for Aluminum," General Atomic report GA-5884 (1964).

Ju71 E. T. Jurney, private communication (1971).

Ka61 J. Kantele, "Activation Cross Sections for 14.5-MeV Neutrons for $\mathrm{B}^{11}, \mathrm{O}^{16}, \mathrm{Al}^{27}$, and $\mathrm{F}^{1 !}$," Bull. Am. Phys. Soc. 6, 252 (1961).

Ka62 J. Kantele and D. G. Gardner, "Some Activation Cross Sections for 14.7-MeV Neutrons," Nucl. Phys. 35, 353 (1962).

Ka72 J L. Kammerdiener, "Neutron Spectra Enitted by $239 \mathrm{Pu}, 238_{U}, 235 \mathrm{U}, \mathrm{Pb}, \mathrm{Nb}, \mathrm{N1}, \mathrm{Al}$, and $\mathrm{C}$ Irrad1ated by 14-MeV Neutrons," Thes-5, University of California at Davis (1972).

Ke59 B. D. Kern, W. E. Thompson, and J. M. Ferguson, "Cross Sections for Some $(n, p)$ and $(n, \alpha)$ Reactions," Nucl. Phys. 10, 226 (1959).

Kh58 M. M. Khaletskil, "Determination of Differential Elastic Scattering Cross Sectionn for 14.8-MeV Neutrons by $(n, a)$ Coincidences," Sov. Phys. -Dokl. 2, 152 (1558).

Kh59 c. S. Khurana and H. S. Hans, "Measurements of $(n, p),(n, a)$, and $(n, 2 n)$ Total Cross Sectlons at li MeV," Nuc1. Phys. 13, 88 (1959).

K170 W. E. Kinney and F. G. Perey, "Al Neutron Elastic- and Inelastic-Scattering Cross Sections from 4.19 to $8.56 \mathrm{MeV}$," Oak Rigge National Laboratory report ORNL-4516 (1970).

Ko58 v. N. Kononov, Yu. Ya. Stavissk11, and V. A. Tolstikov, "Measurement of the Radiative Capture Cross Section of $25 \mathrm{keV}$ Neutrons," At. Energiya $\underline{5}, 564$ (1958).
Ko63 I. A. Korzh and N. T. Sklyar, "Angular Distr1bution of Neutrons of Energy $0.3 \mathrm{MeV}$ Elast1cally Scattered by Atomic Nucle1," Ukr. F12. Zh. 8, 1389 (1963); I. A. Korzh, N. S. Kopytin, M. V. Pasechnik, N. M. Pravdivy, N. T. Sklyar, and I. A. Totsky, "Elastic Scattering of Neutrons with Energy $0.65 \mathrm{MeV}$ by Atomic Nucle1," IJkr. F12. 2h. 8, 1323 (1963). These articles are in Ukranian, not in Russian.

Ko64 I. A. Korzh, N. S. Kopyt1n, M. V. Pasechn1k, N. T. Sklyar, and I. A. Totsky, "Scattering of Neutrons with Energles 0.5 and $0.8 \mathrm{MeV}$ by Iight and Medium Nucle1," At. Energ1ya 16, 260 (1964); translated in Sov. J. At. En. 16, 312 (1965).

La57 A. Langsdorf, Jr., R, O, Lang, and J. E. Monahan, "Angular Distributions of Scattered Neutrons:" Phys. Rev. 107, 1077 (1957).

La62 J. Langmann, private comiantcation to S1gma Center, Brookhaven National Laboratory (1962).

Le58 A. I. Leipunsky, O. D. Kazachkovsky, G. Y. Artyukhov, A. I. Baryshntkov, T. S. Belenovn, v. I. Galkov, Yu. Ya. Stavisski1, E. A. Stumbur, and $L$. E. Sherman, "Measurements of Radiative Capture Cross Sections for Fast Neutrons," Proc. Intern. Conf. Peaceful Uses at. Energy, 2nd, Geneva, 1958 (United Nations, New York, 1959) Vol. 15 , p. 50 .

L155 R. N. Little, Jr., B. P. Leonard, Jr., J. T. Prud home, and $L$. D. Vincent, "Liquid Scintillator Measurements of Angular Elastic ScatterIng of Neutrons from Carbon, Aluminum, and Sulfur," Phys. Rev, 98, 634 (1955).

L166 H. Lisklen and A, Paulsen, "Crgfs Sections for the $\operatorname{Cu}^{63}(n, \alpha) \mathrm{Co}^{60}, \mathrm{~N}^{60}(n, p) \mathrm{Co}^{60}$, and Some Dther Threshold Reactions Using Neutrong from the $\operatorname{Be}^{9}(\alpha, n) c^{12}$ Reaction," Nukleontk 8. 315 (1966).

Lo57 G. N. Lovch1kova, "Measurement of the Angular Distribution of $0.9-\mathrm{MeV}$ Neutrons Elastically Scattered on $\mathrm{B} 1, \mathrm{~Pb}, \mathrm{Sn}, \mathrm{Fe}$, and $\mathrm{Al}, "$ Sov. J. At. En. 2, 197 (1957).

Lo60 G. N. Lovch1kova, "Angular Distribution of Elastically Scattered Neutrons," Sov: Phya. -JETP 11, 1036 (1960).

Ma57 M. H. MacGregor, W. P. Ball, and R. Booth, "Nonelastic Neutron Cross sections at $14 \mathrm{MeV}, "$ Phys. Rev. 108, 726 (1957).

Maj7a R. L. Macklin, N. H. Lazar, and w. S. Lyon, "Neutron Activation Cross Sectlons with Sb-Be Neutrons," Phys. Rev. 107, 504 (1957).

Ma60 G. S. Man1, G. J. McCalium, and A. T. G. Yerguson, "Neutron Cross-Sections in Aluminium," Nucl. Phys. 19, 535 (1960).

Ma63 R. L. Macklin, J. H. Gibbons, and T. Inada, "Average Radiative Capture Cross Sections for 30- and 65-kev Neutrons," Phys. Rev. 129, 2695 (1963). 
Ma65 S. C. Mathur, W. F. Tucker, R. W. Benjamin, and I. L. Morgan, "Angular Distributions of Gamma Rays Froduced by Neutron Bombardment of $\mathrm{Al}, \mathrm{Mg}$, and S1," Nuc1. Phys. 73, 561 (1965).

Ma68 J. Mart1n, D. T. Stewart, and W. M. Currie, "Scattering of 6-MeV Neutrons from Light Nucle1," Nuc1. Phys. Al1 2,564 (1968).

Ma69 R. E. Maerker and F. J. Muckenthaler, "Gamma-Ray Spectra Arising from Thermal-Neutron Capture in Elements Found in Solls, Concretes, and Structural Materials," Oak Ridge National Laboratory report ORNL-4382 (1969).

Me52 A. W. Merrison and E. R. Wiblin, "The Total Neutron Cross-Sections of Cobalt, Silver, Iodine, Alumin1um, Nickel, and Gallium between $1 \mathrm{eV}$ and $5 \mathrm{keV}, "$ Proc. Roy. Soc. (London) 215, 278 (1952).

Me67 H. 0. Menlove, K. L. Coop, H. A. Grench, and R. Sher, "Activation Cross Sections for the $F^{19}(n, 2 n) F^{18}, N^{23}(n, 2 n) N^{22}, \ln ^{55}(n, 2 n) \operatorname{Nin} 54$, In $115(n, 2 n)$ In114m, Ho165 $(n, 2 n) H 0^{164 m, ~ I n I 15 ~(n, ~ n ') ~}$ In $115 \mathrm{~m}$, and $\mathrm{Al}^{27}(\mathrm{n}, \alpha) \mathrm{Na}^{24}$ Reactions," Phys. Rev. 163, 1308 (1967).

Mif́ B. Mitra and A. M. Ghose, "(n,p) Cross Sectiona of Some Low-z Nuclel for 14.8-MeV Neutrons," Nucl. Phys. 83, 157 (1966).

Mió7 B. Minett1 and $A$. Pasquarel11, "Cross Sectlons of the $(n, p)$ and $(n, a)$ Reactions Induced in Manganese by 14.7 MeV-Neutrons," Z. Physik 199, 275 (1967).

M168 A. Mittler, K. C. Chung, M. T. McEllistrem, and J. D. Brandenberger, "Scattering of $8.0-\mathrm{NeV}$ Neutrons from $24_{\mathrm{A} / \mathrm{B}}, 27_{\mathrm{Al}}, 28 \mathrm{~S}, 31_{\mathrm{P}}$, and $32_{\mathrm{s}}, "$ Bull. Am. Phys. Soc, 13, 1420 (1968).

Mu61 S. K. Mukherjee, A. K. Ganguly, and N. K. Majumder, "Activation Cross Sections with 14-MeV Neutrons," Proc. Phys. Soc. (London) 77, 508 (1961).

Mu72 D. W. Muir, private comunication (1972).

Ne71 D. O. Nell1s and P. S. Buchanan, Neutron Scattering and Gamma-Ray Production Cross Sections for $N, 0, A l, S 1, C a$, and $F e, "$ private commusication (1971).

Ny69 K. Nyberg, B. Jönsson, and I. Bergqvist, "HighResolution Measurements of Gamm Rays Produced by 15-MeV Neutrons," European-American Nuclear Data Cnmittee report EANDC(OR)83-L (1969), P. 26.

Or70 V. J. Orphan, N. C. Raemussen, and T. L. Harper, "Line and ConeInuum Gama-Ray Ylelds from Thermal-Neutron Capture in 75 Elements," Gulf General Atomic report GA-10248 (1970).

Or71 V. J. Orphan and C. G. Hoot, "Gamma-Ray Production Cross Sections for Iron and Muminum," Gulf Radiation Technology report GULF-RT-Al0743 (1971).

PaS3 E. B. Pavl and R. L. Clayke, "Cross-Section Measurements of Reactions Induced by Neutrons of 14.5 MeV Energy," Can. J. Phys. 31, 267 (1953).
Pa55 M. V. Pasechnik, "Inelastic Scatterlng of Fast Neutrons by Atomic Nucle1," Proc. Intern. Conf. Peaceful Uses At. Energy, Geneva, 1955 (United Natlons, New York, 1956), Vol. 2, p. 3.

Pa65 A. Paulsen and 4 . Lisklen, "Cross Sections for the Reactions $55_{\mathrm{Mn}}(\mathrm{n}, 2 \mathrm{n}){ }^{54} \mathrm{Mn},{ }^{59} \mathrm{Cc}(\mathrm{n}, 2 \mathrm{n}){ }^{58} \mathrm{Co}$, $\left.{ }^{24} \mathrm{M} / \mathrm{B}, p\right){ }^{24} \mathrm{Na}$ and $27_{\mathrm{Al}}(\mathrm{n}, \alpha)^{24} \mathrm{Na}$ in the 12.6$19.6 \mathrm{MeV}$ Energy Region," J. Nuel. Energy, Parts A/B 19,907 (1965).

Pa70 D. Partington, D. Crumpton, and S. E. Hunt, "Determination of the Energy Dependence of the ${ }^{63} \mathrm{Cu}(\mathrm{n}, 2 \mathrm{n})^{62} \mathrm{Cu}$ and $27_{\mathrm{Al}}(\mathrm{n}, \mathrm{p}){ }^{27} \mathrm{Mg}$ Cross-Sections, and their Application to the Measurement of 14MeV Neutron Fluxes," Anslyst 95, 257 (1970).

Pe57 J. L. Perkin, L. P. $0^{\prime}$ Connor, and R. F. Coleman, "Radiative Capture Cross Sections for 14.5-MeV Neutrons," Proc. Phys. Soc. (London) 72, 505 (1958).

Pe64 J. L. Perk1n, "Gamma Ray Spectra from Fast Neutron Interactions," Nuc1. Phys. 60, 56.1 (1964).

Pe67 G. Petö, 2. MAligy, and I. Hunyadi, "RadiativeCapture Cross Sections for 3-MeV Neutrons," J. Nucl. En. 21, 797 (1967).

Ph52 D. D. Phillips, R, W. Davis, and E. R. Graves, "Inelastic Colilston Cross Sections for $14-\mathrm{MeV}$ Neutrons," Phys. Rev. 88, 600 (1952).

Po56 Kh. R. Poze and N. P. Glazkov, "Inelastic Scattering of $0.3,0.77$, and $1.0 \mathrm{MeV}$ Photoneutrons," Sov. Phys. -JETP 3, 745 (1956).

Po59 A. Poularikas and R. W. Fink, "Absolute Activation Cross Sections for Reactions of Bismuth, Copper, Titanium, and Aluminum with J/4.8-MeV Neutrons," Phys. Rev. 115, 989 (1959).

Po61 H. Pollehn and H. Neuer't, "Bestimmung von Wirkungsquerschnitten einiger Kernreaktiones durch $14 \mathrm{MeV}$-Neutronen nach einer NktIvlerungswethode," 2. Naturf orsch. 16A, 227 (1961).

Po61a V. I. Popov, "Angle Distribution of 3,1-MeV Neutruns Elastically Scattered on Al, $\mathbf{S i}, \mathbf{K}, \mathrm{Ca}$, and Th," Soviet Progress in Neutron Physics (Gosatomikdat, Mrscow, 1961; trsnslated by Consultants Bureau Enterprises, Nev York, 1963), p. 224 .

Pr60 J. T. Prud 'home, I. L. Morgan, J. H. McCrary, J. B. Ashe, and 0 . M. lludson, Jr., "A Study of Neutrons and Ganea Rays from Neutron Induced Reactions in Several Elements," A1r Forr:e Speclal Weapons Center report AFSWC-TR-60-30 (1960).

Ra65 L. A. Rayburn and E. O. Wollan, "Total Neutron Cross Sections at $1.44 \mathrm{eV}, "$ vucl. Phys. 61, 381 (1965).

Ra68 N. Ranakumar, E. Kondalah, and R. W. Flnk, "ireutron Activation Cross Sections at $14.4 \mathrm{MeV}$ for S1 and In Isotopes," Nucl. Phys. A122, 679 (1968).

Ro68 H. Röpke and S. T. Lam, "A Study of the 4.509Mev state in $27_{\mathrm{Al}}$ by the $26_{\mathrm{Mg}}(\mathrm{p}, \gamma)$ Reaction," Can. J. Phys. 46, 1649 (1968). 
Ro69 H. Röpke and N. Anyas-Weiss, "The ${ }^{23} \mathrm{Na}(a, y)^{27} \mathrm{Al}$ Reacticn. A Survey of the Reaction and Some Properties of the $27_{\mathrm{Al}}$ Nucleus," Can. J. Phys. 47. 1545 (1969).

Sa59 C. St. Plerre, M. K. Machwe, and P. Lorrain, "Elastic Scattering of 14-MeV Neutrons by $\mathrm{Al}$, S, I1, and Co," Phys. Rev. 115, 999 (1959).

Sa61 M. Sak1saka, B. Saek1, M. Tomita, and F. Fukuzawa, "Sample-Sandwiched Plastic Scintillators for Activation Measurements by Use of Fast Neutrons," J. Phys. Soc. Japan 16, 1869 (1961).

Sa71 G. N. Salaita, "Absolute Neutron Cross Sections for the Production of the ${ }^{24} \mathrm{Na}$ Isomer from Magnesium and Aluminum," Nucl. Phys. Al70, 193 (1971).

Sc53 V. E. Scherrer, R. B. Theus, and W. R. Faust, "Gamma-Rays from interaction of $14-\mathrm{MeV}$ Neutrons with Various Materials," Phys. Rev. 91, 1476 (1953).

Scúl H. W. Schmitt and J. Halperin, "M" $27(n, a) \mathrm{Na}^{24}$ Cross Section as a Function of Neutron Energy," Phys. Rev. 121, 827 (1961).

Sc66 R. M. Scheciman and J. D. Anderson, "Inclaselc Scatering of 14-MeV Neutrons," Nucl. Phys. 77, 241 (1960).

Sc70 R. B. Schwartz, private communication (1970).

Se47 L. Seren, II. N. Friedlander, and S. H. Turkel, "Thermal Neutron Activation Cross Sections," Phys. Rev. 72, 888 (1947).

Sh62 R. Sher and B. A. Magurno, privale comunication to R. J. Howerton, Lawrence Livermore Laboratory (1962).

St57 V. I. Strizhak, "Inelastic Interaction of 14-. MeV Neutrons with Nucle1," At. Energiya 2, 68 (1957).

St62 T. P. Stuart, J. D. Anderson, and C. Hong, "Elastic Scattering of $24-\mathrm{MeV}$ Neutrons by $\mathrm{Al}$, Fe, Sn, Bi," Phys. Rev. 125, 276 (1962).

St62a P. Strohal, N. Clndro, and B. Eoan, "Reaction Mechanisn and Shell Ef fects from the Interaction of 14.6-MeV tieutrons with Nucle1," Nucl. Phys, 30, 4n (1962).

St65 P. I. Stelson, R, L. Robinsor, H. J. Kis, J. Rapaport, and G. K. Satchler, "Excltation of Collective States by the Inelastic Scatcering of $14 \mathrm{MeV}$ Neutrons," Nucl. Phys. 68, 97 (1965).

St65a J. E. Strain and W. J. Ross, "14-MeV Neutron Reactions," Oak Ridge National Laboratory report ORNL-3672 (1965).

TaS5 H. L. Taylor, O. Lönsjö, and $T, W$. Bonner, "Nonelastic Scatteráng Cross Sections for Fast Neutrons," Phys. Rev. 100, 174 (1955).
Ta69 S. Tanaka, K. Tsukada, Y. Tomita, and M. Mnruyama, "Differential Cross Sections of Aluminum and Silicon for the Elastic and Inelastic Scattering of Neutrons," private communication to W. E. Kinney from Tanaka et al. (1969); "Fast Neucron Scattering from $A l, S 1, S$, and $2 n, "$ Nuclear Data for Keactors (International A:omic Energy Agency, Vienna, 19\%0), P 317.

Te60 H. A. Tewes, A. A. Caretto, A. E. Miller, and D. R. Nethaway, "Excltazion Functions of Neutron Induced Reactions," University of Callfornia Radiation Laboratory report UCRL-6028-T (1960).

Th63 D. B. Thomson, "Nuclear Level Densities and Reaction Mechanisms frow Inelagtic Neutron Scattering," Phys. Rev, 129, 1649 (1963).

Th65 W. E. Thompson and F. C. Engesser, "Gaman Rayk from Interactions of 14.7-HeV Neutrons with Minnesium, Alumin $x$, Calclum, Titanlum, and Iron," United States Naval Radiological Defense Laboratory report USNRDL-TR-861 (196S); F. C. Engeeser and W. G. Thompson, "Gamma Rays Resulting from Interactions of 14.7-HeV Neutrons with Varlous Element's," J. Nucl. Eng. 21, 487 (1967).

T168 פ. N. Tiwar1 and E. Kondalah, "Activation Cross Sections of calcium, Potassium, and Aluminum for 14. 2-MeV Neutrons," Phys, Rev. 167, 1091 (1968).

To62 J. H. Towle and W. B. Gilboy, "Spin Ass1gnments in $\mathrm{Al}^{2 \%}$ from Neutron Scattoring Studies," Nucl. Phys. 39, 300 (1962).

To67 J. H. Towle and R. O. Owens, "Absolute Level Densitics from Neutron Inelastlc Scattering," Nuc.1. Phys. Al100, 257 (1967).

Tr61 E. S. Troubetzkoy, "Statistical Theory of GamanFay Spcrtra Following Nuclear Reactions," Fhys. Rev. 122, 212 (1961).

Ts61 K. Tsukada, S. Tanaka, M. Maruyana, and $Y$. Tomita, "Angular Disteibutions of Fast Neutrons Scattered by $A\}, S 1, P, S$, and $2 n, "$ Proc. Sem1nar Phys. Fast and Intermedlate Reactors, Vlenna, 1961 (International Atomic Energy Agency, Vienna, 1962), p. 75 .

Va67 C. van der Leun, D. M. Sheppard, and P. M. Endt

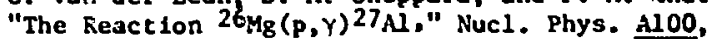
316 (1967).

Ve.58 J. F. Vervier, "Section Efficace de Capture Radiative pour des Neutrons d'une Source Sb-Be," Nucl. Phys. 9, $569(1958 / 59)$.

Ma.55 H. Walt and J. R. Beyster, "Interaction of 4.1MeV Neutrons with Nuclei," Phys. Rev, 98, 677 (1955).

W149 G. C. Wick, "A Theoram on Cross Sections," Phys. Rev. 75, 1459 (1949).

W163 D. Winterhalter, "Angular Distributions of Fast Neutrons Scattered on Mluminiume" Nucl, Phys. 43. 339 (1963). 
Ya57 S. Yasuml, "Nuclear Reactlons Induced by the 14-MeV Neutrons," J. Phys. Soc. Japan 12, 443 (1957).

Yu58 K. Yuasa, "Differentlal Elastic Scattering of 14-MeV Neutrons in Aluminum, Lead, and B1smuth for Large Angles," J. Phys. Soc. Japan 13, 1248 (1958). 